Aus der Division Klinische Neurowissenschaften

(Leiterin: Prof. Dr. med. Dr. med. vet. H. Ehrenreich)

des Max-Planck-Instituts für experimentelle Medizin

in Göttingen

\title{
Cannabinoidrezeptor CB1 und Endothelin-B-Rezeptor: Interaktion im Hippokampus
}

\section{INAUGURALDISSERTATION}

zur Erlangung des Doktorgrades

\author{
der Medizinischen Fakultät \\ der Georg-August-Universität zu Göttingen \\ vorgelegt von
}

Christian Unzicker

aus

Lahn jetzt Wetzlar

Göttingen, 2007 
Dekan: Prof. Dr. med. C. Frömmel

I. Berichterstatterin: Prof. Dr. med. Dr. med. vet. H. Ehrenreich

II. Berichterstatter/in:

III. Berichterstatter/in:

Tag der mündlichen Prüfung: 


\section{Inhalt}

ABBILDUNGSVERZEICHNIS

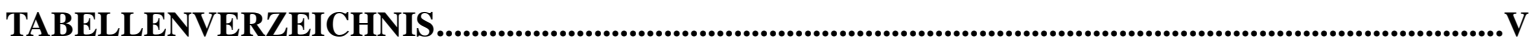

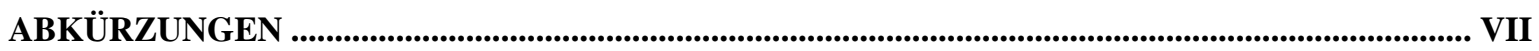

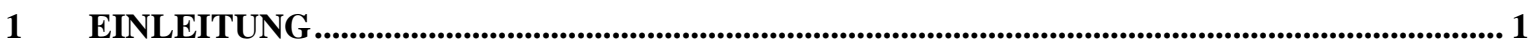

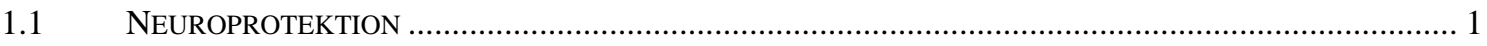

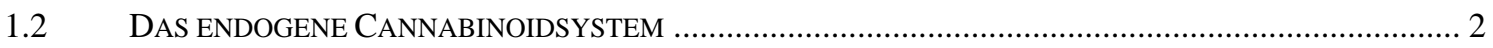

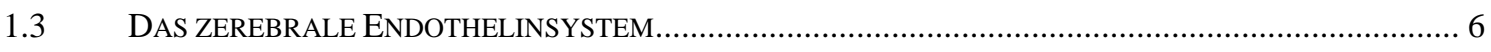

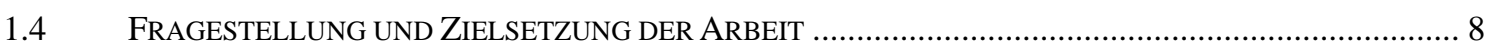

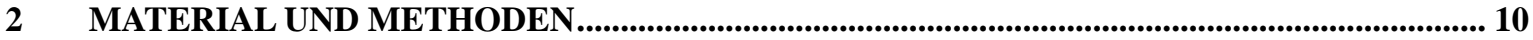

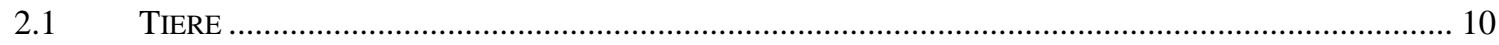

2.1.1 Bestimmung des Genotyps durch PCR: „, Genotyping “ .................................................... 10

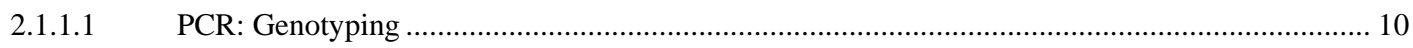

2.1.2 Geschlechtsbestimmung durch PCR: „Sexing “..................................................................11

2.1.2.1 DNA-Gewinnung aus Frischgewebe .......................................................................................11

2.1.2.2 DNA-Gewinnung aus formaldehydfixierten, paraffinierten Rattenhirnschnitten ..........................11

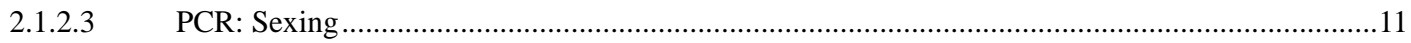

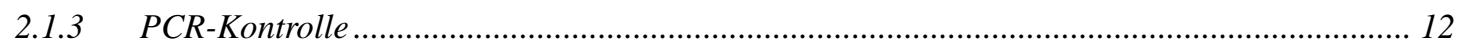

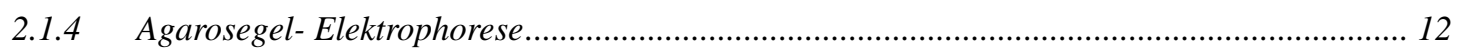

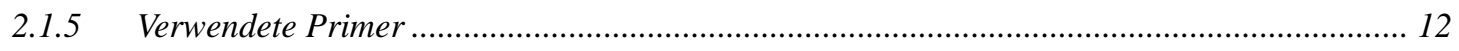

2.1.6 Materialien für PCR: Sexing und Genotyping..................................................................... 13

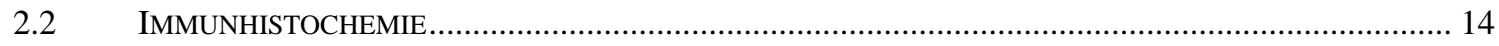

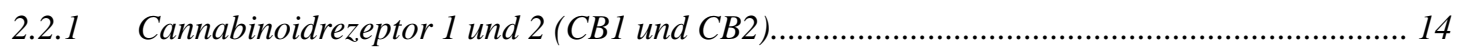

2.2.1.1 Färbung von paraffinierten Schnitten des Rattenhirns.............................................................. 14

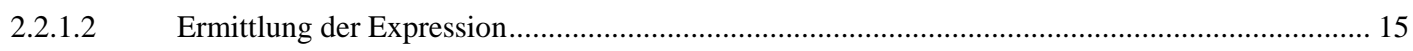

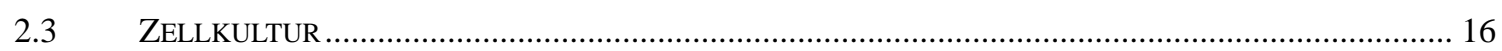

2.3.1 Primärkulturen hippokampaler neuronaler Zellen ........................................................ 16

2.3.1.1 Präparation, Anreicherung, Aussaat und Kulturbedingungen ......................................................... 16

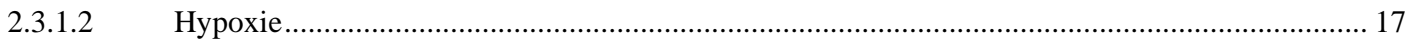

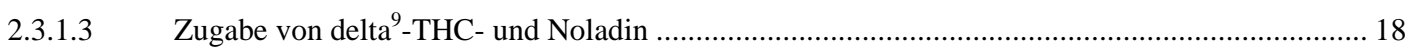

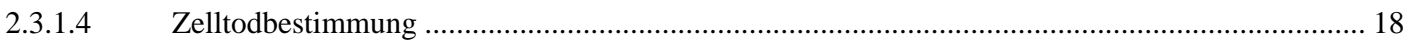

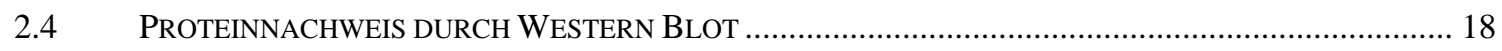

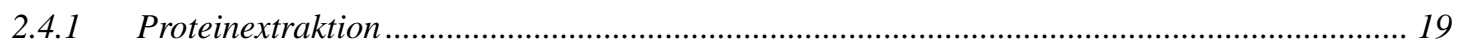

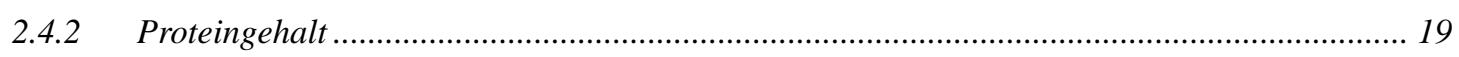

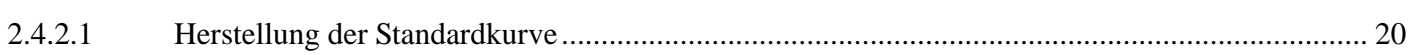

2.4.3 Gelelektrophorese und Blotten.................................................................................... 20

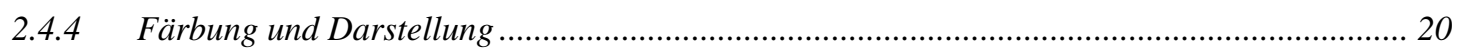

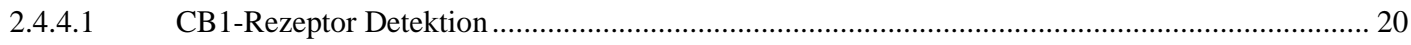


Inhalt

2.4.4.2 Auswertung der CB1-Expression

2.5 VORVERSUCH ZUR BEHANDLUNG VON WISTAR-IMAMICHI-RATTEN UNTER HYPOXIE/ISCHÄMIE MIT DELTA ${ }^{9}$-THC IN VIVO

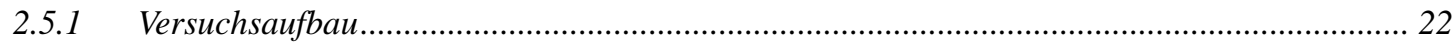

2.5.1.1 Arteria-carotis-communis- Okklusionsmethode mit intraperitonealer THC-Gabe........................ 23

2.5.1.2 Entnahme und Aufbereitung der Rattenhirne ............................................................................. 24

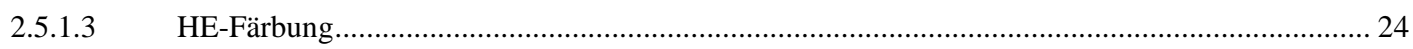

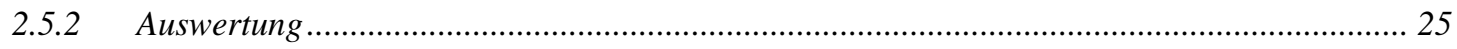

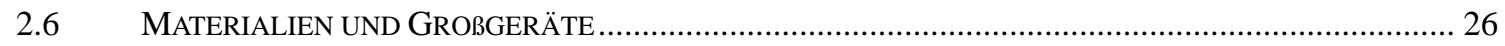

2.6.1 Verbrauchsmaterialien und Geräte..................................................................................... 26

2.6.2 Lösungen, Puffer, Zellkulturmedien .............................................................................. 28

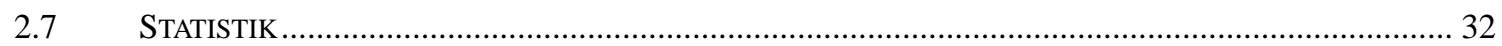

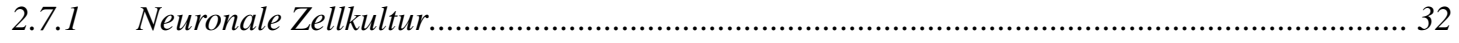

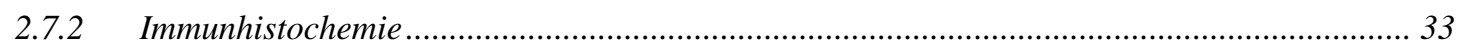

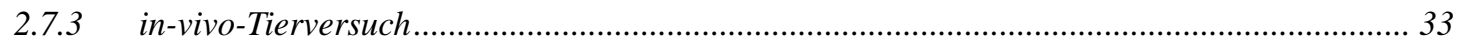

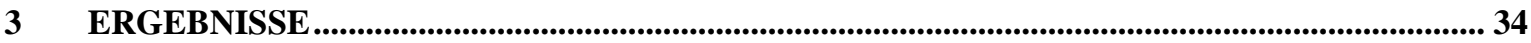

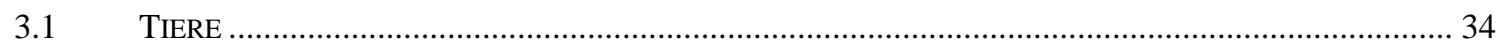

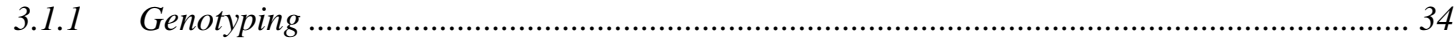

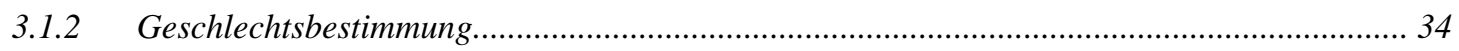

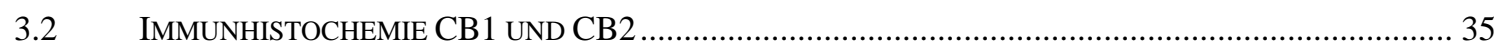

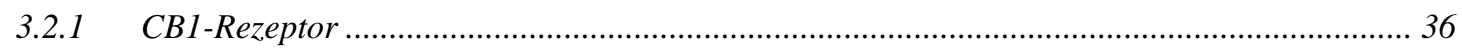

3.2.1.1 Immunoreaktivität der Pyramidalzellschicht............................................................................. 37

3.2.1.2 Immunoreaktivität der Granularzellschicht ............................................................................ 38

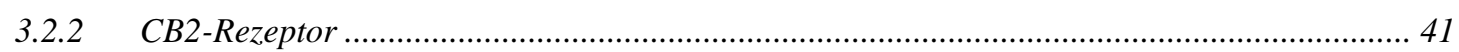

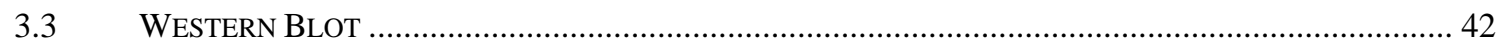

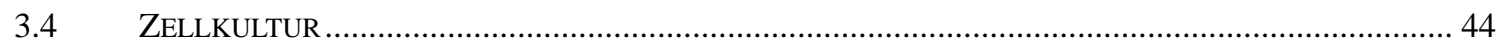

3.4.1 Ergebnisse der Versuche mit kultivierten hippokampalen Neuronen ..................................... 44

3.5 VORVERSUCHE FÜr EINE BeHANDLUNG MIT THC ODER PlaCEBO BEI HYPOXIE/IsCHÄMIE IN VIVO

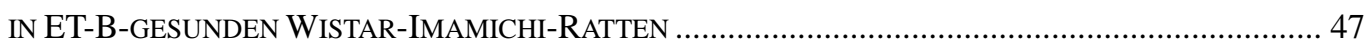

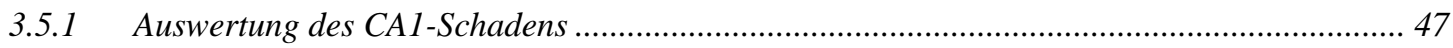

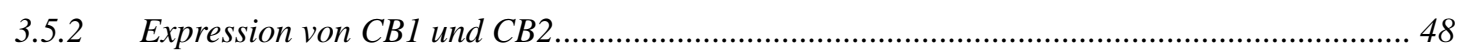

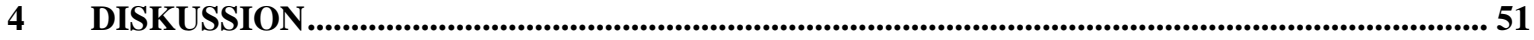

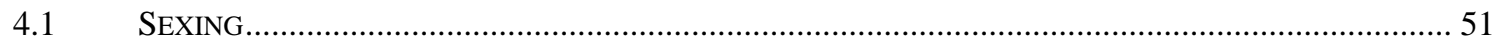

4.2 ALTERS- UND GENOTYPABHÄNGIGE CANNABINOIDREZEPTOREXPRESSION IM RATTENHIRN .......... 52

4.3 NEGATIVE KORRELATION VON IMMUNOREAKTIVITÄT VON CB1 UND ANZAHL APOPTOTISCHER

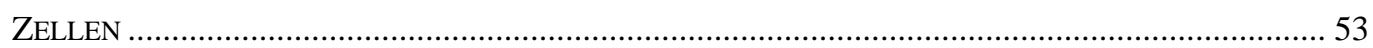

4.4 NEUROPROTEKTIVER EFFEKT VON CANNABINOIDAGONISTEN IN VITRO ................................... 54

4.5 VORVERSUCH HYPOXIE/ISCHÄMIE UND GABE VON THC IN VIVO ................................................ 55

4.6 ET-B und CB1 ALS TEIL EINES NEUROPROTEKTIVEN NETZWERKES? ...................................... 56

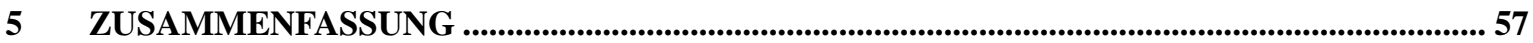


Inhalt

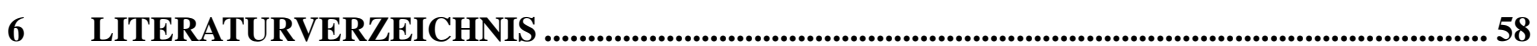




\section{Abbildungsverzeichnis}

Abb. 1: Strukturformel delta9 ${ }^{9}$ THC und Noladin...................... S. 3

Abb. 2: Wirkung von Endothelin 1-3........................................... S. 7

Abb. 3: Versuchsaufbau für die in-vivo-Hypoxie/Ischämie.................. S. 22

Abb. 4: Schema zur Evaluation von HE-gefärbten Schnitten.......... S. 25

Abb. 5: Beispielbilder für das Unterscheiden des Genotyps und des Geschlechts................................................ S. 35

Abb. 6: Exemplarische CB1-Immunoreaktivität...................... S. 36

Abb. 7: Die Immunoreaktivität der Pyramidalzellen................. S. 37

Abb. 8: Die Immunoreaktivität der Granularzellen.................. S. 38

Abb. 9: Die Abhängigkeit der Anzahl apoptotischer Zellen............ S. 40

Abb. 10: Korrelation zwischen Immunoreaktivität von CB1 und Zelltod.......................................................... S. 41

Abb. 11: Expression von CB2 im Cortex............................. S. 42

Abb. 12: Immunoreaktivität von CB1 (irCB1) nach Alter …......... S. 43

Abb. 13: Basale Zelltodrate nach bei Normoxie und Hypoxie............ S. 44

Abb. 14: Zelltod bei Neuronenkulturen vom Wildtyp..................... S. 45

Abb. 15: Zelltod bei ET-B-defizienten (sl/sl) Neuronenkulturen......... S. 46

Abb. 16: HE-Färbung von CA1..................................... S. 48

Abb. 17: Reduktion vitaler Zellen nach THC-Gabe in vivo.............. S. 48

Abb. 18: Expression von CB2 im Cortex .................................... S. 49

Abb. 19 Expression von CB2 in GFAP-positiven Zellen................... S. 49

Abb. 20: CB2-Expression in vivo bei Wistar-Imamichi-Ratten................. S. 50 


\section{Tabellenverzeichnis}

Tab. 1: Darstellung der Verbrauchsmaterialien und Geräte.............. S. 26-28

Tab. 2: Anzahl der Versuchstiere........................................ S. 36

Tab. 3: Statistik des linearen Gesamtmodells........................... S. 39

Tab. 4: Anzahl der Versuchstiere pro Gruppe Placebo/Behandlung..... S. S. 47 


\section{Abkürzungen}

$+\quad$ Plus

A

Adenin

Abb.

Abbildung

$\mathrm{ABC}$

Avidin-Biotin-Komplex

Ak

Antikörper

ATP

Adenosintriphosphat

bFGF

basischer Fibroblastenwachstumsfaktor

BP

Basenpaare

BSA

Bovines Serumalbumin

C

Cytosin

CA

Corpus Ammonis

CB1

Cannabinoidrezeptor Typ 1

CB2

Cannabinoidrezeptor Typ 2

$\mathrm{DAB}$

Diaminobenzidin

delta9-THC

Delta9-Tetrahydrocannabinol

DNA

Desoxyribonukleinsäure

dNTP

Desoxyribonukleosidtriphosphate

EDTA

Ethylendiamin-Tetraessigsäure-Dinatriumsalz-Dihydrat

EGTA

Ethylenglycol-bis( $\beta$-aminoethyl)-N,N, $\mathrm{N}^{\prime}, \mathrm{N}^{\prime}-$

Tetraethylether

ELISA

Enzyme-linked Immunosorbent Assay

ERK

Extrazellularsignalregulierte Kinasen

ET-1

Endothelin 1

ET-2

Endothelin 2

ET-3

Endothelin 3

ET-A

Endothelinrezeptor Typ A 
ET-B

Fa.

FCS

Ff

G

GFAP

HBSS

HEPES

IE

$\operatorname{Ig} G$

Jak2

JNK

MAP-K

MOPS

N

P

PBS

PCR

PFA

$\mathrm{pM}$

POD

SDS

S1

SRY

T

$\mathrm{T}$

Tab.

Taq
Endothelinrezeptor Typ B

Firma

Fötales Kälberserum

Fortfolgend

Guanin

Glial Fibrillary Acidic Protein

Hank's Buffered Salt Solution

N-2-Hydroxyethylpiperazin-N'-2-ethansulfonsäure

Internationale Einheit

Immunglobulin G

Januskinase 2

Jun Kinase

Mitogen-activated Kinase

3-[N-Morpholino]propansulfonsäure

Anzahl

Wahrscheinlichkeit

Phosphat-buffered Saline

Polymerasekettenreaktion

Paraformaldehyd

Pikomolar

Peroxidase

Sodium Dodecylsulfat

Spotting lethal

Sex determining region of $Y$

Time

Thymin

Tabelle

DNA-Polymerase von Thermus aquaticus 
TBE

TBST

UV

V

Vs

WT

ZNS
TRIS-Borat-EDTA-Puffer

Tris-Buffered Saline Tween-20

Ultraviolett

Volt

Versus

Wildtyp

Zentralnervensystem 


\section{$1 \quad$ Einleitung}

\subsection{Neuroprotektion}

Das Gehirn ist von Geburt an zahlreichen Einflüssen ausgesetzt, die Umbaumechanismen induzieren können. Dabei wird es im Zusammenspiel von Zelltod und Proliferation (meist) zum Vorteil verändert. Diese Vorgänge können physiologisch erwünscht sein, wie zum Beispiel beim Lernen, aber im pathologischen Fall auch eine Schädigung nach sich ziehen, zum Beispiel bei neurodegenerativen Erkrankungen, Hypoxie oder akuten Infektionen. Bei akuten Infektionen wie der bakteriellen Meningitis kommt es zu einer Infektion der weichen Hirnhaut, die zum Tod, körperlicher Behinderung oder nachhaltiger Schädigung der intellektuellen Leistungsfähigkeit des Patienten führen kann. Im Versuch der Heilung und Behandlung Betroffener erlangte die Neuroprotektion Bedeutung. Sie umschreibt das höchst mögliche Erhalten und Überleben zellulärer Interaktion und Integrität im Gehirn.

Der Begriff der Neuroprotektion wurde 1988 erstmals im Zusammenhang mit dem Schlaganfall verwendet [ANDINE et al. 1988]. Im experimentellen Schlaganfallmodell an der Ratte konnte hier ein Überlebensvorteil bei Neuronen unter Behandlung mit Antagonisten exzitatorischer Aminosäuren (GlutamatAntagonisten) gezeigt werden, der neuroprotektiv genannt wurde. Neuroprotektion beschreibt aber nicht nur das einfache Überleben von Nervenzellen, sondern auch das Aufrechterhalten deren physiologischer Funktion im Gesamtnetzwerk des Hirns und das physiologische Sterben von Zellen (Apoptose) im Rahmen von Lernprozessen. Diese spielen sich insbesondere im Hippokampus ab [ATALLAH et al. 2004], was die Vulnerabilität der hier lokalisierten Zellen [BILBO et al. 2007], aber auch das Vorhandensein zahlreicher Rezeptorsysteme mit neuroprotektivem Potenzial erklären könnte.

Neuroprotektive Mechanismen konnten rezeptorabhängig und -unabhängig differenziert werden. Die wichtigsten heute bekannten Mechanismen sind unter anderem das Eliminieren von freien Radikalen [HALL et al. 1992], die Reduktion von intrazellulärem Calcium [LAZAREWICZ et al. 1990] und die Aktivierung von intrazellulären Signalwegen wie Jak2 und NF kappa B [DIGICAYLIOGLU und LIPTON 2001]. Zahlreiche Übersichtsarbeiten geben detailliert Auskunft über die bisher bekannten Mechanismen [KAPINYA 2005; MEHTA et al. 2007; SCHWARTZ und KIPNIS 2005; TABAKMAN et al. 2005; ULLRICH et al. 2007; WEINREB et al. 2005; ZHANG F et al. 2004]. 
Insgesamt gab es zum Zeitpunkt der Erstellung der vorliegenden Arbeit über 1200 Studien zum Thema „Neuroprotektion und Wirkungsmechanismus“, die sich aber für das Rattenmodell weitgehend auf die wichtigsten oben genannten Mechanismen zurückführen lassen.

Diese Mechanismen sind unterschiedlich kraftvoll und unterscheiden sich auch im Nebenwirkungsspektrum essenziell. So konnten nur wenige in eine klinische Anwendung umgesetzt werden. Ein Beispiel für die erfolgreiche Translation in den klinischen Gebrauch stellt die Behandlung mit Erythropoetin beim Schlaganfall dar [EHRENREICH et al. 2002].

Selten konnte eine untersuchte Substanz nur über einen der oben genannten Wege neuroprotektiv wirken. Ein Zusammenspiel von unterschiedlichen Wirkmechanismen war auch in vitro nicht immer ganz zu eliminieren. So konnte man zum Ziel der Untersuchungen von Neuroprotektion auf einen multimodalen Ansatz (mehrere Effekte wurden durch einen Wirkstoff erzielt) nicht verzichten.

Die optimale neuroprotektive Substanz hätte also neuronale (oder astrozytäre) Zielstrukturen auf zellulärer Ebene, wie zum Beispiel Rezeptorsysteme, die die Reduktion intrazellulären Calciums, die Verminderung von anaerober Glykolyse, die Steigerung von intrazellulärem ATP fördern oder die erhöhte Freisetzung von exzitatorischen Aminosäuren oder von freien Radikalen vermindern bzw. neutralisieren. Das im Rahmen der Hirnschädigung auftretende Hirnödem würden diese Systeme zusätzlich durch Regulation der Gefäßsysteme, z. B. durch venöse Dilatation und Aufrechterhaltung der Blut-Hirn-Schranke, reduzieren.

Das endogene Cannabinoidsystem erfüllt diese Kriterien. Dazu kommt, dass ein klinischer Einsatz schon für andere Indikationen (Antiemese, Appetitsteigerung) vorliegt und somit eine schnelle Translation in die Klinik möglich wäre.

\subsection{Das endogene Cannabinoidsystem}

Cannabinoide wurden schon seit Jahrtausenden von Menschen zu unterschiedlichen Zwecken konsumiert. Sie wurden zur Linderung von Beschwerden (als Medikament) und zur Erzeugung halluzinogener Zustände bei rituellen oder gesellschaftlichen Ereignissen (als Rauschgift) eingenommen. Eine der ersten medizinischen Schriften, der Papyrus Ebers, beschrieb das Extrakt der CannabisPflanze (Cannabis sativa) in Honig gelöst und vaginal appliziert als hilfreich bei der Geburt schon etwa um 1500 vor Christi Geburt [JOACHIM 1890]. Behandlungserfolge bei Patienten mit Tumorkachexie, chemotherapievermittelter oder postoperativer Nausea und Emesis [KWIATKOWSKA et al. 2004; LAYEEQUE et al. 2006; MECHOULAM und HANU 2001] und Glaukom [TOMIDA et al. 2006] 
nehmen heute einen signifikanten Platz in der klinischen Behandlung durch Applikation von Cannabinoiden ein.

Bei Erkrankungen des Zentralnervensystems (ZNS) wurden Cannabinoide bei Patienten mit neuropathischen Schmerzen [PALAZZO et al. 2006], experimentell nach Neurotrauma oder auch bei Multipler Sklerose als neuroprotektive Substanzen eingesetzt [MECHOULAM und HANU 2001]. Eine Rolle könnten zukünftig auch die Cannabinoidantagonisten in der Therapie von Suchterkrankungen [HEILIG und EGLI 2006] und neuropsychiatrischen Erkrankungen [VINOD und HUNGUND 2006] spielen.

Chemisch isoliert und synthetisiert wurde als erstes (psychoaktives) Cannabinoid das delta'-Tetrahydrocannabinol von Raphael Mechoulam 1972 [MECHOULAM et al. 1972a; MECHOULAM et al. 1972b].

Endogene Cannabinoide, die das Vorhandensein eines physiologischen RezeptorAgonist/Antagonist-Systems wahrscheinlich machten, konnten in Arachidonsäurederivaten wie z. B. 2-Arachidonoylglycerolether (Noladinether oder einfacher Noladin genannt) gefunden werden. Inzwischen sind mindestens vier endogene Cannabinoide mit rezeptorvermittelten und -unabhängigen Wirkungen bekannt [FEZZA et al. 2002; FRIDE 2002; HANUS et al. 2001]. Endogene wie synthetische Cannabinoide wiesen sowohl rezeptorunabhängige wie -abhängige Wirkmechanismen auf. In der chemischen Strukturformel wurden ein endogenes (Noladin) und ein pflanzliches/synthetisches (delta'-THC) in der folgenden Abbildung 1 dargestellt.

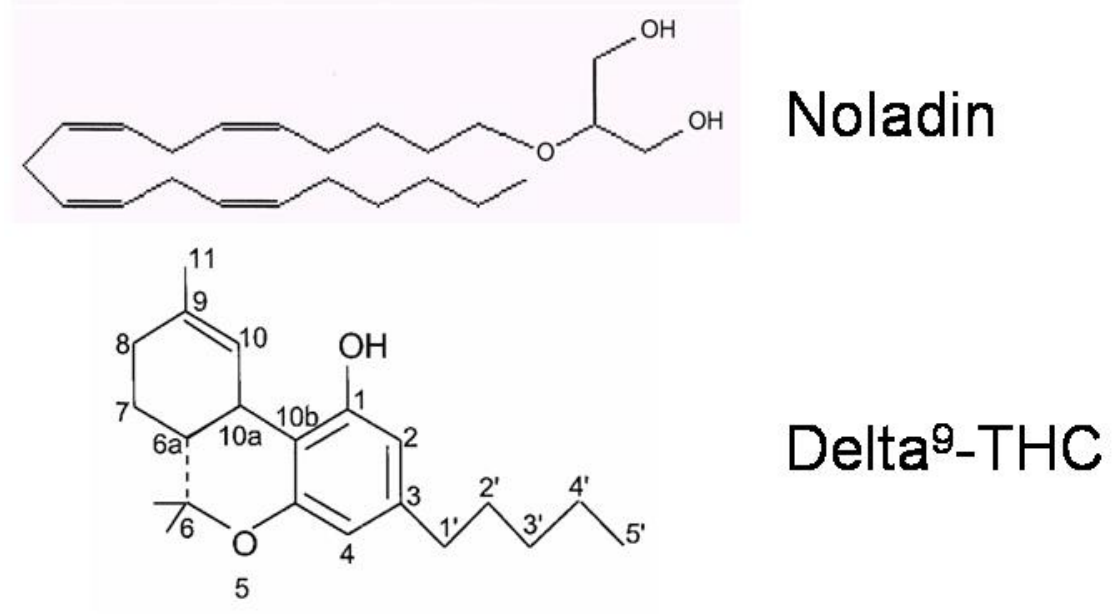

Abb. 1: Chemische Strukturformel des endogenen Arachidonsäurederivates 2Arachidonoylglycerolether (Noladin, oben), sowie des pflanzlichen delta9Tetrahydrocannabinols (delta9 ${ }^{9}$ THC, unten). 
Erstmals wurde im Jahr 1990 ein membranständiger, G-Protein gekoppelter endogener Cannabinoidrezeptor [HOWLETT et al. 1990; MATSUDA et al. 1990] entdeckt und nachfolgend kloniert. Der Rezeptor gab Anhalt für ein endogenes Cannabinoidsystem im Zentralnervensystem. Dieser wurde als zentraler Cannabinoidrezeptor (CB1) bekannt. 1993 wurde ein peripherer Cannabinoidrezeptor (CB2) entdeckt, der 2002 charakterisiert werden konnte [BROWN et al. 2002; MUNRO et al. 1993]. Aktuell wird davon ausgegangen, dass mindestens noch ein weiterer Rezeptor (CB1a) besteht, der bisher nur teilweise charakterisiert wurde [RYBERG et al. 2005].

Die Distribution der Rezeptoren ist organ- und zellspezifisch. So zeigte sich CB1 vornehmlich im Cortex, dem limbischen System, den Basalganglien und dem Cerebellum, aber auch in den Testes und der Milz [BOUABOULA et al. 1993; BREIVOGEL und CHILDERS 1998; GLASS et al. 1997; HERKENHAM et al. 1990]. Dem gegenüber wurde CB2 in Leukozten [ONAIVI et al. 1999] und Mikroglia [CARLISLE et al. 2002; WALTER et al. 2003] gefunden.

Die physiologische Bedeutung ist trotz intensiver Forschungsarbeit über die letzten 10 Jahre nur unzureichend bekannt. Hinweise auf Involvierung in Aufmerksamkeit, Gedächtnis, Gemütsverfassung, Emotionen, motorische wie sensorische Funktion, Verhalten, Immunmodulation, Temperaturregulation und Schmerzwahrnehmung konnten gezeigt werden [BONFILS et al. 2006; BRAIDA und SALA 2000; CALIGNANO et al. 1998; EHRENREICH et al. 1999a; FERRARI et al. 2000; GARDNER und MALLET 2006; HERNANDEZ-TRISTAN et al. 2000; JAMSHIDI und TAYLOR 2001; KONINGS und MAHARAJH 2006; MARSICANO et al. 2002b; MARTIN et al. 2002; NAVARRO et al. 1995; NAVARRO et al. 1997; STEIN et al. 1996]. Diese wurden weitgehend durch die vorbeschriebene Rezeptorlokalisation in immunmodulatorischen Blutzellen und ZNS-Strukturen erklärt.

Eine pathophysiologische Bedeutung kommt dem Cannabinoidsystem bei neuropsychiatrischen Erkrankungen [NEGRETE und KNAPP 1986; ROTTANBURG et al. 1982; SUNDRAM 2006], dem Schlaganfall [BONFILS et al. 2006; UNZICKER et al. 2005] und der Leberzirrhose [BATKAI et al. 2001] zu.

Neuroprotektive Eigenschaften wurden im Hinblick auf das in-vitro- und in-vivoÜberleben von Nervenzellen beschrieben. Dabei werden diese Wirkungen teilweise über CB1, teilweise rezeptorunabhängig vermittelt (siehe unten im Text).

Eine neuroprotektive Wirkung von CB2 ist bisher nicht bekannt, weshalb dieser Rezeptor nur eine untergeordnete Rolle in der vorliegenden Arbeit spielte. CB1a wurde weiterhin nur unzureichend hinsichtlich einer möglichen neuroprotektiven Wirkung untersucht.

CB1-rezeptorvermittelt konnte durch eine Dilatation venöser Gefäße dem Hirnödem entgegengewirkt, durch die Induktion einer milden Hypothermie sowie das 
Aufrechterhalten der Blut-Hirn-Schranke durch Cannabinoide eine neuroprotektive Wirkung erzielt werden [BONFILS et al. 2006; FERNANDEZ-LOPEZ et al. 2006; GRUNDY 2002; MAULER et al. 2003; MECHOULAM et al. 2002; PANIKASHVILI et al. 2006]. Durch Reduktion des intrazellulären Calciums und Entgegenwirkung der glutamatvermittelten Exzitotoxizität konnte eine intrazelluläre neuroprotektive Wirkung erzielt werden [HOWLETT 2005; SHOUMAN et al. 2006]. Die Inhibition von NF kappa B durch CB1-Aktivation zeigte einen Vorteil in der Überlebenswahrscheinlichkeit von Hippokampusneuronen in vivo [PANIKASHVILI et al. 2005].

Auch rezeptorunabhängig konnte durch Cannabinoide (z. B. delta9-THC) eine neuroprotektive Wirkung über das sogar dem Vitamin E überlegene antioxidative Potenzial erzielt werden [HAMPSON et al. 1998; HAMPSON et al. 2000; MARSICANO et al. 2002a].

Das Cannabinoidsystem könnte somit ein interessantes Zielsystem für die Entwicklung neuer Substanzen/Medikamente für die Neuroprotektion darstellen, da es auf eine Vielzahl der möglichen neuroprotektiven Mechanismen einen Einfluss hat. 


\subsection{Das zerebrale Endothelinsystem}

Endotheline wurden zuerst als vasoaktive Peptide im Zusammenhang mit angiologischem Hintergrund beschrieben [YANAGISAWA et al. 1988; YANAGISAWA und MASAKI 1989]. Sie regulierten physiologisch den Gefäßtonus und hatten einen Effekt auf die Herzfunktion [BRUNNER et al. 2006]. Sie spielten pathophysiologisch eine Rolle bei der Hypertonie [TOUYZ und SCHIFFRIN 2003], beim Herzversagen [ANGERIO 2005] und dem Herzinfarkt [CERNACEK et al. 2003; DOGGRELL 2004; FRACCAROLLO et al. 1997; KRAMER et al. 1997]. Eine physiologische oder pathophysiologische Funktion an fast allen Organen des menschlichen Körpers wurde beschrieben [GERSHON 1999; NAMBI 1996].

Es konnten aber in der Folge gefäßunabhängige Funktionen entdeckt werden. Im Gehirn [EHRENREICH und SCHILLING 1995] konnten sowohl gefäßabhängige als auch -unabhängige Effekte nachgewiesen werden. Diese wurden über zwei zellmembranständige Rezeptoren mediiert; Endothelinrezeptor (ET)-A und -B [BERTHIAUME et al. 2000; EHRENREICH et al. 1999b; EHRENREICH et al. 2000; HENRIKSSON et al. 2007; KUC et al. 2006; ZHANG Y et al. 2000]. Die Rezeptoren waren ähnlich den Cannabinoidrezeptoren G-Protein-gekoppelt und hatten Effekte bei der Dilatation und Kontraktion der Gefäße zur Regulation der Durchblutung des Hirngewebes. Die Effekte wurden durch die Endotheline 1-3 (ET-1, ET-2, ET-3) reguliert (siehe Abb. 2): 


\section{Das zerebrale Endothelinsystem}
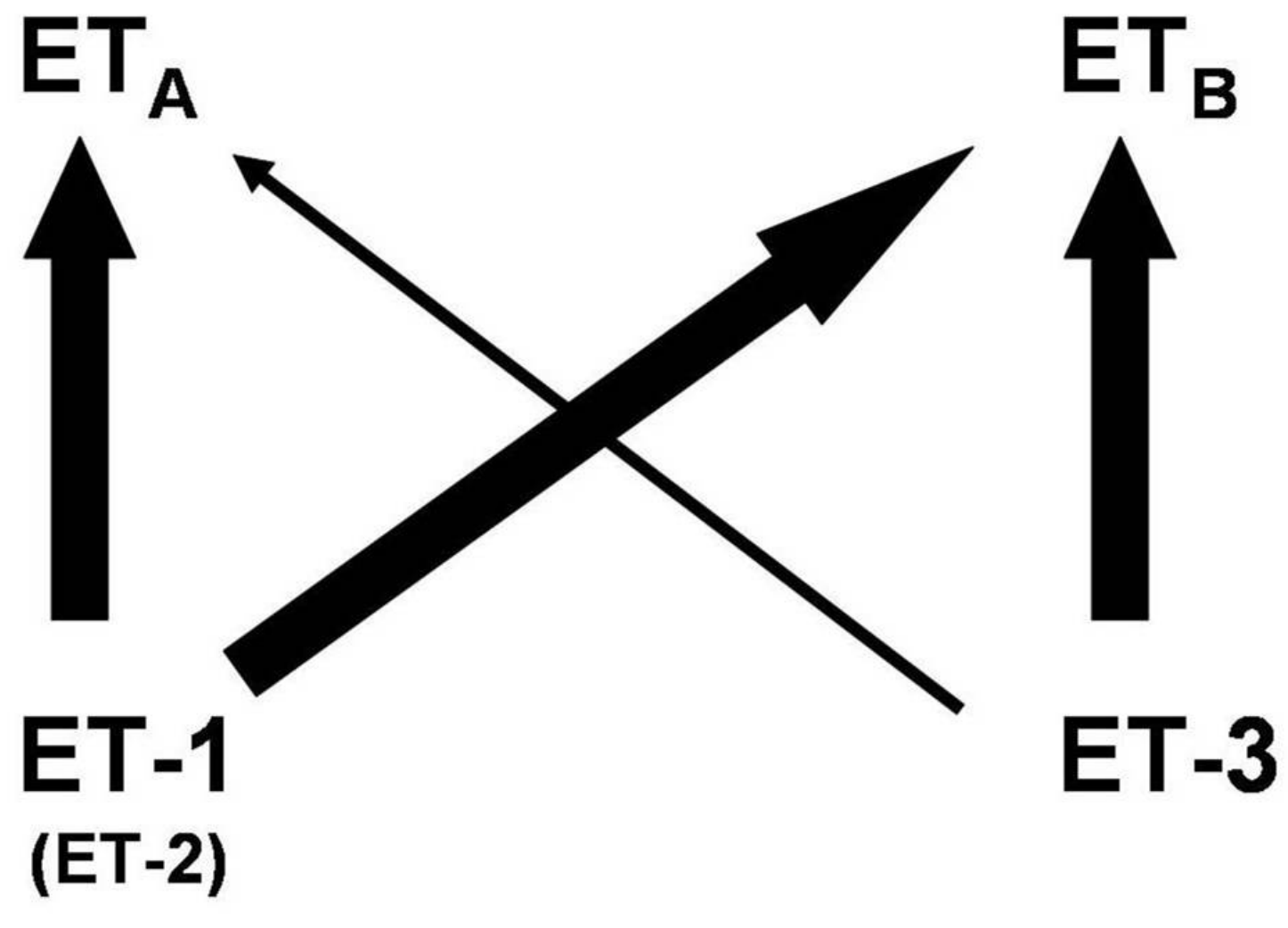

Abb. 2: Wirkung von Endothelin 1-3 auf die zerebralen ET-A und -B. Während ET-A eine Vasokonstriktion auslöst, vermittelt ET-B eine Vasodilatation. Wie in der vereinfachten Abbildung dargestellt, aktiviert ET-1 beide Rezeptoren, während ET-3 eher ET-B aktiviert.

Es etablierte sich die Auffassung, dass Endotheline mittels des G-Proteingekoppelten Rezeptors beim Typ B einen Einfluss auf multiple intrazelluläre Effekte in Neuronen haben. Darunter befanden sich bei Abwesenheit des Rezeptors Auswirkungen auf das Überleben, die Proliferation und Differenzierung neuronaler Zellen [BAYNASH et al. 1994; EHRENREICH et al. 2000; LAHAV et al. 1999; SHINOHARA et al. 2004; YAGAMI et al. 2002; YAGAMI et al. 2005]. Insbesondere ET-B-Agonisten wiesen antiapoptotische Wirkung auf kortikale Rattenneuronen [YAGAMI et al. 2002; YAGAMI et al. 2005] auf. Beim embryonalen bis juvenilen Hirn gab es Hinweise auf eine Abhängigkeit der Expression von ET-B und dem Auftreten von Zelltod, der zudem noch altersabhängig war [EHRENREICH et al. 1999b].

In der Entwicklung und Maturation des sich entwickelnden Gehirns unterstützte ET-B die Stimulation, die Proliferation und das Überleben der neuronalen Vorläu- 
ferzellen durch einen Gi-Protein gebundenen Anstieg der Phosphorylierung von extrazellulären signalregulierten Kinasen (ERK) [SHINOHARA et al. 2004], während das Fehlen von funktionellen ET-B in spotting-lethal (sl/sl) Ratten zu einer erhöhten neuronalen Apoptose, zum Beispiel im Dentatus des Hippokampus, einer Hirnregion, die bekannt für das Vohandensein von neuronalen Vorläuferzellen ist, führte [EHRENREICH et al. 2000; RIECHERS et al. 2004]. Da die Gesamthirnmorphologie jedoch bei diesen Tieren nicht verändert war [EHRENREICH et al. 1999b; EHRENREICH et al. 2000; HOSODA et al. 1994; RIECHERS et al. 2004], könnte zumindest ein partieller Kompensationsmechanismus für die erhöhte Apoptoserate bei ET-B-defizienten Ratten vorliegen.

\subsection{Fragestellung und Zielsetzung der Arbeit}

Gemeinsamkeiten von Endothelinsystem und Cannabinoidsystem ergeben sich in der vasomotorischen Aktivität (CB1 und ET-B) [O'SULLIVAN et al. 2005; TIRAPELLI et al. 2005], den intrazellulären Signalwegen (Inhibition der Adenylatzyklase, Aktivierung der MAP-Kinase und Jun N-terminal Kinase (JNK) sowie der Regulation von nukleären Transkriptionsfaktoren [HOWLETT 2005]), die bei beiden Systemen über G-Proteine antiapoptotische Mechanismen aktivieren. Beide Systeme greifen somit ineinander und könnten möglicherweise voneinander abhängen. Die Untersuchung einer möglichen neuroprotektiven Interaktion beider Systeme sollte darum in der vorliegenden Arbeit vorgenommen werden.

Dies sollte mit den folgenden Methoden am Rattenmodell untersucht werden:

1. Immunhistochemische Untersuchungen sollten eine Darstellung der CB1Expression im Hippokampus von Wildtyptieren und ET-B-defizienten Tieren ermöglichen, sowie die Expression des Rezeptors über drei verschiedene Zeitpunkte (juvenile Ratten: 3-4, 14-15, 21-22 Tage alt) mit unterschiedlichem Anteil an apoptotischen Zellen im Gehirn der Tiere darstellen.

Hierbei sollte eine mögliche Abhängigkeit der Expressionsstärke von CB1 vom Alter in hippokampalen Neuronen in vivo bei sl/sl-Tieren und bei Wildtypen gezeigt werden.

Ein Nachweis des Proteins sollte zusätzlich im Western Blot angestrebt werden, um eine Quantifizierung der Expression mit einer zweiten Methode zu überprüfen.

Eine Alteration der Expression durch Ab- oder Anwesenheit von ET-B sollte mittels einer quantifizierbaren Methode untersucht werden. Hier bot sich ein computergestütztes Verfahren (Scion Image) an, das die Dichte der Expression objektiv 
erfassen konnte. Bei Vorhandensein dieser möglichen Abhängigkeit sollte die der Expression von CB1 vom Überleben von Neuronen weiterhin untersucht werden.

2. Hat die Aktivation von CB1 durch synthetische oder endogene Cannabinoide einen neuroprotektiven Effekt in vivo und in vitro?

Dazu sollte ein neuroprotektiver Effekt von endogenen und synthetischen Cannabinoiden (Noladin und delta9-THC) in primären hippokampalen Neuronen beider Genotypen in vitro nachgewiesen werden.

Zusätzlich sollte in einem in-vivo-Modell die Wirksamkeit einer Applikation von delta9-THC bei Wistar-Imamichi-Ratten im Hypoxiemodell getestet werden, da hier eine erhöhte Expression von CB1 gezeigt wurde [JIN et al. 2000]. Dies wollten wir histologisch für CB1 und CB2 nachvollziehen. Wenn die Stimulation mit THC keinen negativen Effekt auf ET-B-gesunde Ratten hätte, wäre die Durchführung mit ET-B-defizienten Tieren geplant. Diese Vorversuche waren nötig, um die dann wegen der hohen Sterblichkeit der Mutanten aufgrund der HirschsprungKrankheit massiv auszuweitende Zucht zu rechtfertigen. Die Gabe von Noladin empfahl sich in vivo hier methodologisch aufgrund des schnellen Zerfalls der Substanz nicht.

Ziel der Studie ist es, eine mögliche Interaktion oder Abhängigkeit zwischen endogenem Cannabinoid- und Endothelinsystem im Rattenhirn unter pathophysiologischen und nicht pathologischen Voraussetzungen zu zeigen.

Die Erkenntnis einer möglichen Abhängigkeit der Expression von CB1 bei Abwesenheit von funktionellem ET-B könnte einen Hinweis auf eine Interaktion beider Systeme geben. Diese Erkenntnis könnte bei Erkrankungen wie der bakteriellen Meningitis von Wert sein, da dabei wie bei den sl/sl-Tieren eine Reduktion von ETB-Rezeptoren vorliegt [EHRENREICH et al. 2000]. Dies könnte über mögliche neue Behandlungsmöglichkeiten mit Cannabinoiden Aufschluss geben. 


\section{Material und Methoden}

\subsection{Tiere}

Für alle Versuche wurden Ratten des Wistar-Imamichi-Stammes verwendet. Diese Ratten trugen eine autosomal rezessive, 301 Basenpaare umfassende, Depletion des Endothelin-B-Rezeptor-Gens [DEMBOWSKI et al. 2000]. Die Depletion umfasste Exon 1 und Intron 1, die für die erste und die zweite Transmembrandomäne des Rezeptors codierten. Die Genotypen der Ratten wurden durch Verpaarung heterozygoter Rattenpaare hervorgebracht. Der Genotyp und das Geschlecht der Tiere wurden mittels der Polymerasekettenreaktion (PCR) bestimmt (siehe 2.1.1 ff).

Die Vorauswahl der Tiere für Zellkultur, Western Blot und in-vivo-Experimente fand anhand der Bestimmung des anogenitalen Abstandes statt. Ein großer Abstand zwischen Anus und Geschlechtsteil war dabei kennzeichnend für Männchen, ein kleiner für Weibchen.

\subsubsection{Bestimmung des Genotyps durch PCR: „Genotyping“}

Die Genotypen der neugeborenen Tiere wurden durch PCR nachgewiesen. Hierzu wurde genomische DNA mit Primern, die die 301 BP Deletion (CTG CAA CAT GCA ATC GTC CGC A und CAT AGA CTC AAC ACT GTG AT) des ET-B-Gens flankieren, amplifiziert. Dazu wurde Kleinhirngewebe entnommen und nach dem DNeasy-Protokoll von Qiagen DNA gewonnen.

\subsubsection{PCR: Genotyping}

Dafür wurden 0,2 $\mu \mathrm{g}$ DNA pro $50 \mu \mathrm{l}$ PCR-Reaktionsgemisch in PCRReaktiongefäße gegeben. Für 35 Zyklen wurde der Thermocycler wie folgt programmiert:

1) DNA-Denaturierung initial bei $94^{\circ} \mathrm{C}$ für eine Minute

2) Hybridisierung der Primer bei $65^{\circ} \mathrm{C}$ für $30 \mathrm{sec}$

3) Elongation des Primers bei $72^{\circ} \mathrm{C}$ für eine Minute und abschließend

4) Denaturierung der dsDNA bei $92^{\circ} \mathrm{C}$ für eine Minute. 


\subsubsection{Geschlechtsbestimmung durch PCR: „Sexing“}

Die Vorbestimmung des Geschlechts durch den anogenitalen Abstand wurde durch PCR des SRY-Gens verifiziert oder verworfen. Das SRY ist ein Gen, das auf dem Y-Chromosom liegt und somit bei Präsenz ein Männchen erkennt und ein Weibchen ausschließt.

\subsubsection{DNA-Gewinnung aus Frischgewebe}

Kleinhirngewebe (bei Zellkulturversuchen) oder ein Stück des Ohres (bei WesternBlot-Versuchen) wurde den Tieren entnommen und die DNA nach dem DNeasyProtokoll von Qiagen gewonnen.

\subsubsection{DNA-Gewinnung aus formaldehydfixierten, paraffinierten Ratten- hirnschnitten}

Hierbei wurde das Gewebe auf dem Objektträger mit einem Skalpell entfernt und in einem 2-ml-Eppendorfröhrchen aufgefangen. $1200 \mu \mathrm{l}$ Xylol wurden hinzugefügt, das Eppendorfröhrchen $5 \mathrm{~min}$ gevortext. Abnahme des Überstandes und Herauswaschen des Xylols erfolgte zwei Mal mit derselben Menge frischem Ethanol mit anschließendem Zentrifugieren des Eppendorfröhrchens vor Entnahme des Überstandes für 5 min bei höchster Geschwindigkeit. Das paraffinfreie Pellet wird weiter wie unter 2.1.1.1 behandelt.

\subsubsection{PCR: Sexing}

Hierzu wurden 0,5 $\mu \mathrm{g}$ DNA pro $50 \mu \mathrm{l}$ PCR-Reaktionsvolumen in PCRReaktiongefäße gegeben. Für 35 Zyklen wurde der Thermocycler programmiert:

1) DNA-Denaturierung initial bei $94^{\circ} \mathrm{C}$ für eine Minute

2) Hybridisierung der Primer bei $65^{\circ} \mathrm{C}$ für $30 \mathrm{sec}$

3) Elongation des Primers bei $72^{\circ} \mathrm{C}$ für eine Minute und abschließend

4) Denaturierung der dsDNA bei $92^{\circ} \mathrm{C}$ für eine Minute. 


\subsubsection{PCR-Kontrolle}

Zur internen Funktionskontrolle der PCR wurde je eine bekannte Versuchsprobe des zu erwartenden Typs mitaufgetragen. Eine Nullprobe ohne DNA wurde zusätzlich ebenfalls aufgebracht.

\subsubsection{Agarosegel- Elektrophorese}

Amplifizierte DNA wurde mit der Agarose- Gelelektrophorese dargestellt. Dafür wurden 1\% Agarosegel mit 20 Taschen hergestellt und in der Elektrophoresekammer mit TBE-Puffer bedeckt. $50 \mu \mathrm{l}$ der DNA wurden mit $10 \mu \mathrm{l}$ Gel Loading Lösung versetzt, bevor $15 \mu \mathrm{l}$ in davon in eine Tasche eingebracht wurde. Zur Größenbeurteilung wurden in die äußeren Taschen $4 \mu$ l einer DNA-Leiter pipettiert. Für zwei Stunden wurde so bei einer Spannung von $100 \mathrm{~V}$ eine Wanderung der Produkte gen Anode produziert. Die Ethidiumbromidfärbung der DNA innerhalb der Agarose wurde mittels einer UV-Lichtbank bei $302 \mathrm{~nm}$ mit einem Videogerät dargestellt und als Bild ausgedruckt.

\subsubsection{Verwendete Primer}

ET-B

Sense-Primer: 5’AGC CGC TGC GGA CGC GCC TT-`3, Position 267-286

Antisense-Primer: 5'-CAC GAC TTA GAA AGC TAC AC-`3, Position 191-172

Das erwartete Produkt war 600 BP (Wildtyp +/+), beziehungsweise 300 BP groß (ET-B-defizient sl/sl). Heterozygote Tiere (sl/+) zeigten beide Produkte.

SRY (Rattus norvegicus)

Sense-Primer: 5 `CCC GCG GAG GGC ACA AGT-`3, Position 143-163

Antisense-Primer: 5 `-CTC TAC TCC AGT CTT GTC CG-`3, Position 454-435

Das erwartete Produkt war 312 BP groß. 


\subsubsection{Materialien für PCR: Sexing und Genotyping}

PCR-Reaktionsgemisch: $5 \mu \mathrm{l}$ Taq extender reaction buffer, Fa. Stratagene

$0,5 \mu \mathrm{l}$ Taq DNA Polymerase ( $5 \mathrm{U} / \mu \mathrm{l})$, Fa. Gibco

$0,5 \quad \mu \mathrm{l}$ dNTP $(20 \mathrm{mM}), \quad$ Fa. Pharmacia, PharmaciaUltrapure Kit

$20 \mu \mathrm{l}$ Sense-Primer, Fa. IBA-NAPS

$20 \mu \mathrm{l}$ Antisense-Primer, Fa. IBA-NAPS

mit 0,1\% DEPC auf $50 \mu \mathrm{l}$ Endvolumen auffüllen

Hexanukleotide:

$100 \mathrm{pM}\left[\mathrm{d}(\text { Nukleotid) })_{6}-5^{\prime}-\mathrm{PO}_{4}\right] \mathrm{Na}^{+}$

5X TBE-Puffer:

$54 \mathrm{~g}$ Trisbase

27,5 g Borsäure

$20 \mathrm{ml}$ 0,5 M EDTA (pH 8,0)

alles Fa. Sigma, Deisenhofen

auf $11 \mathrm{ddH}_{2} \mathrm{O}$

0,5X TBE-Puffer wird durch 1:10 Verdünnung aus 5X TBE-Puffer hergestellt.

Ethidiumbromidlösung: $10 \mathrm{mg} / \mathrm{ml}$ Ethidiumbromid als wässrige Lösung, Fa. Sigma

Gel Loading Solution, Fa. Sigma

1\% Agarosegel: $\quad$ 1,5 g Agarose, Fa. Gibco

$150 \mathrm{ml} \mathrm{0,5}$ X TBE-Puffer

$6 \mu \mathrm{l}$ Ethidiumbromidlösung

$1 \mathrm{~kb}$ DNA-Leiter: $\quad 50 \mu \mathrm{l}$ DNA-Leiter

$100 \mu \mathrm{l}$ Gel Loading Solution 
$50 \mu l$ Taq-Extender Buffer, Fa. Stratagene

$300 \mu \mathrm{ldd} \mathrm{H}_{2} \mathrm{O}$

\subsection{Immunhistochemie}

Immunhistochemische Färbungen wurden wie unter 2.2.1 folgend durchgeführt.

\subsubsection{Cannabinoidrezeptor 1 und 2 (CB1 und CB2)}

\subsubsection{Färbung von paraffinierten Schnitten des Rattenhirns}

Wistar-Imamichi-Ratten der drei unterschiedlichen Genotypen wurden am postnatalen Tag drei bis vier, 13 bis 15 und 21 bis 23 in tiefer Ethyletheranästhesie dekapitiert. Sofort wurde das Gehirn entnommen und in 4\% Paraformaldehyd fixiert. Im Anschluss wurden die fixierten Gehirne in Paraffin eingebettet, im Mikrotom $1 \mu \mathrm{m}$ fein geschnitten und auf SuperFrost-Objektträger aufgezogen.

Alle weiteren Schritte erfolgten bei Raumtemperatur, wenn nicht gesondert vermerkt. Zum Herauslösen des Paraffins wurden die schnitttragenden Glasobjektträger im Ofen für je 35 min zuerst ohne, dann mit $99.9 \%$ Xylol auf $60^{\circ} \mathrm{C}$ erhitzt. In frischem, raumtemperiertem Xylol wurden die Schnitte zweimalig 5 min abgekühlt.

Gradiertes Ethanol ( 2 x 100\%, 2 × 95\%, 70\%, 50\%) wurde in absteigender Reihenfolge zum Herauswaschen des Xylols verwendet. Abschließend wurde der Schnitt für $5 \mathrm{~min}$ in $\mathrm{dH}_{2} \mathrm{O}$ gewässert.

Zum Blocken der endogenen Peroxidaseaktivität folgte eine Inkubation in 3\% $\mathrm{H}_{2} \mathrm{O}_{2}$ für 10 min. Gewaschen wurde anschließend zuerst in $\mathrm{dH}_{2} \mathrm{O}$, dann in PBS für je 5 min.

Die Schnitte inkubierten anschließend für eine Stunde in der Feuchtkammer mit $10 \%$ Schafserum.

Nach Abschütten des Serums wurden die primären Antikörper (Kaninchen) in Konzentration 1:100 für CB1 und CB2 (in PBS mit 2\% Schafserum) aufpipettiert und die Schnitte für 15 Stunden bei $4^{\circ} \mathrm{C}$ inkubiert. Die Antikörperlösung wurde anschließend mit einer Pipette entnommen und gesammelt, während der Schnitt zweimalig für je $10 \mathrm{~min}$ in PBS gewaschen wurde (Waschschritt). $25 \mu \mathrm{l}$ des biotiny- 
lierten Zweitantikörpers (Ziegen-IgG gegen Kaninchen) wurde mit $75 \mu$ l Schafserum in $5 \mathrm{ml}$ PBS gelöst. Die Schnitte wurden für eine Stunde darin inkubiert. Nach einem weiteren Waschschritt inkubierten sie für eine Stunde in ABCKomplexlösung. Diese wurde zuvor nach Herstellerangaben angesetzt (2 Tropfen von je Lösung A and B in $5 \mathrm{ml}$ PBS). Nach dem letzten Waschschritt wurden die Schnitte zum Visualisieren in Diaminobenzidinlösung (36mg DAB, $10 \mu 130 \% \mathrm{H}_{2} \mathrm{O}_{2}$ in $60 \mathrm{ml}$ TRIS-PBS) für 6 min entwickelt, zweimalig für $10 \mathrm{~min}$ in $\mathrm{dH}_{2} \mathrm{O}$ gewaschen und anschließend in ansteigender Ethanolkonzentration (wie eingangs, beginnend mit 50\%) bis zum Xylol für je 5min gelagert. Die Schnitte wurden mit Eukitt und einem Deckplättchen versiegelt und für zwei Tage unter dem Abzug getrocknet, bis mit der Evaluation unter dem Mikroskop begonnen wurde.

\subsubsection{Ermittlung der Expression}

Rechter und linker Gyrus dentatus des Hippokampus wurden mit einer SPOTDigitalkamera, (Fa. Diagnostic Instruments, Sterling Heights, USA) bei einer Vergrößerung von 1:200 abfotografiert und als Bild (.tiff-Format, 1-2 Megabyte pro Bild) gespeichert. Von jedem Tier wurden pro Hippokampus mindestens zwei, höchstens vier Bilder angefertigt. Diese wurden im Anschluss verblindet und einzeln nacheinander wie folgt ausgewertet.

Nachfolgende Schritte erfolgten mit dem Computerprogramm SCION-Image Version Beta 4.0.2 (C 2000 Scion Corporation, USA).

Zuerst wurden die Farbbilder in Schwarzweißbilder umgewandelt. Evaluiert wurde die Dichte an schwarzen Pixeln pro ausgewähltem Gebiet. Dazu wurden die Pyramidalzellen, die Granularzellen und ein Hintergrundgebiet ohne spezifische Zellfärbung ausgewählt und gemessen. Die Prozedur wurde pro Bild dreimal für jeden der drei Bildbereiche durchgeführt.

Ermittelte Werte wurden in eine EXCEL-Tabelle (Microsoft EXCEL 2002, Fa. Microsoft, USA) überführt. Nachfolgende Schritte wurden mit diesem Programm durchgeführt:

Die Hintergrundfärbung wurde von der ermittelten Immunoreaktivität abgezogen. Pyramidalzellwert und Granulosazellwert wurden zuerst für jeden Hippokampus, dann für jedes Tier anhand der gemessenen Werte gemittelt. Die entstehenden Werte für jedes Tier wurden dann entblindet, sodass die Tiere nach Genotypen und Alter sortiert werden konnten. 


\subsection{Zellkultur}

Für die Zellkulturen wurden ausschließlich 0-24h alte, weibliche Ratten der Genotypen $\mathrm{sl} / \mathrm{sl}$ und +/+ verwendet.

Sie wurden durch Dekapitation getötet, die Köpfe auf einer sterilen, eisgekühlten Petrischale zur Reinraumwerkbank überführt. Alle folgenden Schritte wurden dort unter sterilen Bedingungen durchgeführt.

\subsubsection{Primärkulturen hippokampaler neuronaler Zellen}

Hippokampale Neuronen wurden, mit wenigen Modifikationen, nach dem Protokoll Brewers [BREWER et al. 1993] kultiviert.

\subsubsection{Präparation, Anreicherung, Aussaat und Kulturbedingungen}

1) behutsame sagittale Eröffnung des Schädels, Lateralbewegung der Ossa parietale et frontale

2) vorsichtige Herauslösung des Gehirns auf eine sterile, gekühlte Petrischale

3) unter stereomikroskopischer Sicht Entfernung des Cerebellum, stumpfe Separation der Hemisphären und sorgfältiges Abziehen der Gefäße und Meningen mit Pinzetten

4) nach Aufsuchen der Hippokampi Exstirpation und Säuberung dieser mittels Präparationslöffel

5) Überführung in ein 12-ml-Röhrchen (Fa. Sarstedt) mit 2 mg Papain/ml HBSS, im Wasserbad bei $30^{\circ} \mathrm{C}$ unter moderatem Schütteln Inkubation

6) Papain-Inaktivierung durch HBSS mit 10\%FCS und Entfernung des Überstandes

7) Hinzufügen von $2 \mathrm{ml}$ frischem HBSS, zehnmalige langsame Trituration der Hippokampi mit einer 1-ml-Pipette

8) Entnahme von 1,5 ml Überstand in ein 12-ml-Röhrchen 
9) zweimalige Wiederholung der letzten beiden Schritte mit Sammeln des Zellüberstandes im selben Röhrchen

10) Gradientenzentrifugation der etwa 5-6 ml Zellsuspension mittels unterlegter Dichtegradienten $(35 \%, 25 \%, 20 \%, 15 \%$ Optiprep/ml HBSS), 15min bei $1900 \mathrm{~g}$ $\left(25^{\circ} \mathrm{C}\right.$, ohne Bremse)

11) Gewinnung von circa $2,5 \mathrm{ml}$ angereicherter Zellsuspension aus den Fraktionen 2 und 3

12) Hinzufügen von $5 \mathrm{ml}$ HBSS

13) Zentrifugation $1 \mathrm{~min}$ bei $1000 \mathrm{~g}, 25^{\circ} \mathrm{C}$

14) Entnahme des Überstandes und Auflösung des Pellets in $1 \mathrm{ml}$ NeurobasalA

15) Bestimmung der Zelldichte in der Neubauer-Zählkammer (20 $\mu$ l Zellsuspension/ $20 \mu \mathrm{l}$ Trypanblau)

16) Aussaat der Neuronen in einer Dichte von 50 Zellen/mm $\mathrm{m}^{3}$ auf Poly-D-Lysin beschichteten, runden Deckgläschen in 4-Kammer-Platten

17) Waschen der Zellen nach einstündiger Inkubation mit HBSS und erneutes Auffüllen mit NeurobasalA

19) Kultivierung für 5 Tage im Inkubator bei $37^{\circ} \mathrm{C}, 5 \% \mathrm{CO}_{2}$ ohne Mediumwechsel

Die Zellen wurden nach Ablauf der Inkubationszeit von 5 Tagen bei Bildung von Fortsätzen und Netzwerken zur Immunzytochemie und/oder Hypoxieversuchen verwendet.

\subsubsection{Hypoxie}

Zur Induktion von Zelltod und zum Testen neuroprotektiven Potenzials von Cannabinoiden wurde das Zellmedium zuerst zur Hälfte mit frischem NeurobasalA mit oder ohne Cannabinoid unter Lichtschutz ersetzt.

Zurück im Inkubator wurde dieser mit $161 \mathrm{~N}_{2} / \mathrm{min}$ für 6 min geflutet. Um eine konstante $\mathrm{O}_{2}$-Konzentration $<1 \%$ zu ermöglichen, wurde der Inkubator für die nächsten 15h mit $11 \mathrm{~N}_{2}$ / min äquilibriert. Kontrollkulturen wurden bei Normoxie parallelinkubiert. 


\subsubsection{Zugabe von delta9'-THC- und Noladin}

Die CB1-Agonisten Noladin (2-Arachidonoylglycerolether) und delta9-THC wurden in Alkohol gelöst und als $1 \mathrm{mM}$ und $1 \mu \mathrm{M}$ Stocklösung in Neurobasal aliquotiert und bei $-20^{\circ} \mathrm{C}$ bis zum Verbrauch gekühlt. Für jede Kultur wurde ein neues Aliquot benutzt.

Bei reduziertem Licht während des Pipettierens wurden Mediumkonzentrationen von $10 \mathrm{nM}$ und $10 \mu \mathrm{M}$ delta9-THC und $100 \mathrm{nM}$ und $1 \mu \mathrm{M}$ Noladin zum Versuch verwendet.

Die Ethanolkonzentration in den Lösungen lag zwischen $0,1 \%$ bis 0,0013\%.

\subsubsection{Zelltodbestimmung}

Der Hypoxie folgte zeitnah die Bestimmung des Zelltodes pro Kammer.

Dazu wurden die Neuronen in den Kammern mit $100 \mu$ l 4\% Trypanblaulösung nach Entfernen des Mediums für 30 Sekunden gefärbt. Die blaue Lösung wurde verworfen und die Zellen unter dem Stereomikroskop betrachtet.

Zur quantitativen Bestimmung wurden blau gefärbte Zellen als tote, ungefärbte als lebende Zellen interpretiert. In 5 einander nicht überschneidenden Gesichtsfeldern wurden lebende und tote Zellen, 280-450 Zellen pro Kammer gesamt, ausgezählt. Für jede Kondition wurden zwei Kammern ausgezählt. Alle Konditionen eines Versuchs wurden jeweils an der aus der gleichen Präparation stammenden Zellkultur durchgeführt.

\subsection{Proteinnachweis durch Western Blot}

Für den Nachweis von CB1-Protein im Hippokampus wurden 3-4, 14-15 und 21-22 Tage alten, anästhesierten und dekapitierten, weiblichen Ratten der drei Genotypen der linke sowie der rechte Hippokampus entnommen (Entnahme der Hippokampi nach 2.3.1.1 ), in 1,5-ml-Eppendorfröhrchen sofort auf Trockeneis schockgefroren und bis zur Verwendung bei $-80^{\circ} \mathrm{C}$ gelagert. 


\subsubsection{Proteinextraktion}

Alle Schritte wurden auf Eis oder Trockeneis durchgeführt.

1) Wiegen des Gewebes, Hinzufügen der fünffachen Menge des Eigengewichts an Lysepuffer und viermaliges, abwechselndes Zerstampfen und Gefrieren des Gewebes

2) Lysiertes Gewebe mit 1 ml-Spritze aufziehen und 10 Mal triturieren

3) Transferieren des Lysats in ein 2-ml-Eppendorfröhrchen

4) Zentrifugieren bei $1200 \mathrm{U} / \mathrm{min}$ bei $4^{\circ} \mathrm{C}$ für $45 \mathrm{~min}$

5) Sammeln des Überstandes in einem frischen Eppendorfröhrchen

6) Entnahme von $5 \mu \mathrm{l}$ des Überstandes für die Proteinbestimmung, weiter bei 2.4 .2

7) Hinzufügen 1/3 der Eigenmenge von 4 X Lämmli-Elektrophoresepuffer

8) Erhitzen für 5 min in einem kochenden Wasserbad

Anschließend wurden die Proben bei $-80^{\circ} \mathrm{C}$ gelagert.

\subsubsection{Proteingehalt}

Der Proteingehalt der einzelnen Proben wurde nach der Lowrymethode durchgeführt [DAWSON und HEATLIE 1984; HASSELBLATT et al. 2003; LOWRY et al. 1951].

Dazu wurden sie 1:50 mit $\mathrm{dH}_{2} \mathrm{O}$ verdünnt und je $50 \mu \mathrm{l}$ mit $150 \mu \mathrm{l} \mathrm{dH}_{2} \mathrm{O}$ in ein Eppendorfröhrchen pipettiert. Die Standardkurve wurde ebenfalls in Eppendorfröhrchen pipettiert. Nach Hinzufügen von $1 \mathrm{ml}$ frischer Kupfer-Lösung inkubierten die Zellen 15 min. Im Anschluss wurde $100 \mu$ l Folin-Ciocalneus Phenolreagenz zu jedem Eppendorfröhrchen pipettiert und direkt gevortext.

$200 \mu \mathrm{l}$ jeder Probe wurde im Triplikat auf ein 96-wellplate überführt und die Absorption mit dem ELISA-Reader gemessen.

Anhand der Absorption der Standardkurve (nach 2.4.2.1) konnte die Proteinkonzentration jeder Probe errechnet werden. 


\subsubsection{Herstellung der Standardkurve}

$1 \mathrm{mg} / \mathrm{ml}$ BSA wurde auf die Konzentrationen $0 \mu \mathrm{g} / 150 \mathrm{ml}, 2,5 \mu \mathrm{g} / 150 \mathrm{ml}, 5 \mu \mathrm{g} / 150$ $\mathrm{ml}, 7,5 \mu \mathrm{g} / 150 \mathrm{ml}, 10 \mu \mathrm{g} / 150 \mathrm{ml}, 12,5 \mu \mathrm{g} / 150 \mathrm{ml}, 15 \mu \mathrm{g} / 150 \mathrm{ml}$ und $20 \mu \mathrm{g} / 150 \mathrm{ml}$ verdünnt.

\subsubsection{Gelelektrophorese und Blotten}

NuPAGE precast Gel wurde nach Anleitung präpariert, in die Elektrophoresekammer eingelegt und die Kammern mit jeweils $10 \mu \mathrm{l}$ der Probe befüllt. Nach 35 min bei $200 \mathrm{~V}$ wurde das Gel entnommen und aus seiner Form gelöst. Auf das Gel wurde ein Membranfilterpapier aufgebracht und zwischen Schaumstoffplatten in das Blotgefäß mit Transferpuffer gestellt. Dieses wurde in die mit $\mathrm{ddH}_{2} \mathrm{O}$ befüllte Elektrophoresekammer gedrückt und bei $30 \mathrm{~V} 60$ min geblottet.

Die Membran konnte entnommen werden.

\subsubsection{Färbung und Darstellung}

Die Membran wurde mit Ponceau-S (Fa. Serva) für eine Minute gefärbt, die Marker mit einem wasserfesten Stift nachgezogen, kopiert und durch zweimaliges Waschen in TBST wieder entfärbt.

\subsubsection{CB1-Rezeptor Detektion}

Zur Darstellung des Cannabinoid-1-Rezeptors wurde die Membran wie folgt behandelt:

1) Blocken mit Blockpuffer für eine Stunde im Schüttelbad

2) Inkubation mit CB1-Ak, (1:2000 bei Cayman-Ak, 1:500 bei Biosource-Ak) bei $4^{\circ} \mathrm{C}$ für 15 Stunden im Schüttelbad

3) Waschen mit TBST drei Mal 10 min (Waschschritt)

4) Inkubation mit POD-Zweitantikörper gegen Kaninchen-IgG

5) Waschschritt 
6) Trocknen der Membran mit Filterpapier

7) Bedecken mit ECL (+) Lösung für 5 min, danach Absaugen mit Filterpapier

8) beidseitiges Bedecken mit einer transparenten Folie

9) Auflegen von Fotopapier und Entwickeln desselben.

\subsubsection{Auswertung der CB1-Expression}

Das entwickelte Foto wurde eingescannt und als .tiff Datei gespeichert.

Mit SCION-Image wurde das Bild in ein Schwarzweißbild umgewandelt, und anschließend die Zahl schwarzer Pixel pro festgelegtem Bildausschnitt und der Hintergrund gemessen.

Alle gemessenen Werte wurden in eine Microsoft EXCEL-Tabelle eingefügt und dort weiterverarbeitet. Zur Bestimmung des Endwertes wurde der Hintergrundwert abgezogen. 


\subsection{Vorversuch zur Behandlung von Wistar-Imamichi- Ratten unter Hypoxie/Ischämie mit delta ${ }^{9}$-THC in vivo}

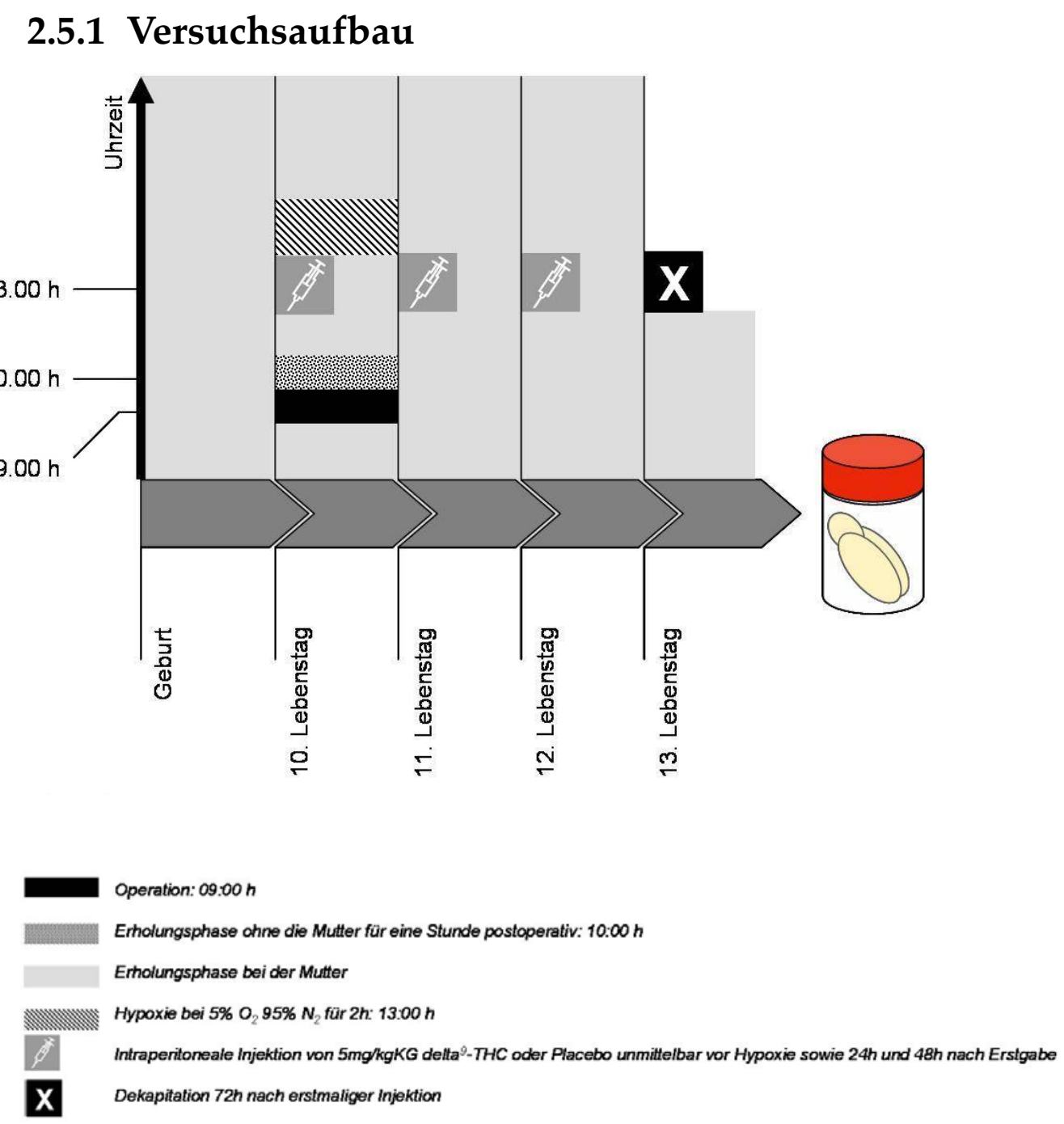

Abb. 3: Zeitlicher Aufbau für die in-vivo-Hypoxie/Ischämie-Vorversuche bei Wistar-ImamichiRatten: Gabe von Placebo oder delta ${ }^{9}-$ THC nach Okklusion der A. carotis communis einmalig vor Hypoxie/Ischämie, sowie 24 und 48 Stunden nach Erstgabe. Dekapitation der Tiere 72 Stunden nach THC-Erstgabe. 


\subsubsection{Arteria-carotis-communis-Okklusionsmethode mit intraperitonealer THC-Gabe}

Zehn Tage alte Wistar-Imamichi-Ratten wurden mit Halothan anästhesiert und die rechte Arteria carotis communis durch mittellinige Halsinzision exponiert. Nach vorsichtiger Präparation wurde das Blutgefäß mit einem 5-0 Seidenfaden zweimal ligiert und permanent okkludiert [EHRENREICH et al. 2005; SIREN et al. 2002].

Nach einer Erholungsphase von einer Stunde bei der Mutter wurden die Tiere mit einer intraperitonealen Injektion von $5 \mathrm{mg} / \mathrm{kg}$ Körpergewicht delta9-THC oder Placebo für zwei Stunden unter Hypoxie $\left(95 \% \mathrm{~N}_{2}, 5 \% \mathrm{O}_{2}\right)$ gestellt. Im Anschluss wurden die Tiere wieder der Mutter zugeführt.

Im Verlauf wurde die Behandlung 24 und 48 Stunden nach Hypoxie fortgesetzt und die Injektion mit THC oder Placebo zur gleichen Uhrzeit wiederholt

Der Versuchsaufbau wurde in Abb. 3 dargestellt. 


\subsubsection{Entnahme und Aufbereitung der Rattenhirne}

Die Versuchstiere wurden mit Halothan tief narkotisiert und durch Dekapitation getötet. Eine vorsichtige Hirnentnahme mit Pinzette und Spatel erfolgte nach weiter Eröffnung der Schädelkalotte und des dorsalen Neuralkanals in der Mittellinie. Entnommene Hirne wurden sofort in 4\% PFA-Lösung überführt und bis zur weiteren Verwendung im Kühlschrank bei $4^{\circ} \mathrm{C}$ aufbewahrt.

Nach Paraffineinbettung wurden die gekühlten Paraffinblöcke auf einem Schlittenmikrotom $1 \mu \mathrm{m}$ stark geschnitten und auf Glasobjektträger aufgebracht.

Ein Teil der Schnitte, mindestens zwei pro Tier, wurde mit Hämatoxylin und Eosin gefärbt.

\subsubsection{HE-Färbung}

Deparaffinierung und Rehydratation erfolgte wie bei 2.2.1.1, danach wurde der Schnitt für $8 \mathrm{~min}$ in Hämalaun gefärbt, mit $\mathrm{dH}_{2} \mathrm{O}$ abgespült, zwei Mal in $\mathrm{HCl}-$ Ethanol eingetaucht, unter laufendem Leitungswasser 10 min gespült und im Anschluss 6 min in Eosin gegengefärbt.

Zuletzt wurde eine Dehydratation und Versiegelung wie bei 2.2.1.1 beschrieben durchgeführt. 


\subsubsection{Auswertung}

HE-gefärbte Schnitte wurden nach folgendem Schema in Abb. 4 doppelblind untersucht:

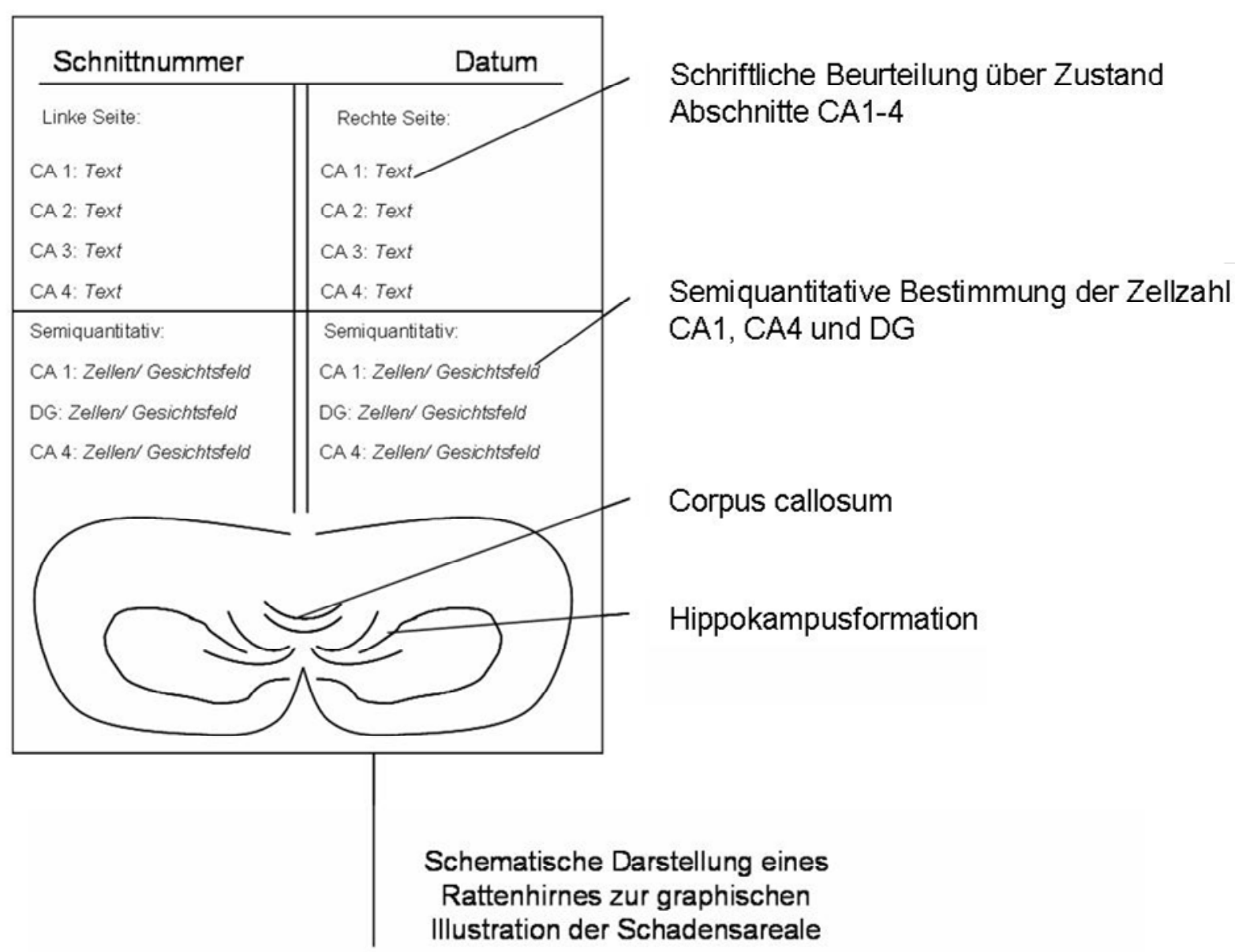

Abb. 4: Schema zur Evaluation von HE-gefärbten Schnitten mit qualitativer und quantitativer Auswertung.

Zusätzlich wurden die toten und die lebenden Zellen im CA1 des Hippokampus unter dem Mikroskop gezählt. 


\subsection{Materialien und Großgeräte}

\subsubsection{Verbrauchsmaterialien und Geräte}

Materialien und Großgeräte wurden in Tab. 1 dargestellt.

\section{(1) VERBRAUCHSMATERIALIEN}

\author{
Name \\ anti-CB1 Antikörper \\ anti-CB2 Antikörper \\ anti-CB1 Antikörper \\ Halothan Eurim
}

$1 \mathrm{ml} ; 1,5 \mathrm{ml} ; 2 \mathrm{ml}$ Eppendorfröhrchen

4 wellplate

12 wellplate

96 wellplate

Petrischale, klein

Petrischale, mittel

Petrischale, groß

50-mL-Falcontube

12-ml-Röhrchen

Ethanol

Xylol

Noladin

delta9-THC

biotinylated anti-rabbit Ak

3`3-Diaminobenzidin

biotinylated anti-goat Ak

Flourescein anti-goat Ak

texas red anti-rabbit Ak

Normal goat serum

Normal sheep serum

Normal horse serum

Optiprep

HBSS

Neurobasal A

$\mathrm{ABC}$ kit

\section{Hersteller}

Cayman Chemical, Ann Arbor, USA

Cayman Chemical, Ann Arbor, USA

Biosource, Solingen, DE

EurimPharm, Piding, DE

Eppendorf AG, Hamburg, DE

Roskilde, Wiesbaden, DE

Roskilde, Wiesbaden, DE

Roskilde, Wiesbaden, DE

Roskilde, Wiesbaden, DE

Roskilde, Wiesbaden, DE

Roskilde, Wiesbaden, DE

BD Biosciences, Heidelberg, DE

Sarstedt, Nümbrecht, DE

Merck, Darmstadt, DE

Merck, Darmstadt, DE

Prof. Dr. R. Mechoulam, Jerusalem, Israel

Sigma RBI, Deisenhofen ,DE

Vector, Burlingame, USA

Sigma, Deisenhofen, DE

Vector, Burlingame, USA

Vector, Burlingame, USA

Vector, Burlingame, USA

Jackson ImmunoResearch, Baltimore, USA Jackson ImmunoResearch, Baltimore, USA Jackson ImmunoResearch, Baltimore, USA Fresenius Kabi Norge AS, Oslo, Norwegen

Invitrogen Gibco, Karlsruhe, DE

Invitrogen Gibco, Karlsruhe, DE

Vector, Burlingame, USA 


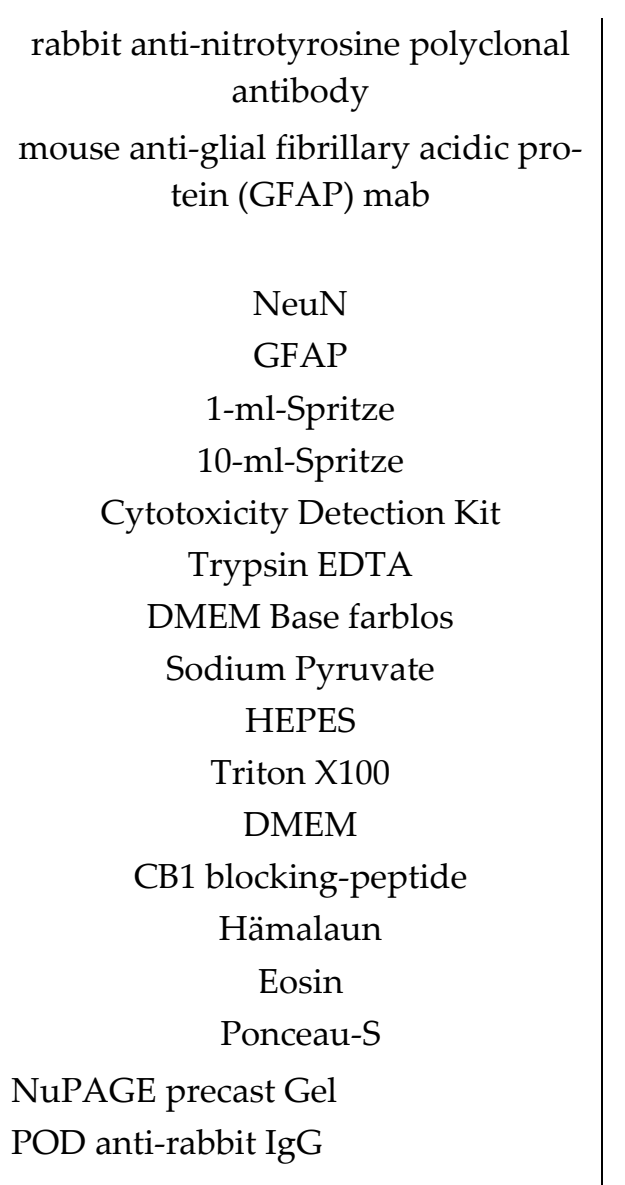

(2) GERÄTE

Name
Inkubator

Liebherr glass line

GFL 3015 Rotating Platform

Herafreeze $\left(-80^{\circ} \mathrm{C}\right)$

Vortex-Genie2

LaminAir® HB 2472

Ofen GFL 7601

Wasserbad GFL 1083

Thermocycler

Blockthermo Typ UBD2

Megafuge 2.0R

Eppendorf Centrifuge 5415 C

Telaval 31 Mikroskop GASI

Binokularmikroskop

MRX TC Revelation

Osmometer Automatik

RCT basic heater

T3 Thermocycler

DNA Thermal Cycler 480
Chemicon, Temecula, USA

Boehringer, Mannheim, DE

Chemicon, Temecula, USA

Sigma, Deisenhofen, DE

B.Braun AG, Melsungen, DE

B.Braun AG, Melsungen, DE

Roche Diagnostics GmbH, DE

BioWhittaker Europe, Verviers, Belgien

Sigma, Deisenhofen, DE

Invitrogen Gibco, Karlsruhe, DE

Invitrogen Gibco, Karlsruhe, DE

Sigma, Deisenhofen, DE

Invitrogen Gibco, Karlsruhe, DE

Cayman Chemicals, Ann Arbor, USA

Merck, Darmstadt, DE

Merck, Darmstadt, DE

Serva Electrophoresis, Heidelberg, DE

Invitrogen, Karlsruhe, DE

Vector, Burlingame, USA

\section{Hersteller}

Heraeus instruments, Osterode, DE

Liebherr, Bieberach, DE

GFL, Burgwedel, DE

Heraeus instruments, Osterode, DE

Scientific Industries, USA

Heraeus instruments, Osterode, DE

GFL, Burgwedel, DE

GFL, Burgwedel, DE

Eppendorf AG, Hamburg, DE

Schütt, Göttingen, DE

Heraeus Sepatech, Hanau, DE

Eppendorf AG, Hamburg, DE

Zeiss, Jena, DE

Schott, Mainz, DE

Zeiss, Jena, DE

Dynex Technologies, Berlin, DE

Knauer, Berlin, DE

KIKA Labortechnik, Staufen, DE

Biometra, Göttingen, DE

Perkin Elmer, Überlingen, DE 
PowerPac 200

Digital pH Meter pH 525

privileg 8021 Mikrowelle

Seralpur PRO $90 \mathrm{CN}$
Bio-Rad, München, DE

WTW, Weilheim, DE

privileg, Fürth, DE

seral Reinstwasser-Systeme, DE

Tab. 1: Tabellarische Darstellung der (1) Verbrauchsmaterialien und (2) Geräte und jeweiligem Hersteller. Die Abkürzung DE entspricht dem Herkunftsland Deutschland, USA entspricht dem Herkunftsland der Vereinigten Staaten von Amerika.

\subsubsection{Lösungen, Puffer, Zellkulturmedien}

\begin{tabular}{|c|c|c|}
\hline PBS $10 \times(p H 7,3):$ & $\mathrm{dd} \mathrm{H}_{2} \mathrm{O}$ & $1600 \mathrm{~g}$ \\
\hline & $\mathrm{NaCl}$ & $160 \mathrm{~g}$ \\
\hline & $\mathrm{KCl}$ & $4 \mathrm{~g}$ \\
\hline & $\mathrm{Na}_{2} \mathrm{HPO}_{4} \times 7(2) \mathrm{H}_{2} \mathrm{O}$ & $23 \mathrm{~g}$ \\
\hline & $\mathrm{KH}_{2} \mathrm{PO}_{4}$ & $4 \mathrm{~g}$ \\
\hline
\end{tabular}

Auffüllen mit ddH2 $\mathrm{O}_{2}$ bis 2L. Verdünnung auf PBS $1 \mathrm{X}$ vor Benutzung.

Alle Chemikalien wurden von Fa. Merck, Darmstadt, bezogen.

Zitratpuffer (A): $\quad$ Zitronensäuremonohydrat

Zitratpuffer (B): $\quad$ Natriumzitrat-Dihydrat
$21,01 \mathrm{~g} / 1000 \mathrm{ml} \mathrm{ddH}{ }_{2} \mathrm{O}$

$29,41 \mathrm{~g} / 1000 \mathrm{ml} \mathrm{ddH} \mathrm{H}_{2} \mathrm{O}$

Beide Puffer Merck, Darmstadt. Zitratpuffer wurde aus $3 \mathrm{ml}$ Puffer A und $17 \mathrm{ml}$ Puffer B hergestellt. Einstellung auf pH 6.0, dann 1:10 Verdünnen mit dd $\mathrm{H}_{2} \mathrm{O}$.
Formalin ( $\mathrm{pH} 7,2)$ :
$\operatorname{PBS}\left(60^{\circ} \mathrm{C}\right)$
$500 \mathrm{ml}$
Paraformaldehyd
$20 \mathrm{mg}$

Von Fa. Serva, Heidelberg. $\mathrm{NaOH}$ und $\mathrm{HCl}$ je $1 \mathrm{mM}$ von Merck, Darmstadt zum Einstellen des $\mathrm{pH}$ und der Lösung von PFA. 
Tris-PBS (pH 7,6):

TRIZMA $\mathrm{HCl}$

$7,88 \mathrm{~g}$

PBS $10 x$

$50 \mathrm{~g}$

Fa Sigma, Deisenhofen. Mit $\mathrm{dH}_{2} \mathrm{O}$ auf $500 \mathrm{ml}$ auffüllen.

Lysepuffer $(500 \mathrm{ml}): \quad 50 \mathrm{mM}$ TRIZMA HCl

$150 \mathrm{mM} \mathrm{NaCl}$

$4,4 \mathrm{~g}$

$40 \mathrm{mM} \mathrm{NaF}$

$0,84 \mathrm{~g}$

5 mM EDTA

$0,93 \mathrm{~g}$

5 mM EGTA

$0,95 \mathrm{~g}$

$1 \mathrm{mM} \mathrm{Na}_{3} \mathrm{VO}_{4}$

91,95 mg

$1 \%(\mathrm{v} / \mathrm{v})$ Igepal

$5 \mathrm{ml}$

$0,1 \%(\mathrm{~m} / \mathrm{v})$ Na-desoxycholat

$0,5 \mathrm{~g}$

$0,1 \%(\mathrm{w} / \mathrm{v})$ SDS

$5 \mathrm{ml}$

$100 \mathrm{mM}$ Phenylmethysulfonylfluorid in Ethanol, Aprotinin $10 \mathrm{mg} / \mathrm{ml}$, Leupeptin $1 \mathrm{mg} / \mathrm{ml}$, Pepstatin $10 \mathrm{mg} / \mathrm{ml}$

4 X Lämmli-Elektrophoresepuffer $(10 \mathrm{ml})$ :

$\begin{array}{ll}1 \mathrm{M} \text { TRIZMA HCl } & 2,5 \mathrm{ml} \\ (\mathrm{pH} 8,3) & 0,8 \mathrm{~g} \\ \text { SDS } & 4 \mathrm{ml} \\ \text { Glycerin } & 2 \mathrm{ml} \\ \text { Beta-Mercaptoethanol } & 4 \mathrm{mg} \\ \text { Pyronin Y } & 1,5 \mathrm{ml} \\ \mathrm{dH}_{2} \mathrm{O} & \end{array}$


Cu-Lösung:

100 Teile $2 \% \mathrm{Na}_{2} \mathrm{CO}_{3}$ in $0,1 \mathrm{M} \mathrm{NaOH}, \mathrm{Fa}$. Roth

Je 1 Teil K-Na-Tartrat in $\mathrm{H}_{2} \mathrm{O}$ und $\mathrm{CuSO}_{4}$ in $\mathrm{H}_{2} \mathrm{O}$, Fa. Merck, Darmstadt.

MES-Running-buffer $20 \mathrm{X}$ wurde auf $1 \mathrm{X}$ verdünnt mit $\mathrm{dH}_{2} \mathrm{O}$ (1 l):

$\begin{array}{ll}\text { MOPS } & 104,6 \mathrm{~g} \\ \text { Tris Base } & 60,6 \mathrm{~g} \\ \text { SDS } & 10,3 \mathrm{~g} \\ \text { EDTA } & 3,0 \mathrm{~g}\end{array}$

Transferpuffer (1 1):

Bicine $(25 \mathrm{mM})$

$4,08 \mathrm{mg}$

Bis-Tris $(25 \mathrm{mM})$

$5,23 \mathrm{mg}$

EDTA

$0,29 \mathrm{mg}$

Methanol

$200 \mathrm{ml}$

Auffüllen mit $\mathrm{ddH}_{2} \mathrm{O}$

TBST (1 l, pH 8):

0,1 M Tris

$12,11 \mathrm{~g}$

$1,5 \mathrm{M} \mathrm{NaCl}$

$87,66 \mathrm{~g}$

Tween20

$1 \mathrm{ml}$

Blockpuffer:

$5 \mathrm{~g}$ Milchpulver ohne Fett in $100 \mathrm{ml}$ TBST

$\begin{array}{lll}\text { ECL (+) Lösung: } & \text { ECLA } & 2,5 \mathrm{ml} \\ & \text { Lösung B } & 63 \mu \mathrm{l}\end{array}$


Medien für die Zellkultur von primären Hippokampusneuronen waren je nach Arbeitsschritt (siehe 2.3.1 ff) HBSS- oder NeurobasalA -basiert.

HBSS wurde während der Präparation verwendet. Zugesetzt wurden:

$$
\begin{array}{ll}
\text { B27, serumfrei } & 5 \mathrm{ml} / 500 \mathrm{ml} \\
\text { Penicillin + Streptomycin } & (50 \mathrm{IE}+0,05 \mathrm{mg}) / \mathrm{ml}
\end{array}
$$

NeurobasalA wurde zur Kultivierung von primären Neuronen verwendet. Zugesetzt wurden:

$$
\begin{array}{ll}
\text { B27, serumfrei } & 5 \mathrm{ml} / 500 \mathrm{ml} \\
\text { Penicillin + Streptomycin } & (50 \text { IE. }+0,05 \mathrm{mg}) / \mathrm{ml} \\
\text { L-Glutamine } & 0,5 \mathrm{mM} \\
\text { bFGF } & 5 \mathrm{ng} / \mathrm{ml}
\end{array}
$$

Penicillin und Streptomycin, Pyruvat, L-Glutamat Fa. Invitrogen.

bFGF und B27 Fa. Life Technologies. 


\subsection{Statistik}

In der hier vorliegenden Arbeit wurden die folgenden statistischen Verfahren gemeinsam mit der Abteilung II des Instituts für Statistik und Ökonometrie der Georg-August-Universität Göttingen ausgesucht und angewandt. Eine Wahrscheinlichkeit $\mathrm{p}<0.05$ wurde als signifikant, $\mathrm{p}<0.01$ als hochsignifikant angenommen. $n$ wurde als die Anzahl Tiere pro Gruppe, $t$ wurde als der Zeitpunkt Lebenstage definiert.

Alle Analysen wurden mit R Version 1.9.1 (R Developement Core Team, Wien, Österreich) durchgeführt.

\subsubsection{Neuronale Zellkultur}

$\mathrm{Zu}$ untersuchen war, ob die Gabe von Noladin und THC in zwei verschiedenen Konzentrationen einen Einfluss auf die Zelltodrate von ET-B-defizienten Tieren respektive Wildtypen/Heterozygoten unter Hypoxie hat.

Dazu wurde folgende Vorgehensweise gewählt: Für jeden Tiertyp war ein Vergleich der Kontrollgruppe mit den vier Behandlungsmethoden notwendig. Da jeweils eine Zellkultur pro Gruppe vom selben Tier stammte, lag eine verbundene Stichprobe vor.

Auf Grund der geringen Stichprobenanzahl und Schiefe der Verteilung wurde wiederum ein nichtparametrisches Testverfahren gewählt, der Wilcoxon-MatchedPairs-Signed-Ranks-Test.

Da je Stichprobe vier Behandlungen mit der Kontrollgruppe verglichen werden mussten, lag die Situation eines multiplen Tests vor. Somit musste das Niveau des Tests korrigiert werden, hierzu wurde die Holm-Methode gewählt. Die Ergebnisse wurden in Mittelwerten angegeben und teilweise in Prozent der normoxischen beziehungsweise hypoxischen Placebokontrolle ausgedrückt. 


\subsubsection{Immunhistochemie}

$\mathrm{Zu}$ untersuchen war die Vermutung, dass zu den Zeitpunkten $\mathrm{t}=14$ und $\mathrm{t}=21$ bei den ET-B-defizienten eine höhere Menge CB1 als bei der Vergleichsgruppe bestehend aus Heterozygoten und Wildtypen vorlag. Hieraus ergab sich die Nullhypothese gleichen und die Alternative höheren Anteils CB1 (einseitiger Test).

Auf Grund der geringen Stichprobenmenge und Schiefe der Verteilung wurde ein nichtparametrischer Test gewählt, der Mann-Whitney-U-Test für unverbundene Stichproben (auch genannt Wilcoxon-Rangsummentest oder auch nur WilcoxonTest). Dieser wurde separat für die Zeitpunkte $t=14-15$ und $t=21-22$ mit den Originaldaten durchgeführt. Die im Bild vorliegende Normierung auf $100 \%$ bei $t=3-4$ diente lediglich der graphischen Veranschaulichung. Die Immunoreaktivität wurde dort in Prozent des Wechsels der Dichte angegeben.

Um den besonderen Effekt der ET-B-defizienten Tiere an den Tagen 14 und 21 im Vergleich zu den Wildtypen bzw. Heterozygoten zu verdeutlichen, wurde ein gemeinsames Modell notwendig, das alle Faktoren gleichzeitig miteinbeziehen konnte.

Eine einfache Varianzanalyse war nicht geeignet, da Zähldaten vorlagen und diese die nötigen Normalverteilungsannahmen nicht erfüllten. Ein geeignetes Modell war ein verallgemeinertes lineares Modell mit Poissonfamilie.

Es sollte zudem überprüft werden, ob eine Korrelation zwischen Auftreten von CB1-Rezeptoren und Abnahme der Zelltodrate besteht. Dazu wurde der Rangkorrelationskoeffizient gemäss Spearman berechnet.

\subsection{3 in-vivo-Tierversuch}

Gezählte Zellen pro Feld (bei 1:200 Vergrößerung) wurden in Gruppen nach Kondition zusammengefasst und mit dem Student-T-Test ausgewertet.

Der Fisher-exakt-Test wurde beim Vergleich der CB2-Gruppen verwendet. 


\section{Ergebnisse}

Alle Versuche wurden verblindet durchgeführt und erst nach Fertigstellung der Ergebnisse wieder offengelegt. Ein Ausschluss von Kultur, Tier oder Experiment wurde vor Entblindung veranlasst, sofern ein gewichtiger Grund vorlag. Sollte es in einem Versuch einen Ausschluss gegeben haben, so ist dieser beim Gruppenunterpunkt aufgeführt. Alle Fehlerindikatoren wurden im Standardfehler des Mittelwertes angegeben. Statistische Tests wurden bei $\mathrm{p}<0.05$ als signifikant angesehen, bei $\mathrm{p}<0.01$ als hochsignifikant.

\subsection{Tiere}

Es wurden insgesamt 173 Tiere zu Versuchszwecken getötet. Davon waren 38 nicht älter als 24 Stunden, 103 zwischen 3 und 22 Tagen und 32 Tiere 8-10 Tage alt.

\subsubsection{Genotyping}

Die Bestimmung des Genotypes mit PCR fand in allen verwendeten Tieren statt.

Bei den 76 Tieren der CB1-Immunhistochemie wurde sie vor Anlage des verwendeten Paraffinblocksatzes durchgeführt.

Ein Mal wurde ein heterozygotes als ET-B-defizient vermutet. Dieses Tier wurde aus dem Versuch vor Entblindung ausgeschlossen.

\subsubsection{Geschlechtsbestimmung}

Von 76 Tieren für die Immunhistochemie des CB1-Rezeptors wurde bei 69 eine erfolgreiche Bestimmung des Geschlechts vom Paraffinschnitt vorgenommen. Bei 4 Tieren war die Bestimmung des Geschlechts mit dieser Methode auch nach Wiederholung nicht eindeutig. Für drei Tiere standen keine weiteren hippokampalen Schnitte für die Untersuchung zur Verfügung.

38 Tiere für die Zellkultur waren in allen Fällen weiblichen Geschlechts.

Die Bestimmung des Geschlechts durch Messung des anogenitalen Abstandes wurde in 38 Fällen von 38 durch PCR bestätigt (siehe Abb. 5). 
Ergebnisse

Für den in-vivo-Versuch wurden alle 32 Ratten als weiblich durch PCR bestätigt.

Die Durchführung der Geschlechtsbestimmung hatte das Ziel, eine möglichst einheitliche Versuchsgruppe zu isolieren.
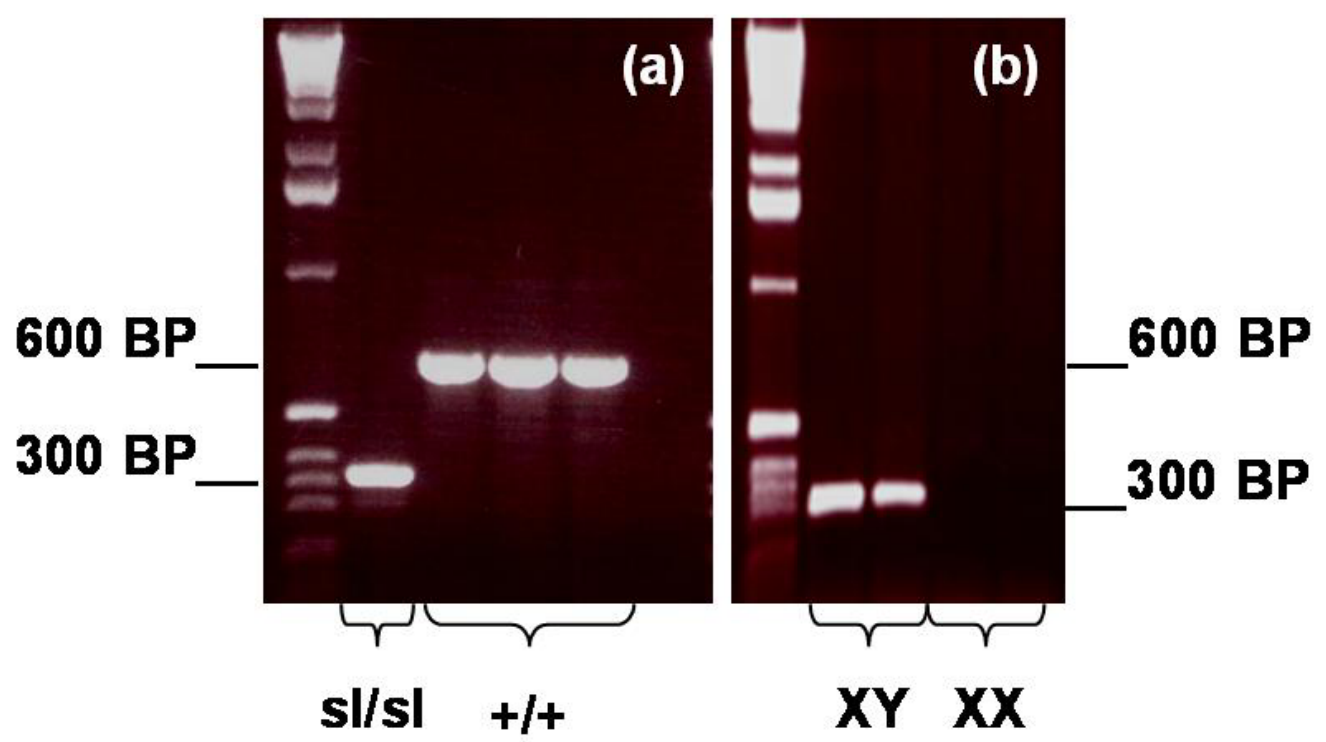

Abb. 5: Repräsentative Abbildungen für PCR-Befunde: (a) Beispielbild für das Unterscheiden des Genotyps: „Genotyping“-PCR. ET-B-Defizienz (s1/sl; 300 BP) und Wildtyp (+/+; 600 BP). (b) Beispielbild für das Unterscheiden des Geschlechts: „Sexing“-PCR. Weibliche Tiere (XX) zeigen keine Bande, männliche Tiere (XY) zeigen ein Produkt bei 312 BP.

\subsection{Immunhistochemie CB1 und CB2}

In den Untersuchungen der Immunhistochemie des Cannabinoidrezeptors 1 (CB1) im Hippokampus wurden insgesamt 76 Wistar-Imamichi-Ratten verwendet. Diese verteilten sich auf je drei Genotypen zu drei verschiedenen Zeitpunkten: 3-4, 1415, 21-22 Tage alt. Die Gruppengrößen waren wie in Tab. 2 dargestellt. 


\begin{tabular}{|r|c|c|c|}
\hline Alter/Genotyp & Wildtyp (+/+) & Heterozygot (s1/+) & $\begin{array}{c}\text { ET-B-defizient } \\
\text { (sl/sl) }\end{array}$ \\
\hline 3-4 Tage & 8 & 15 & 9 \\
\hline 14-15 Tage & 6 & 5 & 7 \\
\hline 21-22 Tage & 6 & 14 & 6 \\
\hline
\end{tabular}

Tab. 2: Anzahl der Versuchstiere in Gruppen nach Genotyp und Alter.

\subsubsection{CB1-Rezeptor}

Eine spezifische Färbung von Neuronen fand sich im Gyrus dentatus des Hippokampus aller Tiere wie schon zuvor beschrieben [MOLDRICH und WENGER 2000; PETTIT et al. 1998].

Bei den 76 Ratten wurden 145 Schnitte gefärbt. Auf diesen waren 280 Hippokampi, von denen 450 Fotos aufgenommen wurden. Diese ergaben 1833 Messungen, 910 für die Pyramidalzellschicht, 923 für die Granularzellschicht (exemplarisch dargestellt in Abb.6).
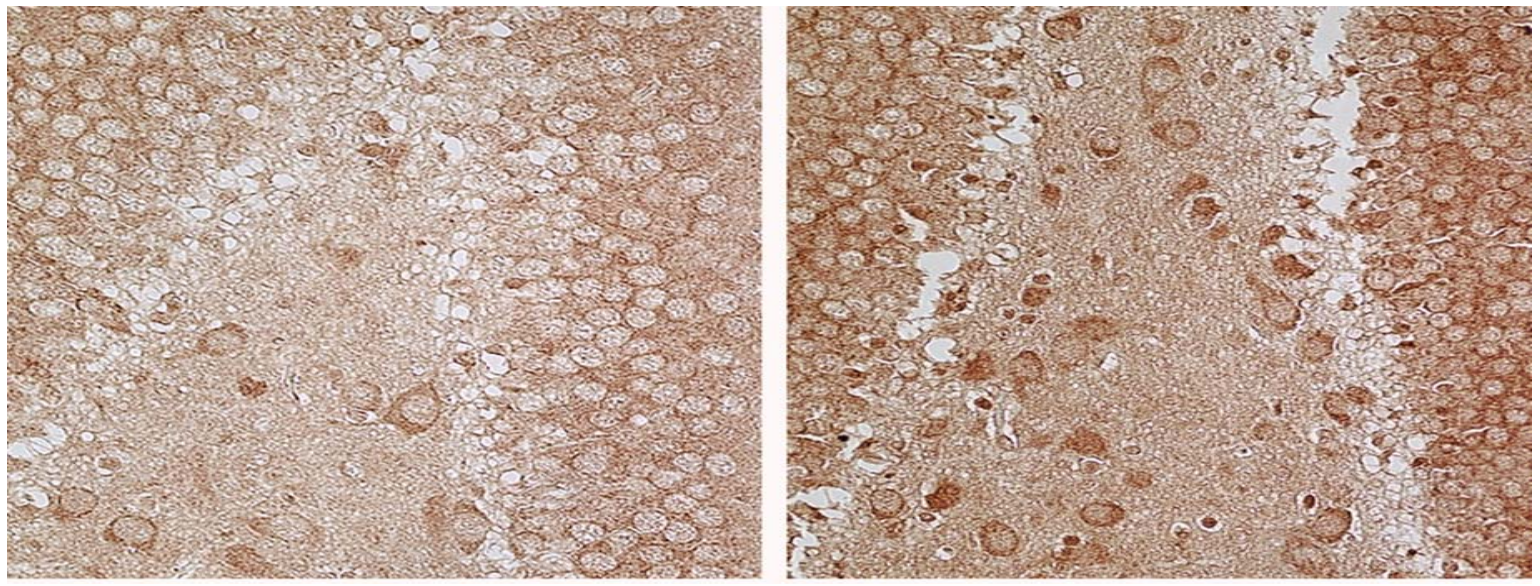

Abb. 6: Dargestellt sind exemplarisch CB1-Immunoreaktivität im Gyrus dentatus: links gesunde Wildtypen (+/+), rechts ET-B-Defizienz (sl/sl).

Zur Auswertung wurde hier jeweils die Dichte der schwarzen Pixel pro ausgewählter Bildfläche erfasst, gemessen in zwei Regionen des Gyrus dentatus des 
Hippokampus; der Pyramidalzellschicht (CA4) und der Granularzellschicht. Der Hintergrund wurde durch den Bereich mit ungefärbten beziehungsweise unspezifisch gefärbten Zellen zwischen Granularzellen und zweitem Ventrikel definiert.

Die Immunoreaktivität, (irCB1) ursprünglich dargestellt in [Opt.Dichte/ $\mu \mathrm{m}^{2}$ ] wird in \% der Veränderung der Intensität dargestellt. Dabei wurde die Kondition eines Genotyps vom Tag 3-4 als Ausgangswert (=100\%) benutzt, die weiteren daran gemessen, um die Veränderung der Expression darzustellen.

\subsubsection{Immunoreaktivität der Pyramidalzellschicht}

Innerhalb des Pyramidalzellschicht ergab sich keine signifikante Änderung der Immunoreaktivität innerhalb und zwischen den Gruppen (s. Abb. 7).

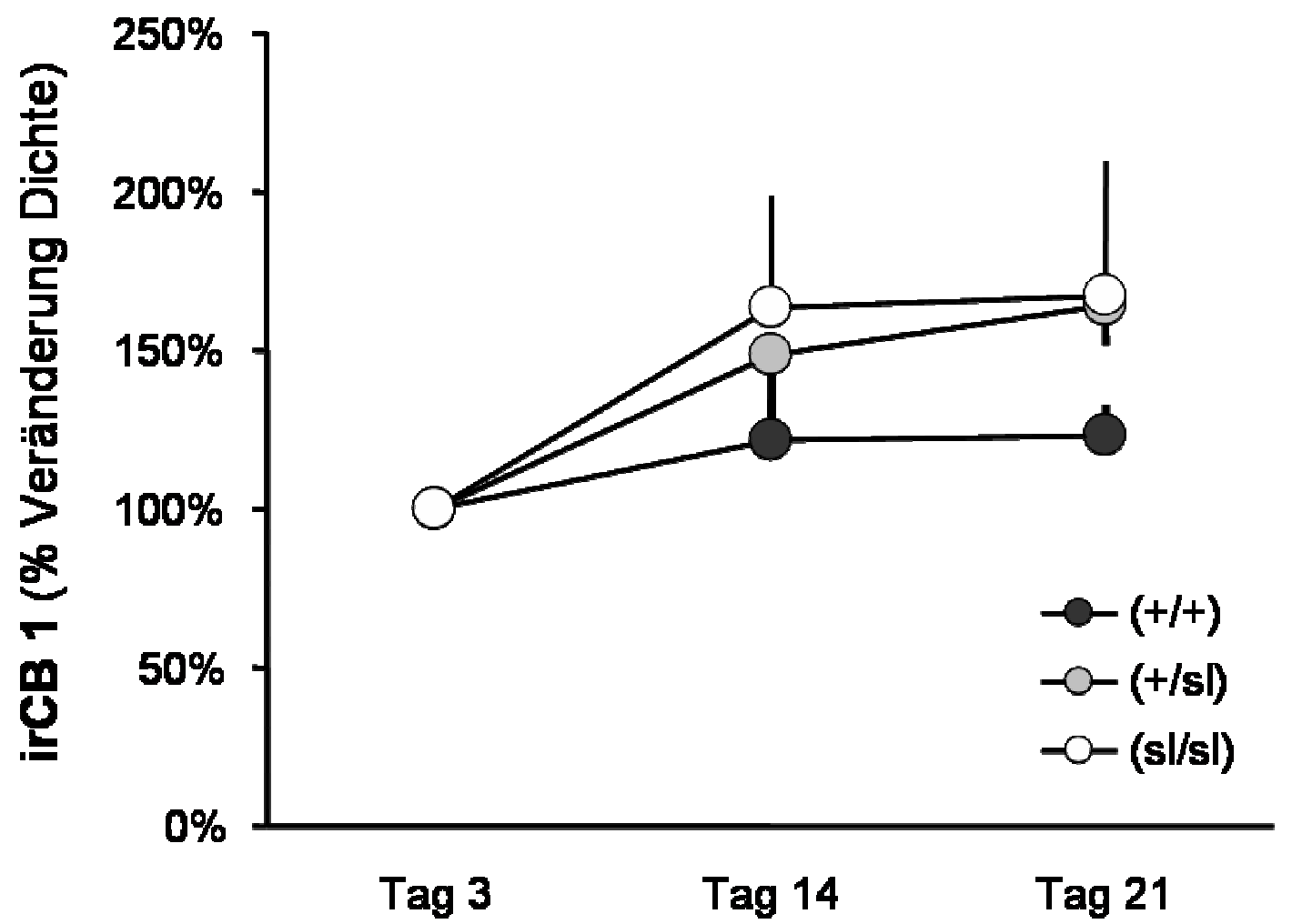

Abb. 7: Dargestellt ist die Immunoreaktivität von CB1 (irCB1) nach Alter bei Wildtypratten, Heterozygoten und sl/sl-Mutanten in Pyramidalzellen des Hippokampus. Diese zeigte sich nicht signifikant verändert, weder zwischen dem Alter der Tiere, noch zwischen den Gruppen. 


\subsubsection{Immunoreaktivität der Granularzellschicht}

Innerhalb des Granularzellschicht zeigte sich ein signifikanter $(p<0.05)$ Unterschied in der Änderung der Immunoreaktivität ET-B-defizienter Ratten. Die Tiere hatten im Durchschnitt einen Anstieg um 106\% bei der Gruppe der 14-15 Tage alten und um 95\% bei den 21-22 Tage alten Tieren, bezogen auf den jeweiligen vier Tage alten Genotyp, zu verzeichnen (s. Abb. 8).

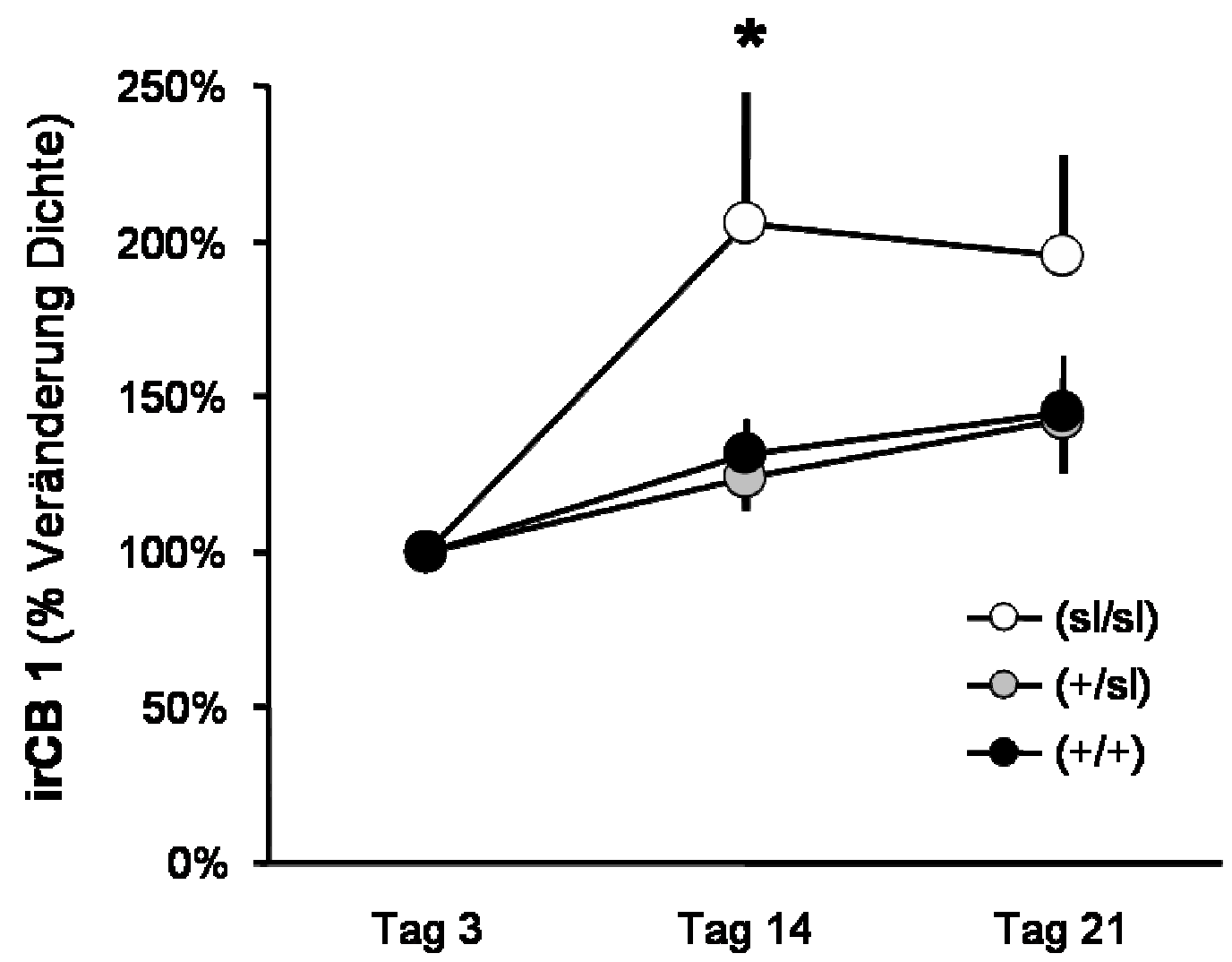

Abb. 8: Dargestellt ist die Immunoreaktivität von CB1 (irCB1) nach Alter bei Wildtypratten, Heterozygoten und sl/sl -Mutanten in Granularzellen des Hippokampus. Die Immunoreaktivität der Granularzellen zeigte bei ET-B-defizienten 14 Tage alten Tieren eine signifikant höhere Immunoreaktivität.

Im gemeinsamen Modell, dem verallgemeinerten linearen Modell mit Poissonfamilie (s. Tab. 3), erklären die ET-B-defizienten Ratten am Tag 14 und 21 einen Teil der Modellvarianz hochsignifikant bzw. signifikant bei der Evaluation der Granularzellschicht-Immunoreaktivität. Dies wurde zur Überprüfung der Signifikanz im 
Gesamtmodell eingeführt [YANG et al. 2005]. Eine signifikante Änderung des Risikoprofils der Änderung der Expression konnte hier sowohl für den Lebenstag, als auch den Genotyp gegenüber dem Wildtypen errechnet werden. Für die Pyramidalzellschicht ergab sich dieses Profil nicht.

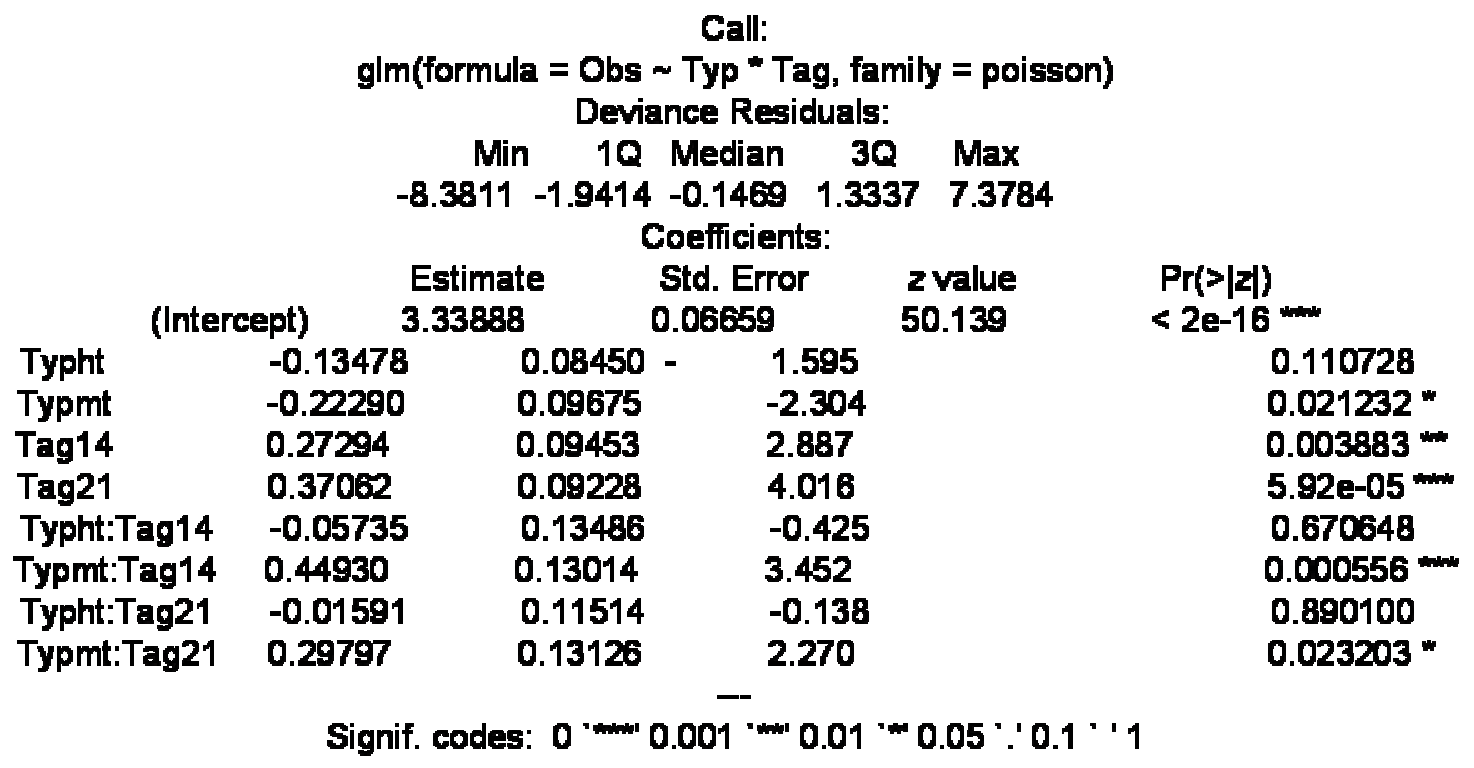

Tab. 3: Statistik des linearen Gesamtmodells mit Poissonfamilie für Wildtypen, Heterozygote und ET-B-Defizienz über die drei Beobachtungszeiträume: Ein Teil der Modellvarianz erklärt die ET-B-defizienten Tiere am Tag 14 und 21 signifikant bzw. hochsignifikant unterschiedlich.

Bei nachfolgenden Schnitten fand sich in früheren Untersuchungen [EHRENREICH et al. 2000] eine signifikant niedrigere Apoptoserate unter den 1415 und 21-22 Tage alten Tiere gegenüber den 3-4 Tage alten Tieren. Bei ET-BDefizienz konnte eine erhöhte Apoptoserate zwischen Genotypen Tag 14-15 und Tag 21-22 festgestellt werden (siehe Abb. 9). 


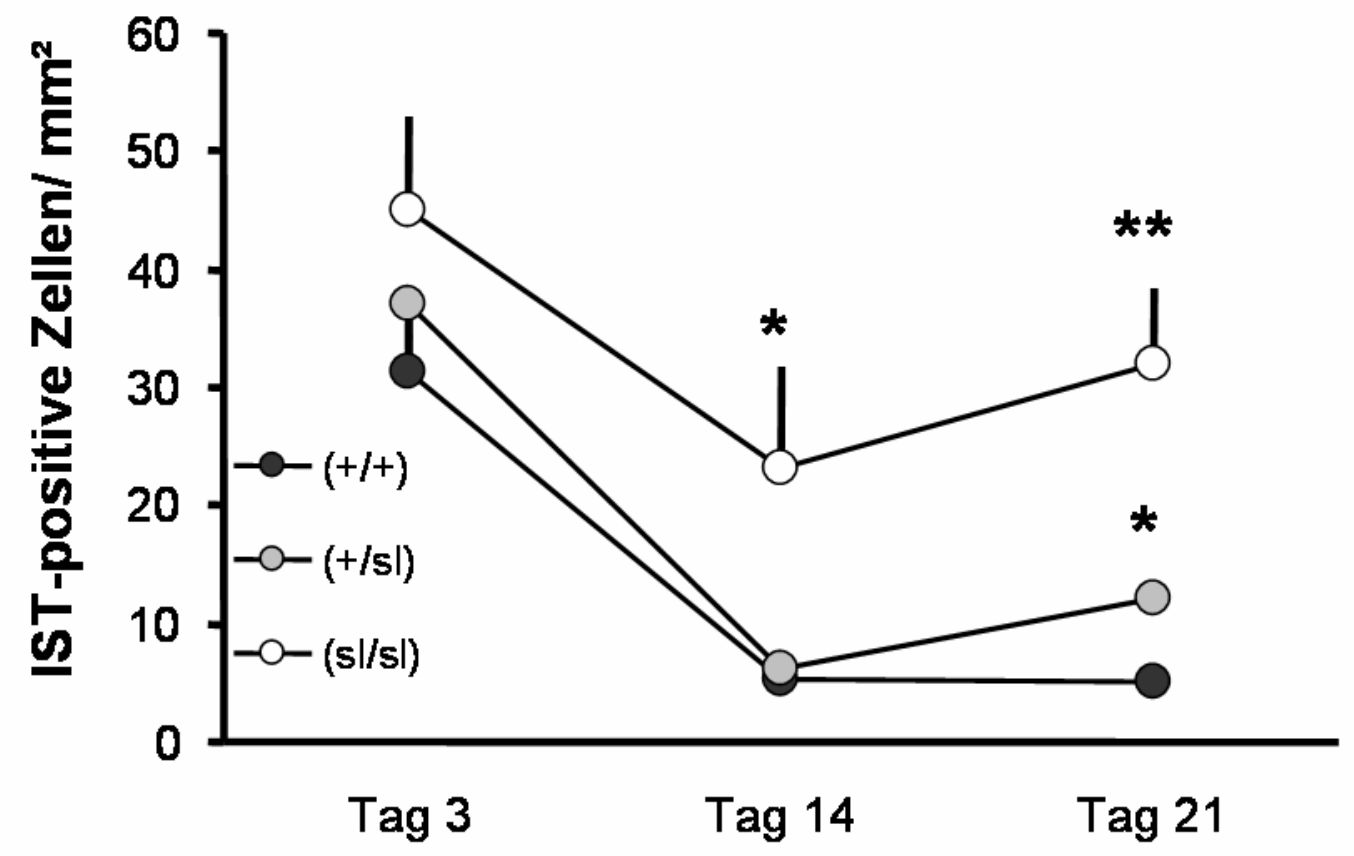

Abb. 9: Die Abhängigkeit der Anzahl apoptotischer (IST-positiver) hippokampaler Neuronen von Alter und Genotyp bei Wistar-Imamichi-Ratten an den postnatalen Tagen 3, 14, 21 (modifiziert von EHRENREICH et al. 2000, Seite 995): Anzahl von IST-positiven Zellen bei ET-BDefizienz an Tag 14 und 21 ist erhöht.

Eine Korrelation zwischen dem Auftreten von CB1-Rezeptoren und der Abnahme apoptotischer Zellen konnte mit dem Spearman-Rangkorrelationskoeffizient bei ET-B-defizienten Tieren $t=14-15$ und $t=21-22$ nachgewiesen werden $(\mathrm{p}<0.05)$. Die Anzahl apoptotischer Zellen wurde dabei von HE-Färbungen benachbarter Schnitte des jeweils selben Tieres gezählt. Eine hohe CB1- Immunoreaktivität zeigte dabei eine niedrigere Apoptoserate. Bei Wildtypen ergab sich dieser Zusammenhang nicht (s. Abb. 10). Ebenso ergab sich kein Zusammenhang bei den 4 Tage alten Tieren unabhängig vom Genotyp. 

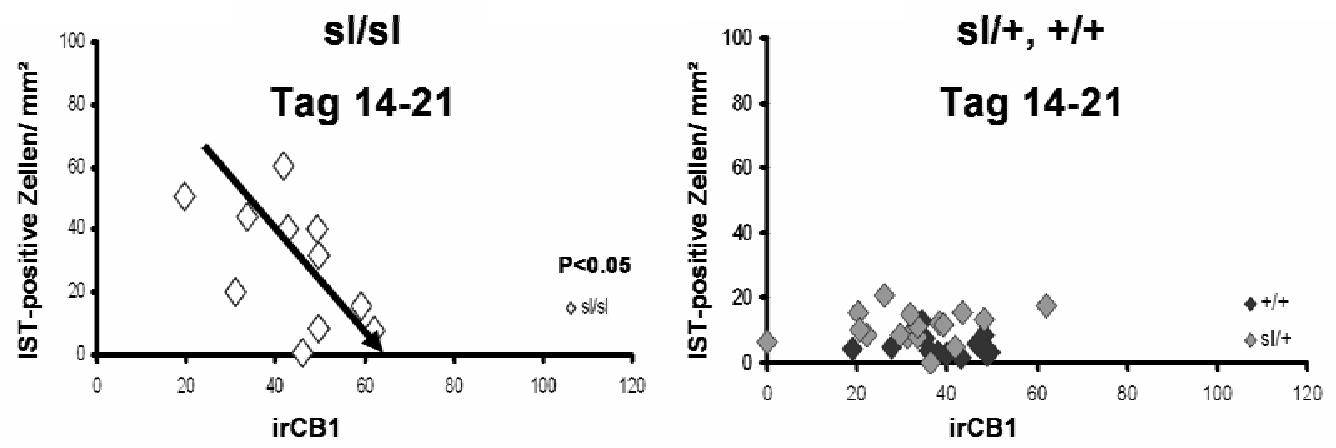

Abb. 10: Korrelation zwischen Anzahl an IST-positiven Zellen und Immunoreaktivität von CB1 im Gyrus dentatus des Hippokampus bei ET-B-defizienten Tieren (links). Keine Abhängigkeit bei Tieren ohne funktionelle ET-B-Defizienz (rechts).

\subsubsection{CB2-Rezeptor}

Eine Expression des Rezeptors wurde in wenigen Zellen des Corpus callosum, des Cerebellum sowie in Blutgefäßen des Rattenhirns, nicht jedoch in hippokampalen Neuronen festgestellt. Ein Auftreten von CB2-Expression in Hippokampusneuronen der verwendeten Genotypen und Zeitpunkte wurde nicht festgestellt.

Ergebnisse für die Expression von CB2 nach Gabe von THC oder Placebo in vivo sind unter Punkt 3.5 dargestellt. 


\subsection{Western Blot}

Je drei weibliche Tiere pro genetischer Gruppe (Wildtyp, Heterozygot, ET-Bdefizient) und Alter (3-4, 14-15, 21-22 Tage alt) wurden untersucht (gesamt 27 Tiere). Die Expression von CB1 im Hippokampus wurde mit zwei unterschiedlichen CB1-Antikörpern unterschiedlicher Hersteller (von Fa. Biosource und Fa. Cayman Chemicals) nachgewiesen.

Die Färbung ließ sich in der Kontrolle mit Blockpeptid nicht darstellen (siehe Abb. 11).

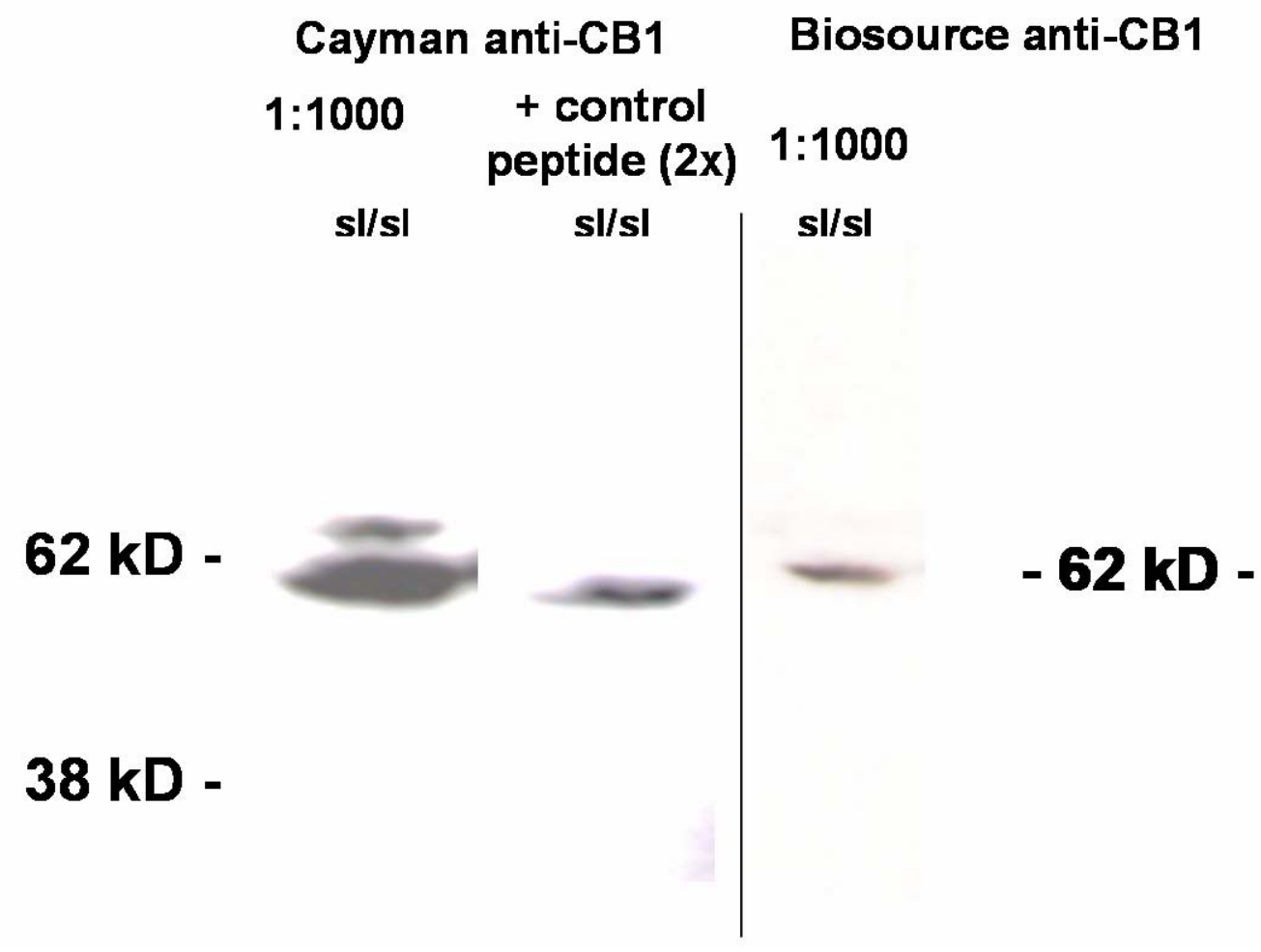

Abb. 11: Dargestellt wurden CB1-Protein aus Hippokampusgewebe bei 62 kD im Western Blot. Die Detektion erfolgte mit zwei verschiedenen Antikörpern (Fa. Cayman Chemicals links, Fa. Biosource rechts im Bild) in ET-B-defizienten (sl/sl) Ratten. Bei Anwendung des Blocking Peptides (control peptide) konnte eine signifikante Reduktion erreicht werden (Mitte).

Alle drei verwendeten Genotypen und Altersgruppen wiesen CB1-RezeptorExpression auf. Auf jedem Blot wurden jeweils drei verschiedene Genotypen eines Alters aufgebracht. Die Messung der Immunoreaktivität der zum Vergleich unter- 
einander erlaubten Gruppen ergab keinen Unterschied ( $p=0.08$ bei Tag 21, $p=0.09$ bei Tag 14). Zur besseren Visualisierung wurden die Ergebnisse im Format wie bei der Immunhistochemie aufgetragen (s. Abb. 12).

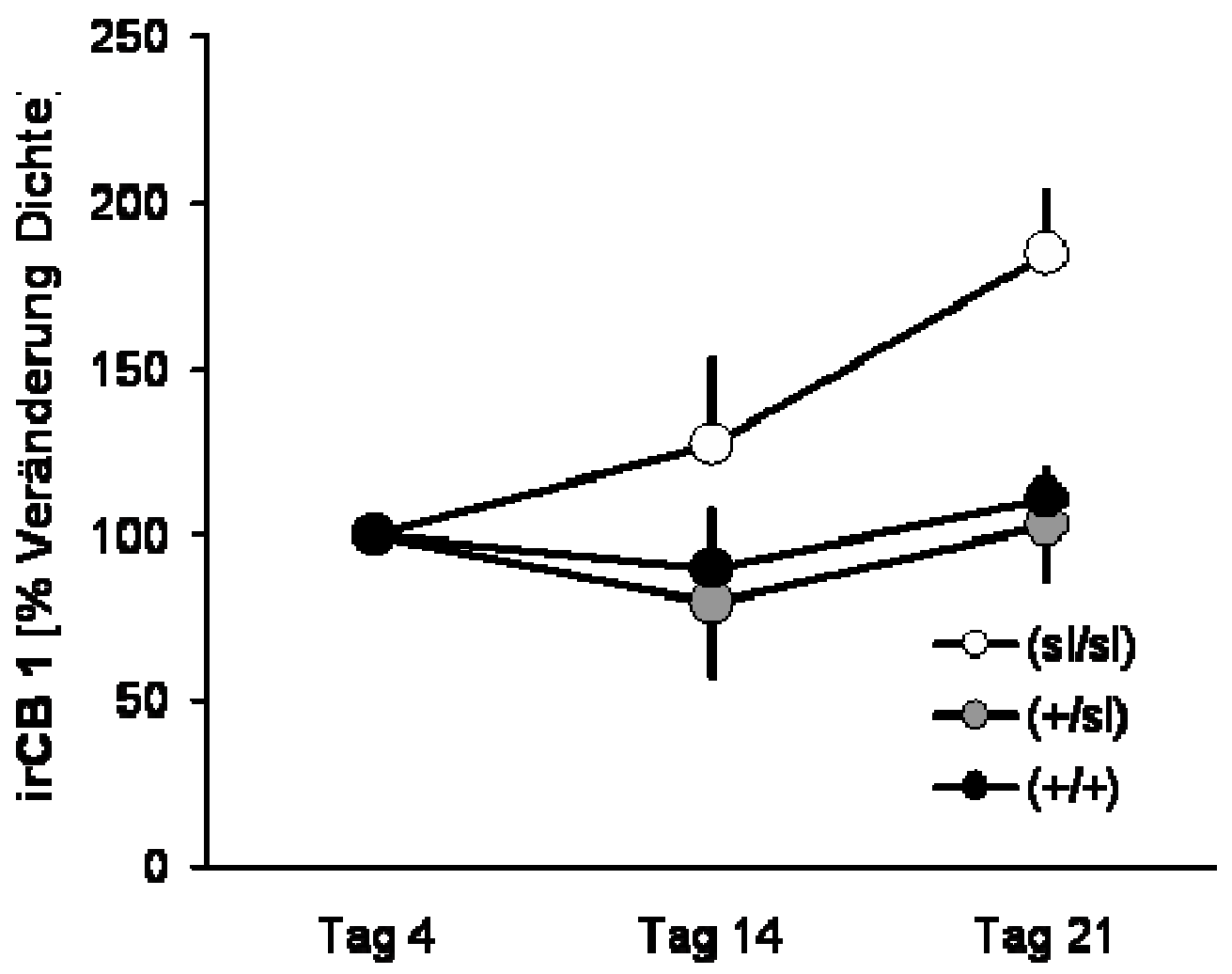

Abb. 12: Dargestellt ist die Immunoreaktivität von CB1 (irCB1) nach Alter bei Wildtypratten, Heterozygoten und s1/sl-Mutanten im Hippokampus. Die Immunoreaktivität im Western Blot zeigte eine ansteigende Dichte von CB1 bei ET-B-defizienten (sl/sl), nicht jedoch bei Wildtypen (+/+) oder heterozygoten (s1/+) Tieren. 


\subsection{Zellkultur}

37 ausschließlich weibliche Tiere wurden für Zellkulturversuche verwendet. Ein Tier wurde vor Versuchsbeginn ausgeschlossen (siehe 3.1.1).

\subsubsection{Ergebnisse der Versuche mit kultivierten hippokampalen Neuronen}

Bei den Neuronen wurde der Zelltod in \% der Gesamtzellzahl ermittelt.

ET-B-defiziente Neuronen hatten eine höhere Zelltodrate als Wildtypzellen. Das galt sowohl für die normoxischen (+/+: $12,7 \%$ vs. sl/sl: $24.5 \%)$, als auch für die hypoxischen ( $24,4 \%$ vs. $48,9 \%$ ) Neuronenkulturen (s. Abb. 13).

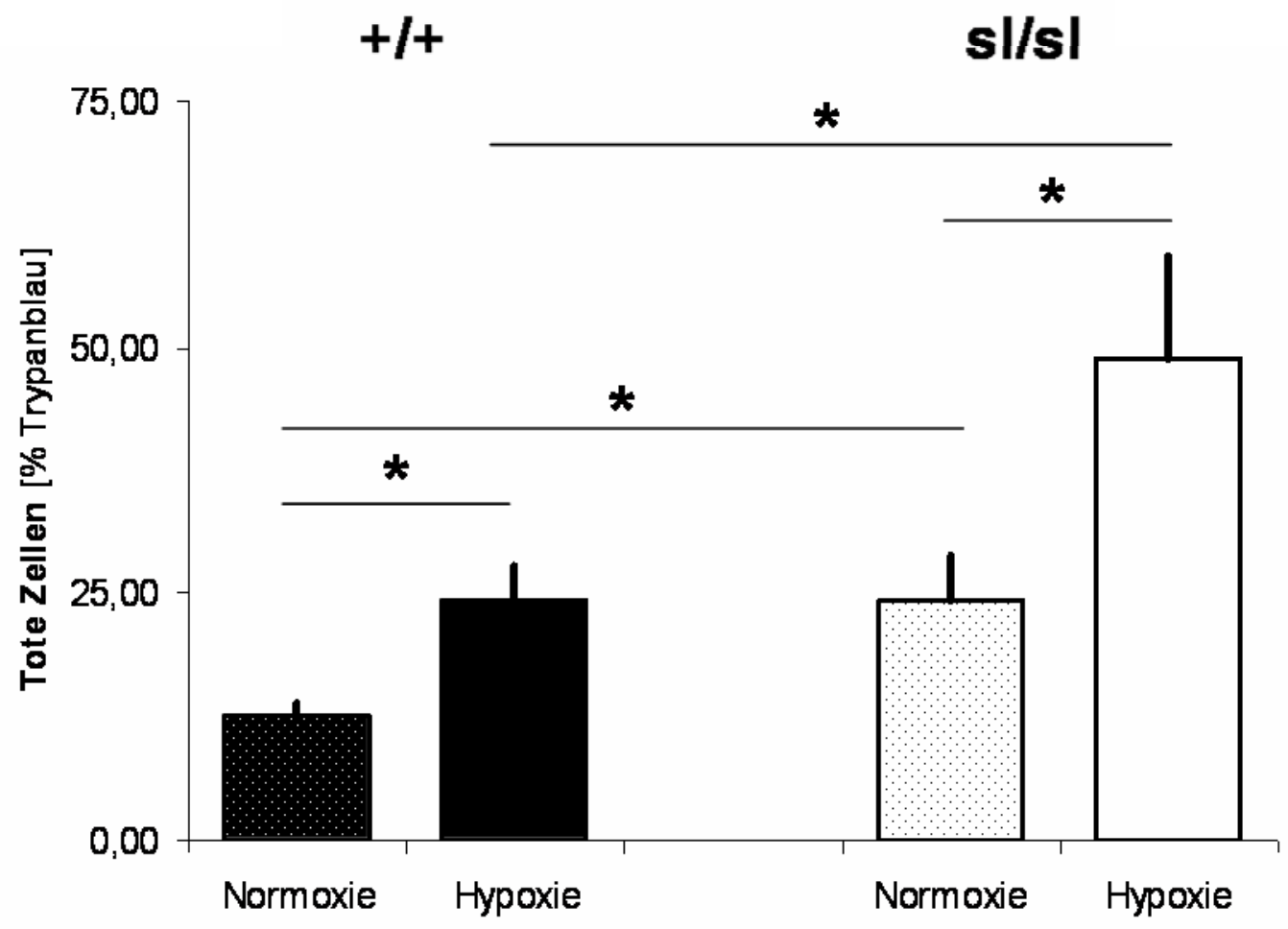

Abb. 13: Dargestellt sind Unterschiede in der basalen Zelltodrate unter Normoxie sowie nach Hypoxie in Abhängigkeit vom Genotyp Wildtyp (+/+) und ET-B-Defizienz (sl/sl) bei primären Neuronenkulturen. 
Die Gabe der CB1-Agonisten Noladin oder THC hatte bei Wildtypneuronen in den verwendeten Konzentrationen keine signifikante Auswirkung auf den Tod oder das Überleben von hippokampalen Neuronen in vitro. Die Zelltodrate blieb bei allen hypoxischen Konditionen im Durchschnitt zwischen 25\% und 22\% (s. Abb. 14).

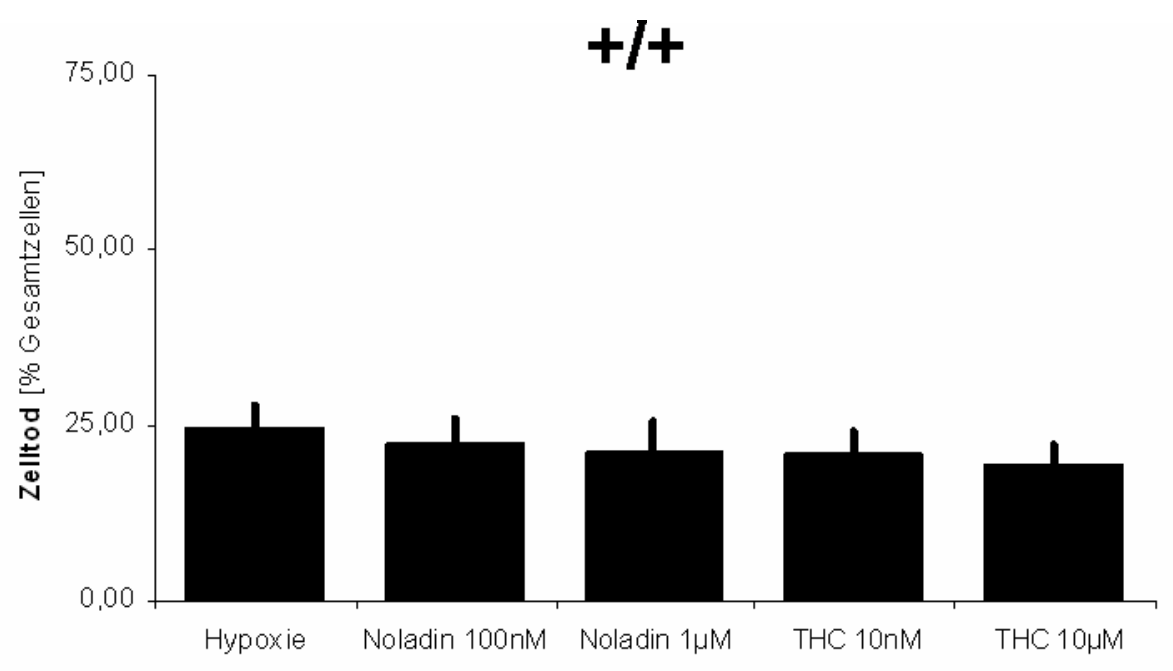

Abb. 14: Dargestellt ist die Zelltodrate bei primären Wildtypneuronenkulturen (+/+) nach Gabe von zwei unterschiedlichen Konzentrationen THC oder Noladin: Keine Veränderung in der Zelltodrate im Vergleich zur hypoxischen Kontrolle nach Gabe von Noladin oder THC.

Bei den Neuronen von ET-B-defizienten Ratten gab es in den niedrigeren Dosierungen bei Noladin $(100 \mathrm{nM})$ eine erste $(\mathrm{p} / 4<0.0125)$, bei THC $(10 \mathrm{nM})$ eine zweite $(\mathrm{p} / 3<0.0167)$ signifikante Reduktion trypanblauer Zellen. Der Zelltod wurde von $48.9 \%$ auf 30,9\% (Noladin) sowie auf 32,5\% (THC) abgesenkt. Beide höheren Konzentrationen (THC $10 \mu \mathrm{M}$, Noladin $1 \mu \mathrm{M}$ ) wiesen mit dieser Methode keine signifikante Veränderung des Zelltods auf (s. Abb. 15). 


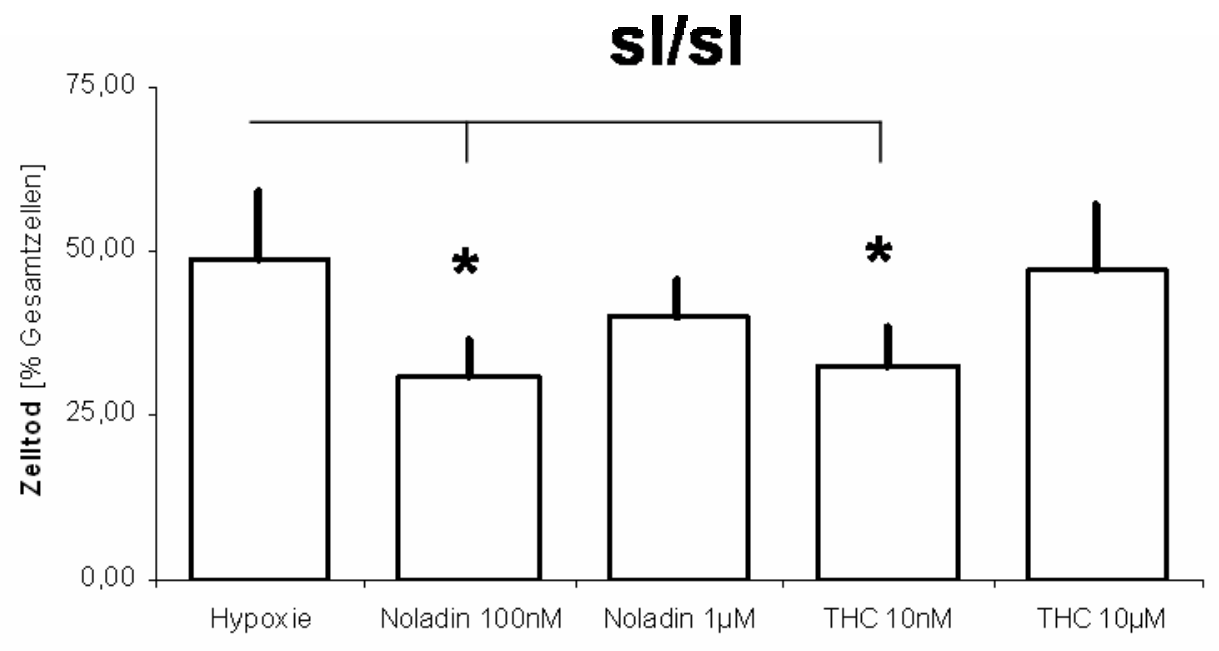

Abb. 15: Dargestellt ist die Zelltodrate bei primären Neuronenkulturen mit ET-B-Defizienz (sl/sl) nach Gabe von zwei unterschiedlichen Konzentrationen THC oder Noladin: Signifikante Reduktion des Zelltodes bei Zugaben von $10 \mathrm{nM}$ THC oder $1 \mu \mathrm{M}$ Noladin. 


\subsection{Vorversuche für eine Behandlung mit THC oder Placebo bei Hypoxie/Ischämie in vivo in ET-B- gesunden Wistar-Imamichi-Ratten}

32 weibliche Wistar-Imamichi-Ratten im Alter zwischen 8-10 Tagen wurden für die Versuche verwendet.

Bei der Entnahme des Hirns stellte sich bei drei Tieren ein Hydrozephalus dar. Diese Tiere gehörten alle zum selben Wurf einer normoxischen Kontrollgruppe. Ein weiteres Tier dieses Wurfes wurde schon vor der Entblindung nicht in die Auswertung miteinbezogen.

Zwei Tiere starben während und kurz nach der Operation. Ein Tier musste am ersten postoperativen Tag getötet werden, da nach der intraperitonealen Injektion eine Blutung auftrat.

Zwei Tiere gehörten zu einer normoxischen Kontrollgruppe.

Die endgültig für den Versuch verwendeten Tiere teilten sich wie folgt auf (siehe Tab. 4):

\begin{tabular}{|r|c|}
\hline & $\boldsymbol{n}$ \\
\hline Placebo & 12 \\
\hline $\mathbf{5} \mathbf{~ m g / k g ~ K o ̈ r p e r g e w i c h t ~ d e l t a ~}{ }^{9}$-THC & 11 \\
\hline
\end{tabular}

Tab. 4: Anzahl der Versuchstiere pro Gruppe Placebo oder Gruppe Behandlung mit delta9 ${ }^{9}$-THC.

\subsubsection{Auswertung des CA1-Schadens}

Ausgezählt wurden lebende und tote Neuronen in CA1 des Hippokampus als Wert zum Einschätzen des Schadens auf Neuronen mit oder ohne Behandlung mit delta'-THC.

Die Werte wurden in Zellen/Feld angegeben. Es ergab sich eine hochsignifikante $(\mathrm{p}<0.01)$ Reduktion überlebender Zellen mit gleichzeitigem Anstieg toter Zellen gegenüber Placebotieren bei Tieren, die mit 5mg/kg Körpergewicht delta ${ }^{9}-\mathrm{THC}$ behandelt wurden.

Die Gesamtzellzahl von lebenden plus toten Zellen war in beiden Gruppen gleich (s. Abb. 16 und 17). 

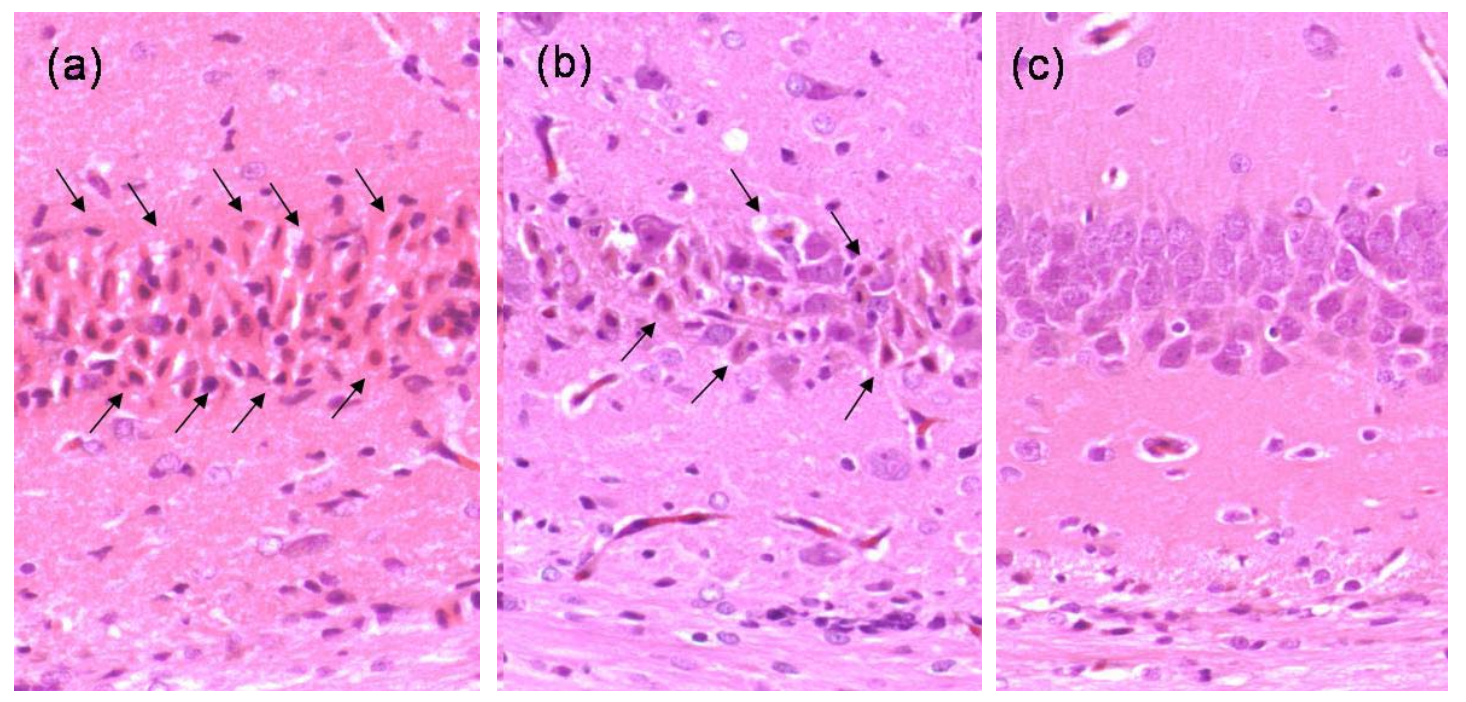

Abb. 16: HE-Färbung von CA1: Repräsentative Darstellung der Reduktion von überlebenden Zellen nach Hypoxie/Ischämie und THC-Gabe (a) vs. Placebo (b) und normoxischer Kontrolle (c). Schwarze Pfeile markieren einige der toten Zellen.

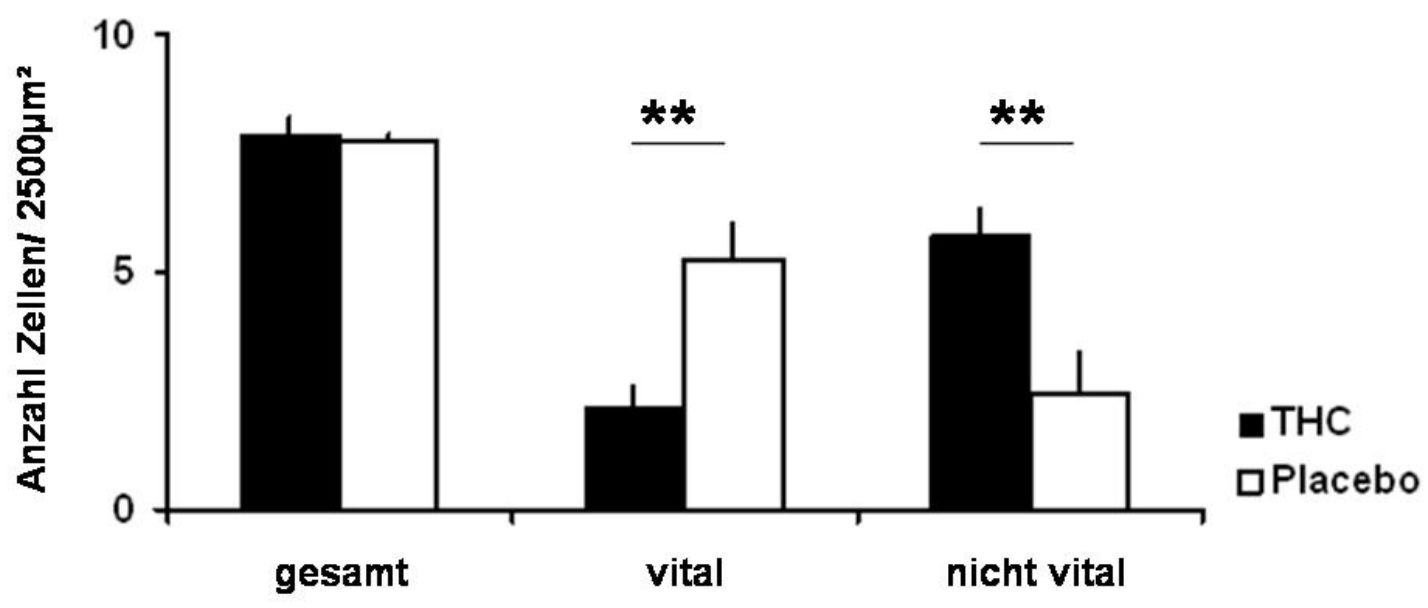

Abb. 17: Reduktion vitaler Zellen nach THC-Gabe in vivo. Abgebildet sind die Anzahl Zellen in CA1 (links), davon vitale Zellen (Mitte) und tote (nicht vitale) Zellen (rechts), bei THCBehandlung vs. Placebo bei Tieren ohne ET-B-Defizienz. Ein Zählfeld entspricht $50 \mu \mathrm{m} \times 50 \mu \mathrm{m}$

\subsubsection{Expression von $\mathrm{CB} 1$ und $\mathrm{CB} 2$}

Eine unterschiedliche Expression von CB1 im Hippokampus und Cortex nach Applikation von THC oder Placebo bei Hypoxie/Ischämie konnte zwischen den Gruppen nicht festgestellt werden. 
Ergebnisse

Es ergab sich jedoch interessanterweise bei Tieren mit THC-Behandlung eine erhöhte Expression von CB2 in nichtneuronalen Zellen. Diese waren im läsionsseitigen Cortex und Corpus callosum auffällig (siehe Abb. 18)
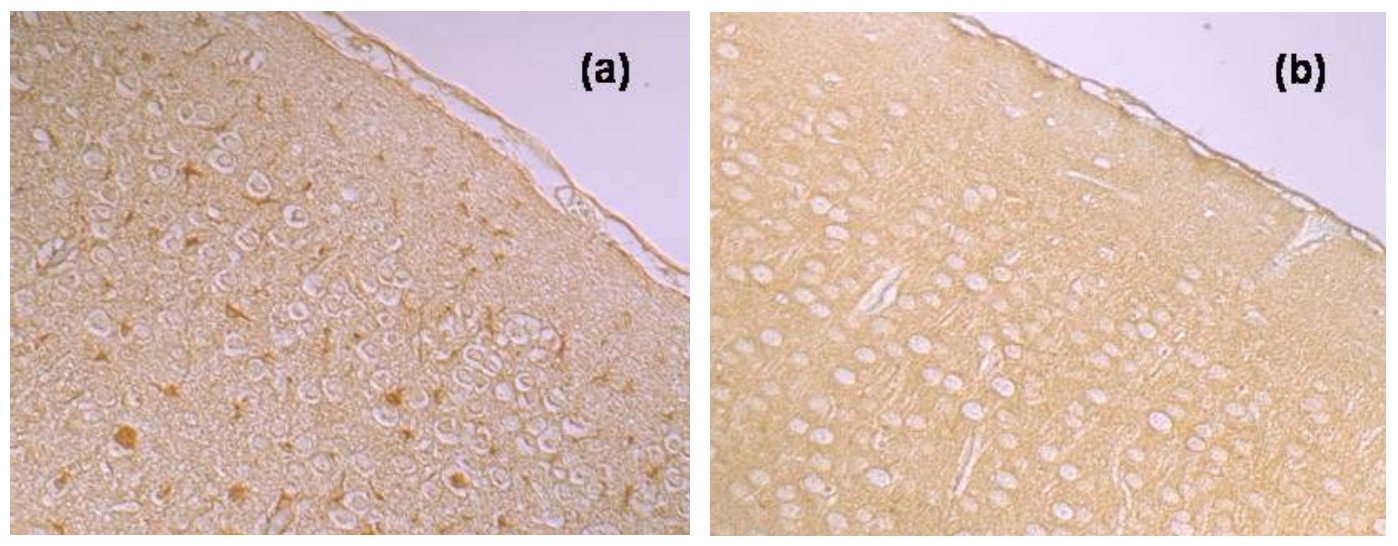

Abb. 18: Repräsentative Darstellung der Expression von CB2 im Cortex: (a) in nichtneuronalen Zellen nach Hypoxie und THC-Gabe. Keine CB2-Expression in Placebotieren (b).

Diese Expression von CB2 ergab sich in nichtneuronalen, GFAP-positiven Zellen (siehe Abb. 19).
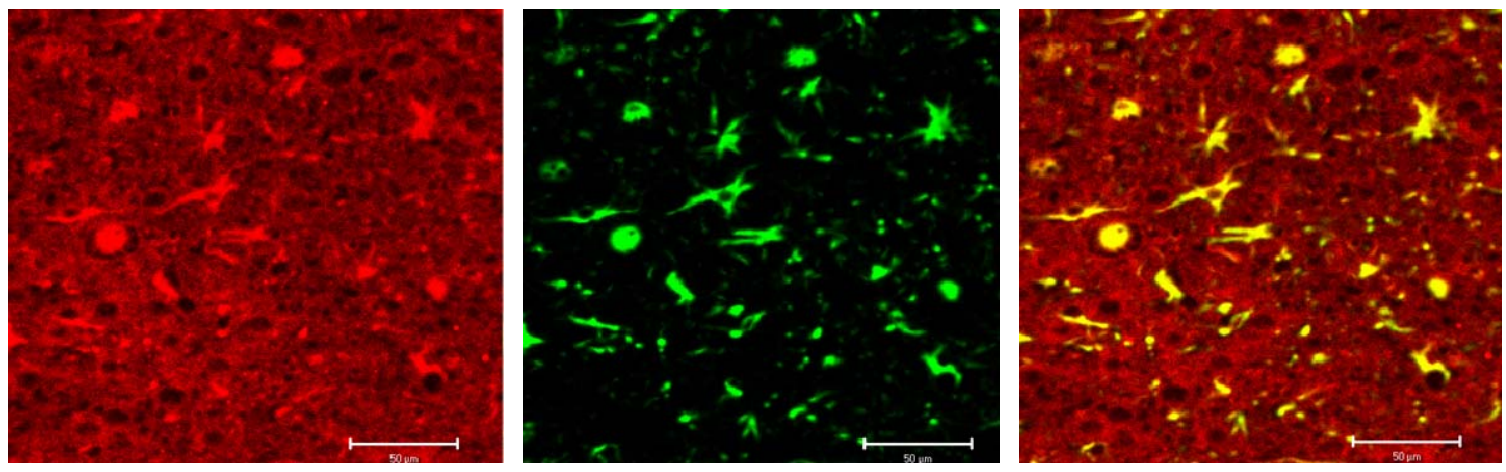

Abb. 19: Kortikale CB2 Expression in nichtneuronalen, GFAP-positiven Zellen in vivo nach Gabe von THC und Hypoxie/Ischämie. Expression von CB2 (links), GFAP (Mitte) sowie zusammen (rechts). 
Das Auftreten von CB2-Expression in nichtneuronalen Zellen des Cortex von THC-behandelten Ratten unter Hypoxie/Ischämie in vivo war signifikant unterschiedlich ( $\mathrm{p=0.005)}$ zur Kontrollgruppe mit Placebo (siehe Abb. 20).

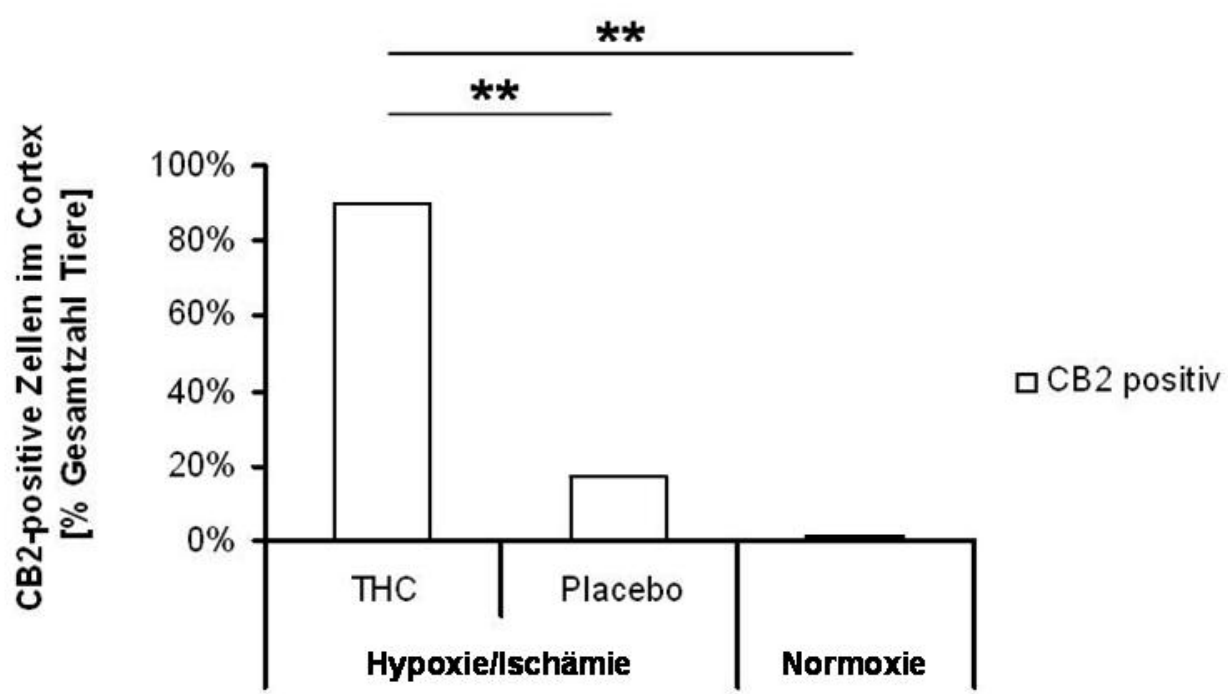

Abb. 20: Signifikant erhöhtes Auftreten von CB2-positiven Zellen im Cortex bei WistarImamichi-Ratten in vivo nach Hypoxie/Ischämie und Gabe von THC im Vergleich zu Placebogabe und normoxischen Kontrolltieren. 


\section{Diskussion}

Die vorliegende Arbeit zeigt erstmals einen Substitutionseffekt von CB1 bei funktioneller ET-B-Defizienz im Rattenmodell. Es ergab sich eine Abhängigkeit vom Auftreten von CB1 bei ET-B-defizienten Tieren umgekehrt proportional zum Zelltod. Ratten mit intaktem Endothelinsystem zeigten diese Abhängigkeit nicht. Im Gegensatz zum CB1-Rezeptor konnte eine Alteration der CB2-Expression innerhalb der Genotypen nicht gezeigt werden. Eine Applikation von CB1-Agonisten bei primären Hippokampusneuronen führte zu einer Reduktion der Zelltodrate bei Noladin und delta-9-THC in vitro. Auch dieser Effekt konnte nur bei ET-BDefizienz, nicht aber bei Wildtypen nachgewiesen werden. In Vorversuchen mit ET-B-gesunden Ratten im kombinierten Hypoxie-/Ischämiemodell konnte ein protektiver Effekt von THC in vivo nicht nachgewiesen werden. Im Gegenteil, es kam innerhalb der THC-Gruppe zu erhöhtem neuronalen Schaden in Cortex und Hippokampus. Daher wurde auf das Ausweiten des Versuchs auf Tiere mit ET-BDefizienz verzichtet.

Die Teilergebnisse werden nachfolgend diskutiert.

\subsection{Sexing}

Die Bestimmung des Geschlechts mittels PCR hat sich bewährt. Sie stellte eine sichere und weitgehend untersucherunabhängige Methode dar. Zwar war die Bestimmung des Geschlechts in 99\% der Fälle mittels Abschätzen des anogenitalen Abstandes suffizient, jedoch sollte ein möglicher Irrtum mittels dieser zweiten Methode in den Versuchen mit kleiner Stichprobengröße ausgeschlossen werden. Dies diente der Möglichkeit, einen rein weiblichen Versuchsaufbau in der Zellkultur und den in vivo Versuchen zu erreichen. Ein begründeter Verdacht des Unterschiedes zwischen männlichen und weiblichen Tieren lag hier nicht vor. Hier sollten intersexuelle Unterschiede in vitro ausgeschlossen werden, da gezeigt werden konnte, dass weibliche und männliche Tiere unterschiedlich auf Hypoxie reagieren [HEYER et al. 2005].

Eine rein weibliche Subgruppe zur Auswertung zu definieren, war indes beim immunhistochemischen Nachweis von CB1 für die jeweiligen Genotypen und Altersstufen nicht möglich, da die Gruppengröße in diesem Fall zu klein gewesen wäre, um eine Aussage zu treffen. 


\subsection{Alters- und genotypabhängige Cannabinoidrezep- torexpression im Rattenhirn}

Gemessen wurde die Expressionsstärke in der Granular- und Pyramidalzellschicht des Hippokampus (CA4) auf CB1 und CB2.

Die Immunoreaktivität von CB1 ergab sowohl ein positives Ergebnis für die Pyramidal- als auch die Granularzellschicht des Hippokampus.

Der Anstieg der Immunoreaktivität innerhalb und zwischen den Gruppen der Pyramidalschicht war nicht signifikant unterschiedlich. Die Messung war hier jedoch schwierig, weil eine CB1-Expression im Kern nicht auftrat. Da der Nucleus/SomaIndex im Vergleich zu den Granularzellen groß war (und sie somit stark von der Schnittebene der Zelle abhing), konnte eine Beurteilung des Unterschieds mit der gewählten semiquantitativen Methode nur unzureichend stattfinden. Eine Signifikanz konnte nicht erreicht werden, auch wenn der Trend der Immunoreaktivität in Richtung des Trends der Granularzellschicht ging. Ein möglicher Grund hierfür war die hohe Variabilität.

In der Granularzellschicht gab es einen Anstieg der Expression von CB1 über die gewählten Zeitpunkte (Tage 14 und 21) zum Ausgangswert (Tag 3) in sl/sl-Tieren. Im Wildtyp ergab sich dieser Unterschied nicht.

Im Western Blot konnte aufgrund der geringen Stichprobengröße kein signifikanter Unterschied in der Expression dargestellt werden. Ein weiterer Grund könnte die geringere Genauigkeit der Methode gegenüber der immunhistochemischen Auswertung sein. Hier konnte ein geringer Unterschied wie in der Immunhistochemie aufgrund der Methode nicht entsprechend herausgearbeitet werden. So machten die Variablen (Belichtungszeit, anderes Gel, Anpassung des Hintergrundes) für diese Methode eine Vergleichbarkeit unsicherer.

Es gelang jedoch ein Nachweis von CB1 in allen drei Genotypen und in den verwendeten Altersstufen, der sich bei Verwendung des Blockpeptids als spezifische Färbung herausstellte und die Spezifität des Antikörpers, auch im Test gegen den Biochem-Ak, validierte. Ein Anstieg der Rezeptorexpression war im weiteren Verlauf aufgrund des Versuchsaufbaus innerhalb der Gruppen weiterhin nicht ausgeschlossen. Ein direkter Vergleich war aber bei unterschiedlichen Variablen statistisch und methodisch nicht möglich.

Eine Färbung hippokampaler Neuronen mit CB2 konnte in keiner der Stichproben dargestellt werden. Dieses Ergebnis stellte einen Normalbefund dar [GONG et al. 
2006]. Das ET-B- und das CB2-System schien nach unserer Untersuchung bei hippokampalen Neuronen in vivo gegenseitig keine darstellbare Alteration aufzuweisen.

Eine Interaktion des CB2-Rezeptors mit Hinblick auf die Interaktion des Endothelin- mit dem Cannabinoidsystems blieb hiermit in ET-B-defizienten Tieren unwahrscheinlich, jedoch nicht völlig ausgeschlossen. Weitere Untersuchungen könnten hier jedoch einen Aufschluss über eine mögliche Interaktion von ET-B und CB2, z.B. in Astrozyten, zeigen [BENITO et al. 2005].

\subsection{Negative Korrelation von Immunoreaktivität von CB1 und Anzahl apoptotischer Zellen}

Ein altersabhängiger Anstieg der Rezeptorexpression in den verschiedenen Genotypen von CB1 konnte mit dem linearen Modell mit Poissonfamilie bestätigt werden. Dies war schon zuvor an immaturen Tieren beschrieben worden, wenn auch nicht detailliert im Hippokampus [ROMERO et al. 1997]. Neu war hier, dass eine Überexpression des Rezeptors in 13-14 und 21-22 Tage alten, ET-B-defizienten Tieren aufgezeigt werden konnte. Das führte zu der These, dass in Tieren mit ET-BDefizienz eine zumindest partielle neuroprotektive Wirkung des nicht funktionellen ET-B durch eine vermehrte Expression von CB1 substituiert werden könnte.

Die letzte These unterstützte, dass nur bei sl/sl-Tieren, nicht bei Wildtypen, eine negative Korrelation zwischen Immunoreaktivität von CB1 und Anzahl apoptotischer Zellen bestand (Abb. 10).

Eine hohe Expression von CB1 unter pathophysiologischen Bedingungen wurde schon im experimentellen Ischämiemodell nachgewiesen [JIN et al. 2000]. Auch hier könnte dies auf einen ähnlichen Mechanismus hinweisen. Die Überexpression von CB1 bei ET-B-Defizienz könnte der Hinweis für einen endogenen Substitutionseffekt der Systeme untereinander darstellen.

Da das endogene Cannabinoidsystem bei Agonisten einer nachfrageorientierten Synthese aus Fettsäurederivaten unterliegt, um zum Beispiel einem CalciumInflux entgegenzuwirken, könnte auch die Rezeptorexpression einer solchen „Synthesis on Demand“ unterliegen [MARSICANO et al. 2003].

Ein „Rezeptor-on-demand“-Mechanismus könnte eine ähnliche Rolle im Zellüberleben spielen wie die Cannabinoidsynthese selbst.

In Vorarbeiten konnte gezeigt werden, dass die Apoptoserate bei Tieren am Tag 4 bei zwei Stichproben erhöht war (ET-B-Defizienz und Heterozygot) 
[EHRENREICH et al. 2000]; eine Möglichkeit, die auf eine physiologische Regulation hinweisen könnte, die CB1-unabhängig war. Dies konnte auch in der Korrelation gezeigt werden. Eine Abhängigkeit von CB1-Expression und Anzahl apoptotischer Zellen ergab sich deshalb bei vier Tage alten Tieren nicht. Bei 14-21 Tage alten Tieren könnte jedoch die Abhängigkeit des Überlebens der Neuronen von der CB1-Expression einem Prozess der Gehirnmodellierung entsprechen, der sich über Tag 14-21 in Wildtypen durch das Vorhandensein von ET-B physiologisch verliert. Die Abhängigkeit des Auftretens neuroprotektiver Rezeptorsysteme vom Alter wurde schon für Cannabinoide, Endotheline und Erythropoietin vorbeschrieben [FERNANDEZ-RUIZ et al. 1999; FRIDE und SHOHAMI 2002; KNABE et al. 2004; ROMERO et al. 1997]. Eine Regulation und Interaktion dieser Systeme wäre somit sehr wahrscheinlich.

Der Cannabinoidrezeptor scheint bei der Wistar-Imamichi-Ratte jedoch nur bei Abwesenheit von ET-B eine Rolle an den Lebenstagen 14 bis $21 \mathrm{zu}$ spielen. In dieser Zeit liegt bei juvenilen Tieren eine besondere neuronale Vulnerabilität vor, da das ET-B-Rezeptorsystem einen wichtigen Überlebensfaktor im Gehirn darstellt [SIREN et al. 2002]. Die Aktivierung von antiapoptotischen Signalwegen, wie z. B. der des ERK-Signalweges durch endogene Cannabinoide [RUBINO et al. 2004], könnte dabei eine wichtige Rolle beim Zellüberleben der ET-B-defizienten Ratten spielen [YAGAMI et al. 2002; YAGAMI et al. 2005] und einen Grund für die Überexpression darstellen.

\subsection{Neuroprotektiver Effekt von Cannabinoidagonisten in vitro}

Mit der Kultur primärer hippokampaler Neuronen von Wildtypen und ET-Bdefizienten Ratten sollte die neuroprotektive Fähigkeit des endogenen CannabisAgonisten Noladin und des synthetischen Cannabis-Agonisten delta9Tetrahydrocannabinol in vitro getestet werden. Es ergab sich hier, dass die ET-BDefizienz eine erhöhte Apoptoserate unter Normoxie und Hypoxie mit sich brachte. ET-B stellte einen Überlebensfaktor in Neuronenkulturen dar.

In den niedriger gewählten Konzentrationen konnte eine Reduktion des Zelltodes bei ET-B-Defizienz im Vergleich zur Kontrolle durch die Gabe von Cannabinoiden erreicht werden. Bei höherer Konzentration war dieser Effekt nicht mehr nachzuweisen. Die Gabe von Cannabinoiden konnte somit einen Teil des Zelltodes innerhalb der primären Neuronenkulturen reduzieren.

Interessanterweise war auch hier kein Effekt durch Cannabinoidgabe innerhalb der Wildtypkulturen präsent, auch wenn dies in diversen Arbeiten, jedoch mit anderem Versuchsaufbau, gezeigt werden konnte [GILBERT et al. 2007; LASTRES- 
BECKER et al. 2005]. Hier wurde statt Hypoxie exzitatorische Zytotoxizität untersucht. Dies erklärt möglicherweise den Unterschied im Zellüberleben. Die Hypoxie allein scheint jedoch kein ausreichender Stimulus für eine cannabinoidvermittelte Neuroprotektion im angewandten Versuchsaufbau mit Wistar-ImamichiWildtypen darzustellen. Viel eher stellt die Gabe von Cannabinoidrezeptoragonisten in vitro einen Überlebensvorteil bei ET-B-Defizienz dar.

\subsection{Vorversuch Hypoxie/Ischämie und Gabe von THC in vivo}

Die erhöhte CB1-Expression in ET-B-defizienten Ratten und deren negative Korrelation mit dem Auftreten von Apoptose zeigen, dass das Cannabinoidsystem eine Rolle in der Entwicklung von Wistar-Imamichi-Ratten ab dem Alter von 14 Tagen spielt. Eine erhöhte Expression von CB1 in Wildtypen konnte im Hypoxie/Ischämiemodell in diesem Alter ebenfalls gezeigt werden [JIN et al. 2000].

Eine neuroprotektive Wirkung im Hypoxie-/Ischämiemodell an der juvenilen Ratte durch delta9-THC-vermittelte Aktivation von CB1 sollte jetzt zunächst an ET-Bgesunden Tieren untersucht werden. Dabei war das Ziel, in Wistar-ImamichiRatten eine nichttoxische oder neuroprotektive Wirkung zu erzielen [NAGAYAMA et al. 1999; VAN DER STELT et al. 2001], um dann im Anschluss die eigentlichen Versuche mit ET-B-defiziente Ratten durchzuführen.

Ein neuroprotektiver Effekt konnte jedoch in diesem Versuch nicht nachgewiesen werden. Einen größeren Hirnschaden und eine höhere Zelltodrate nach Hypoxie/Ischämie wurden im Gegenzug in der CA1-Region des Hippokampus der THC-behandelten Ratten gefunden (Abb. 17). Die Gabe von THC zur Reduktion von Zellschädigung oder -tod bei Hypoxie/Ischämie durch CB1-Aktivation war somit nicht erfolgreich. Auch ließ sich eine erhöhte Expression von CB1 anders als bei JIN et al. weder in Placebotieren, noch in THC-behandelten Tieren nachweisen.

Dies ging jedoch mit den Voruntersuchungen aus der Neuronenzellkultur und den Korrelationsversuchen einher, die eine Neuroprotektion durch das endogene Cannabinoidsystem bei Wildtypen im gewählten Versuchsaufbau unwahrscheinlich machten. Eine zusätzlich schädigende Wirkung hatten wir jedoch hier nicht eruieren können.

Gründe dafür könnten die Methode, das Alter der Tiere und der Versuchsaufbau darstellen. Bei ausgewachsenen Tieren konnten mit der verwendeten Dosis THC neuroprotektive Effekte in Wildtypen gezeigt werden [NAGAYAMA et al. 1999]. Bei den hier verwendeten Tieren handelte es sich jedoch um juvenile Ratten. Für diese könnte die verwendete Dosis toxisch gewesen sein. 
Die vorausgegangenen Zellkulturversuche zeigten, dass nur die niedrigen Cannabinoiddosen einen protektiven Effekt hatten. Toxische Effekte könnten hier neben Überdosierung auf zwei weiteren Wegen eine Rolle spielen: auf neuronaler Ebene könnte die Induktion von ERK [DERKINDEREN et al. 2003] durch CB1 eine Induktion von proapoptotischen Signaltransduktionswegen bewegen [EHRENREICH et al. 2005]. Auf nichtneuronaler Ebene könnte die Induktion von systemischer Hypotonie eine Rolle spielen [GARCIA et al. 2001; WAGNER et al. 2001]. Gezeigt werden konnte, dass die Gabe von THC in Konzentrationen von 0,5 - 16 mg/ kg Körpergewicht die Durchblutung im Gehirn senkt [BLOOM et al. 1997]. Eine Hypotonie während der Hypoxie könnte die Schadensareale in vulnerablen Arealen wie dem Hippokampus vergrößert haben.

\subsection{ET-B und CB1 als Teil eines neuroprotektiven Netzwerkes?}

Bei funktioneller Abwesenheit des ET-B-Rezeptors ergab sich eine erhöhte Apoptoserate in vivo, die vermutlich durch ein Auftreten von CB1 abgemildert werden konnte. Auch in vitro zeigten Ratten mit ET-B-Defizienz gegenüber Wildtypen mehr Schaden unter Hypoxie [SIREN et al. 2002]. Da beide Rezeptoren ERKvermittelt Neuroprotektion entfalten können, könnte hier der gemeinsame intrazelluläre Regulationsmechanismus liegen [MARSICANO et al. 2003; MECHOULAM et al. 2002; NAGAYAMA et al. 1999; YAGAMI et al. 2002; YAGAMI et al. 2005]. Nichtneuronale Effekte, z. B. über die Aktivierung von Astrozyten durch CB2 [ASHTON et al. 2007] sowie vaskuläre Effekte spielen aber offensichtlich ebenfalls eine Rolle. Im in-vitro-Modell konnten diese Effekte weitgehend durch die Abwesenheit von Astrozyten ausgeschlossen werden.

Zukünftig wäre ein Versuchsaufbau mit CB1-knockout Tieren interessant. In Mäusen war das Auftreten von erhöhter neuronaler Vulnerabilität gezeigt worden [PARMENTIER-BATTEUR et al. 2002]. Das erhöhte Auftreten von ET-B bei diesen Tieren würde diese These noch unterstützen und ein neuroprotektives Netzwerk befürworten.

Zusätzlich sollte im Anschluss untersucht werden, ob bei Patienten mit bakterieller Meningitis [EHRENREICH et al. 2000] ebenfalls eine Überexpression von CB1 besteht, da hier dann analog den in-vitro-Versuchen eine Reduktion des Zelltodes, und damit ggf. eine Verbesserung der Lebensqualität, erreicht werden könnte. 


\section{Zusammenfassung}

Zellmembranständige Rezeptoren wie CB1 und ET-B spielen eine Rolle im Zellüberleben im juvenilen Rattenhirn. Diese Arbeit beleuchtet anhand eines ET-BSubtraktionsmodells eine mögliche Interaktion zwischen diesen zwei Rezeptorsystemen im Gehirn juveniler Wistar-Imamichi-Ratten.

Bei Abwesenheit von funktionellem ET-B ergab sich eine Hochregulation der CB1Expression. Die Anzahl toter Zellen bei Abwesenheit von ET-B war hierbei umgekehrt proportional zur Rezeptorexpression von CB1. Tiere mit intaktem Endothelinsystem wiesen diese Abhängigkeit nicht auf. Die Aktivation von CB1 durch Noladin und delta9-THC zeigte sich im Hypoxiemodell in vitro in primären hippokampalen Neuronenkulturen nur bei ET-B-Defizienz neuroprotektiv wirksam. In Wildtypen war diese neuroprotektive Wirkung durch CB1-Agonistengabe nicht nachzuweisen. Ein endogener Substitutionseffekt von CB1 bei ET-BDefizienz konnte hiermit gezeigt werden.

In Vorversuchen wies die Gabe von THC bei Hypoxie/Ischämie in vivo bei juvenilen Wistar-Imamichi-Ratten keinen protektiven Effekt auf. Die Zelltodrate und der Hirnschaden waren im Gegenzug im Cortex und Hippokampus erhöht. Eine Erklärung dafür könnte in einer möglichen systemischen Hypotonie nach THC-Gabe liegen. Ein Neuauftreten von CB2 und GFAP koexprimierenden Zellen im Cortex und Hippokampus wurde nachgewiesen.

Das endogene Cannabinoidsystem spielt eine Rolle in der Substitution funktioneller ET-B-Defizienz beim Überleben neuronaler Zellen. Eine Aktivierung von CB1 konnte in vitro eine neuroprotektive Wirkung vermitteln. Auch wenn die Applikation von THC keinen Überlebensvorteil bei Hypoxie/Ischämie in vivo erbrachte, ist die Erkenntnis eines endogenen Substitutionseffektes von CB1 bei ET-B-Defizienz für die weitere wissenschaftliche Beleuchtung von Rezeptorinteraktionen von Bedeutung. Eine klinische Anwendung könnte dies bei Menschen mit krankheitsassoziierter, reduzierter ET-B-Expression erlangen, wie z. B. bei bakterieller Meningitis. 


\section{Literaturverzeichnis}

ANDINE P, LEHMANN A, ELLREN K, WENNBERG E, KJELLMER I, NIELSEN T, HAGBERG H (1988): The excitatory amino acid antagonist kynurenic acid administered after hypoxic-ischemia in neonatal rats offers neuroprotection. Neurosci Lett 90, 208-212.

ANGERIO AD (2005): The role of endothelin in heart failure. Crit Care Nurs Q 28 , 355-359.

ASHTON JC, RAHMAN RM, NAIR SM, SUTHERLAND BA, GLASS M, APPLETON I (2007): Cerebral hypoxia-ischemia and middle cerebral artery occlusion induce expression of the cannabinoid CB2 receptor in the brain. Neurosci Lett $\underline{412}$, 114-117.

ATALLAH HE, FRANK MJ, O'REILLY RC (2004): Hippocampus, cortex, and basal ganglia: insights from computational models of complementary learning

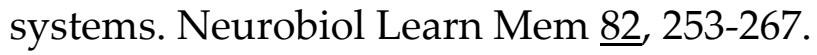

BATKAI S, JARAI Z, WAGNER JA, GOPARAJU SK, VARGA K, LIU J, WANG L, MIRSHAHI F, KHANOLKAR AD, MAKRIYANNIS A (2001): Endocannabinoids acting at vascular CB1 receptors mediate the vasodilated state in advanced liver cirrhosis. Nat Med $\underline{7}$, 827-832.

BAYNASH AG, HOSODA K, GIAID A, RICHARDSON JA, EMOTO N, HAMMER RE, YANAGISAWA M (1994): Interaction of endothelin-3 with endothelin-B receptor is essential for development of epidermal melanocytes and enteric neurons. Cell $\underline{79}$, 1277-1285.

BENITO C, KIM WK, CHAVARRIA I, HILLARD CJ, MACKIE K, TOLON RM, WILLIAMS K, ROMERO J (2005): A glial endogenous cannabinoid system is upregulated in the brains of macaques with simian immunodeficiency virus-induced encephalitis. J Neurosci $\underline{25}$, 2530-2536. 
BERTHIAUME N, YANAGISAWA M, D'ORLEANS-JUSTE P (2000): Contribution of endogenous endothelin-1 and endothelin-A-receptors to the hypertensive state of endothelin-B heterozygous (+/-) knockout mice. J Cardiovasc Pharmacol $\underline{36}$, S72-74.

BILBO SD, NEWSUM NJ, SPRUNGER DB, WATKINS LR, RUDY JW, MAIER SF (2007): Differential effects of neonatal handling on early life infectioninduced alterations in cognition in adulthood. Brain Behav Immun 21, 332342.

BLOOM AS, TERSHNER S, FULLER SA, STEIN EA (1997): Cannabinoid-induced alterations in regional cerebral blood flow in the rat. Pharmacol Biochem Behav 57, 625-631.

BONFILS PK, REITH J, HASSELDAM H, JOHANSEN FF (2006): Estimation of the hypothermic component in neuroprotection provided by cannabinoids following cerebral ischemia. Neurochem Int $\underline{49}$,508-518.

BOUABOULA M, RINALDI M, CARAYON P, CARILLON C, DELPECH B, SHIRE D, LE FUR G, CASELLAS P (1993): Cannabinoid-receptor expression in human leukocytes. Eur J Biochem 214, 173-180.

BRAIDA D, SALA M (2000): Cannabinoid-induced working memory impairment is reversed by a second generation cholinesterase inhibitor in rats. Neuroreport $\underline{11}$, 2025-2029.

BREIVOGEL CS, CHILDERS SR (1998): The functional neuroanatomy of brain cannabinoid receptors. Neurobiol Dis $\underline{5}, 417-431$.

BREWER GJ, TORRICELLI JR, EVEGE EK, PRICE PJ (1993): Optimized survival of hippocampal neurons in B27-supplemented Neurobasal, a new serum-free medium combination. J Neurosci Res $\underline{35}$, 567-576. 
BROWN SM, WAGER-MILLER J, MACKIE K (2002): Cloning and molecular characterization of the rat CB2 cannabinoid receptor. Biochim Biophys Acta 1576, 255-264.

BRUNNER F, BRAS-SILVA C, CERDEIRA AS, LEITE-MOREIRA AF (2006): Cardiovascular endothelins: essential regulators of cardiovascular homeostasis. Pharmacol Ther 111, 508-531.

CALIGNANO A, LA RANA G, GIUFFRIDA A, PIOMELLI D (1998): Control of pain initiation by endogenous cannabinoids. Nature $\underline{394}$, 277-281.

CARLISLE SJ, MARCIANO-CABRAL F, STAAB A, LUDWICK C, CABRAL GA (2002): Differential expression of the CB2 cannabinoid receptor by rodent macrophages and macrophage-like cells in relation to cell activation. Int Immunopharmacol 2, 69-82.

CERNACEK P, STEWART DJ, MONGE JC, ROULEAU JL (2003): The endothelin system and its role in acute myocardial infarction. Can J Physiol Pharmacol 81, 598-606.

DAWSON JM, HEATLIE PL (1984): Lowry method of protein quantification: evidence for photosensitivity. Anal Biochem 140, 391-393.

DEMBOWSKI C, HOFMANN P, KOCH T, KAMROWSKI-KRUCK H, RIEDESEL H, KRAMMER HJ, KAUP FJ, EHRENREICH H (2000): Phenotype, intestinal morphology, and survival of homozygous and heterozygous endothelin B receptor--deficient (spotting lethal) rats. J Pediatr Surg $\underline{35}$ 480-488.

DERKINDEREN P, VALJENT E, TOUTANT M, CORVOL JC, ENSLEN H, LEDENT C, TRZASKOS J, CABOCHE J, GIRAULT JA (2003): Regulation of extracellular signal-regulated kinase by cannabinoids in hippocampus. J Neurosci 23, 2371-2382. 


\section{Literaturverzeichnis}

DIGICAYLIOGLU M, LIPTON SA (2001): Erythropoietin-mediated neuroprotection involves cross-talk between Jak2 and NF-kappaB signalling cascades. Nature $\underline{412}$, 641-647.

DOGGRELL SA (2004): The endothelin system and its role in acute myocardial infarction. Expert Opin Ther Targets $\underline{8}$, 191-201.

EHRENREICH H, SCHILLING L (1995): New developments in the understanding of cerebral vasoregulation and vasospasm: the endothelin-nitric oxide network. Cleve Clin J Med 62, 105-116.

EHRENREICH H, RINN T, KUNERT HJ, MOELLER MR, POSER W, SCHILLING L, GIGERENZER G, HOEHE MR (1999a): Specific attentional dysfunction in adults following early start of cannabis use. Psychopharmacology (Berl) 142, 295-301.

EHRENREICH H, OLDENBURG J, HASSELBLATT M, HERMS J, DEMBOWSKI C, LOFFLER BM, BRUCK W, KAMROWSKI-KRUCK H, GALL S, SIREN AL (1999b): Endothelin B receptor-deficient rats as a subtraction model to study the cerebral endothelin system. Neuroscience 11 , 1067-1075.

EHRENREICH H, NAU TR, DEMBOWSKI C, HASSELBLATT M, BARTH M, HAHN A, SCHILLING L, SIREN AL, BRUCK W (2000): Endothelin b receptor deficiency is associated with an increased rate of neuronal apoptosis in the dentate gyrus. Neuroscience 95, 993-1001.

EHRENREICH H, HASSELBLATT M, DEMBOWSKI C, CEPEK L, LEWCZUK P, STIEFEL M, RUSTENBECK HH, BREITER N, JACOB S, KNERLICH F (2002): Erythropoietin therapy for acute stroke is both safe and beneficial. Mol Med $\underline{8}, 495-505$.

EHRENREICH H, HASSELBLATT M, KNERLICH F, VON AHSEN N, JACOB S, SPERLING S, WOLDT H, VEHMEYER K, NAVE KA, SIREN AL (2005): A 
hematopoietic growth factor, thrombopoietin, has a proapoptotic role in the brain. Proc Natl Acad Sci U S A 102, 862-867.

FERNANDEZ-LOPEZ D, MARTINEZ-ORGADO J, NUNEZ E, ROMERO J, LORENZO P, MORO MA, LIZASOAIN I (2006): Characterization of the Neuroprotective Effect of the Cannabinoid Agonist WIN-55212 in an In Vitro Model of Hypoxic-Ischemic Brain Damage in Newborn Rats. Pediatr Res 60, 169-173.

FERNANDEZ-RUIZ JJ, BERRENDERO F, HERNANDEZ ML, ROMERO J, RAMOS JA (1999): Role of endocannabinoids in brain development. Life Sci $\underline{65}, 725-736$.

FERRARI F, OTTANI A, GIULIANI D (2000): Inhibitory effects of the cannabinoid agonist HU 210 on rat sexual behaviour. Physiol Behav 69, 547-554.

FEZZA F, BISOGNO T, MINASSI A, APPENDINO G, MECHOULAM R, DI MARZO V (2002): Noladin ether, a putative novel endocannabinoid: inactivation mechanisms and a sensitive method for its quantification in rat tissues. FEBS Lett $\underline{513}$, 294-298.

FRACCAROLLO D, HU K, GALUPPO P, GAUDRON P, ERTL G (1997): Chronic endothelin receptor blockade attenuates progressive ventricular dilation and improves cardiac function in rats with myocardial infarction: possible involvement of myocardial endothelin system in ventricular remodeling. Circulation 96, 3963-3973.

FRIDE E (2002): Endocannabinoids in the central nervous system--an overview. Prostaglandins Leukot Essent Fatty Acids 66, 221-233.

FRIDE E, SHOHAMI E (2002): The endocannabinoid system: function in survival of the embryo, the newborn and the neuron. Neuroreport $13,1833-1841$. 


\section{Literaturverzeichnis}

GARCIA N, JR., JARAI Z, MIRSHAHI F, KUNOS G, SANYAL AJ (2001): Systemic and portal hemodynamic effects of anandamide. Am J Physiol Gastrointest Liver Physiol 280, G14-20.

GARDNER A, MALLET PE (2006): Suppression of feeding, drinking, and locomotion by a putative cannabinoid receptor 'silent antagonist'. Eur J Pharmacol $\underline{530}, 103-106$.

GERSHON MD (1999): Endothelin and the development of the enteric nervous system. Clin Exp Pharmacol Physiol 26, 985-988.

GILBERT GL, KIM HJ, WAATAJA JJ, THAYER SA (2007): Delta9tetrahydrocannabinol protects hippocampal neurons from excitotoxicity. Brain Res 1128, 61-69.

GLASS M, DRAGUNOW M, FAULL RL (1997): Cannabinoid receptors in the human brain: a detailed anatomical and quantitative autoradiographic study in the fetal, neonatal and adult human brain. Neuroscience $77,299-318$.

GONG JP, ONAIVI ES, ISHIGURO H, LIU QR, TAGLIAFERRO PA, BRUSCO A, UHL GR (2006): Cannabinoid CB2 receptors: immunohistochemical localization in rat brain. Brain Res 1071, 10-23.

GRUNDY RI (2002): The therapeutic potential of the cannabinoids in neuroprotection. Expert Opin Investig Drugs 11, 1365-1374.

HALL ED, YONKERS PA, ANDRUS PK, COX JW, ANDERSON DK (1992): Biochemistry and pharmacology of lipid antioxidants in acute brain and spinal cord injury. J Neurotrauma 9 Suppl 2, S425-442.

HAMPSON AJ, GRIMALDI M, AXELROD J, WINK D (1998): Cannabidiol and (-) Delta9-tetrahydrocannabinol are neuroprotective antioxidants. Proc Natl Acad Sci U S A 95, 8268-8273. 
HAMPSON AJ, GRIMALDI M, LOLIC M, WINK D, ROSENTHAL R, AXELROD J (2000): Neuroprotective antioxidants from marijuana. Ann N Y Acad Sci $\underline{899}, 274-282$.

HANUS L, ABU-LAFI S, FRIDE E, BREUER A, VOGEL Z, SHALEV DE, KUSTANOVICH I, MECHOULAM R (2001): 2-arachidonyl glyceryl ether, an endogenous agonist of the cannabinoid CB1 receptor. Proc Natl Acad Sci U S A 98 , 3662-3665.

HASSELBLATT M, BUNTE M, DRINGEN R, TABERNERO A, MEDINA JM, GIAUME C, SIREN AL, EHRENREICH H (2003): Effect of endothelin-1 on astrocytic protein content. Glia $\underline{42}$, 390-397.

HEILIG M, EGLI M (2006): Pharmacological treatment of alcohol dependence: target symptoms and target mechanisms. Pharmacol Ther $\underline{111}$ 855-876.

HENRIKSSON M, STENMAN E, VIKMAN P, EDVINSSON L (2007): MEK1/2 inhibition attenuates vascular ET(A) and ET (B) receptor alterations after cerebral ischaemia. Exp Brain Res 178, 470-476.

HERKENHAM M, LYNN AB, LITTLE MD, JOHNSON MR, MELVIN LS, DE COSTA BR, RICE KC (1990): Cannabinoid receptor localization in brain. Proc Natl Acad Sci U S A $\underline{87}$ 1932-1936.

HERNANDEZ-TRISTAN R, AREVALO C, CANALS S, LERET ML (2000): The effects of acute treatment with delta9-THC on exploratory behaviour and memory in the rat. J Physiol Biochem $\underline{56}$ 17-24.

HEYER A, HASSELBLATT M, VON AHSEN N, HAFNER H, SIREN AL, EHRENREICH H (2005): In vitro gender differences in neuronal survival on hypoxia and in 17beta-estradiol-mediated neuroprotection. J Cereb Blood Flow Metab 25, 427-430. 


\section{Literaturverzeichnis}

HOSODA K, HAMMER RE, RICHARDSON JA, BAYNASH AG, CHEUNG JC, GIAID A, YANAGISAWA M (1994): Targeted and natural (piebald-lethal) mutations of endothelin-B receptor gene produce megacolon associated with spotted coat color in mice. Cell $\underline{79}$, 1267-1276.

HOWLETT AC (2005): Cannabinoid receptor signaling. Handb Exp Pharmacol, 5379.

HOWLETT AC, BIDAUT-RUSSELL M, DEVANE WA, MELVIN LS, JOHNSON MR, HERKENHAM M (1990): The cannabinoid receptor: biochemical, anatomical and behavioral characterization. Trends Neurosci $\underline{13}$, 420-423.

JAMSHIDI N, TAYLOR DA (2001): Anandamide administration into the ventromedial hypothalamus stimulates appetite in rats. Br J Pharmacol $\underline{134}$, 1151-1154.

JIN KL, MAO XO, GOLDSMITH PC, GREENBERG DA (2000): CB1 cannabinoid receptor induction in experimental stroke. Ann Neurol $\underline{48}$, 257-261.

JOACHIM H: Papyros Ebers Das älteste Buch über Heilkunde. Reimer, Berlin 1890

KAPINYA KJ (2005): Ischemic tolerance in the brain. Acta Physiol Hung 92, 67-92.

KNABE W, KNERLICH F, WASHAUSEN S, KIETZMANN T, SIREN AL, BRUNNETT G, KUHN HJ, EHRENREICH H (2004): Expression patterns of erythropoietin and its receptor in the developing midbrain. Anat Embryol (Berl) 207, 503-512.

KONINGS M, MAHARAJH HD (2006): Cannabis use and mood disorders: patterns of clinical presentations among adolescents in a developing country. Int J Adolesc Med Health 18, 221-233. 
KRAMER BK, ITTNER KP, BEYER ME, HOFFMEISTER HM, RIEGGER GA (1997): Circulatory and myocardial effects of endothelin. J Mol Med $\underline{75}$, 886-890.

KUC RE, MAGUIRE JJ, DAVENPORT AP (2006): Quantification of endothelin receptor subtypes in peripheral tissues reveals downregulation of ET(A) receptors in ET(B)-deficient mice. Exp Biol Med (Maywood) 231, 741-745.

KWIATKOWSKA M, PARKER LA, BURTON P, MECHOULAM R (2004): A comparative analysis of the potential of cannabinoids and ondansetron to suppress cisplatin-induced emesis in the Suncus murinus (house musk shrew). Psychopharmacology (Berl) $\underline{174}$ 254-259.

LAHAV R, HEFFNER G, PATTERSON PH (1999): An endothelin receptor B antagonist inhibits growth and induces cell death in human melanoma cells in vitro and in vivo. Proc Natl Acad Sci U S A 96, 11496-11500.

LASTRES-BECKER I, MOLINA-HOLGADO F, RAMOS JA, MECHOULAM R, FERNANDEZ-RUIZ J (2005): Cannabinoids provide neuroprotection against 6-hydroxydopamine toxicity in vivo and in vitro: relevance to Parkinson's disease. Neurobiol Dis $\underline{19}, 96-107$.

LAYEEQUE R, SIEGEL E, KASS R, HENRY-TILLMAN RS, COLVERT M, MANCINO A, KLIMBERG VS (2006): Prevention of nausea and vomiting following breast surgery. Am J Surg 191, 767-772.

LAZAREWICZ JW, PLUTA R, PUKA M, SALINSKA E (1990): Diverse mechanisms of neuronal protection by nimodipine in experimental rabbit brain ischemia. Stroke 21, IV108-110.

LOWRY OH, ROSEBROUGH NJ, FARR AL, RANDALL RJ (1951): Protein measurement with the Folin phenol reagent. J Biol Chem 193, 265-275. 
MARSICANO G, MOOSMANN B, HERMANN H, LUTZ B, BEHL C (2002a): Neuroprotective properties of cannabinoids against oxidative stress: role of the cannabinoid receptor CB1. J Neurochem $\underline{80}$ 448-456.

MARSICANO G, WOTJAK CT, AZAD SC, BISOGNO T, RAMMES G, CASCIO MG, HERMANN H, TANG J, HOFMANN C, ZIEGLGANSBERGER W (2002b): The endogenous cannabinoid system controls extinction of aversive memories. Nature $\underline{418}$, 530-534.

MARSICANO G, GOODENOUGH S, MONORY K, HERMANN H, EDER M, CANNICH A, AZAD SC, CASCIO MG, GUTIERREZ SO, VAN DER STELT $M$ (2003): CB1 cannabinoid receptors and on-demand defense against excitotoxicity. Science $\underline{302}, 84-88$.

MARTIN M, LEDENT C, PARMENTIER M, MALDONADO R, VALVERDE O (2002): Involvement of CB1 cannabinoid receptors in emotional behaviour. Psychopharmacology (Berl) $\underline{159}$ 379-387.

MATSUDA LA, LOLAIT SJ, BROWNSTEIN MJ, YOUNG AC, BONNER TI (1990): Structure of a cannabinoid receptor and functional expression of the cloned cDNA. Nature 346, 561-564.

MAULER F, HINZ V, AUGSTEIN KH, FASSBENDER M, HORVATH E (2003): Neuroprotective and brain edema-reducing efficacy of the novel cannabinoid receptor agonist BAY 38-7271. Brain Res 989, 99-111.

MECHOULAM R, HANU L (2001): The cannabinoids: an overview. Therapeutic implications in vomiting and nausea after cancer chemotherapy, in appetite promotion, in multiple sclerosis and in neuroprotection. Pain Res Manag $\underline{6}$, 67-73.

MECHOULAM R, BRAUN P, GAONI Y (1972a): Syntheses of 1 tetrahydrocannabinol and related cannabinoids. J Am Chem Soc 94 , 61596165. 
MECHOULAM R, VARCONI H, BEN-ZVI Z, EDERY H, GRUNFELD Y (1972b): Synthesis and biological activity of five tetrahydrocannabinol metabolites. J Am Chem Soc 94, 7930-7931.

MECHOULAM R, SPATZ M, SHOHAMI E (2002): Endocannabinoids and neuroprotection. Sci STKE 2002, RE5.

MEHTA SL, MANHAS N, RAGHUBIR R (2007): Molecular targets in cerebral ischemia for developing novel therapeutics. Brain Res Brain Res Rev $\underline{54}$, 3466.

MOLDRICH G, WENGER T (2000): Localization of the CB1 cannabinoid receptor in the rat brain. An immunohistochemical study. Peptides 21, 1735-1742.

MUNRO S, THOMAS KL, ABU-SHAAR M (1993): Molecular characterization of a peripheral receptor for cannabinoids. Nature $\underline{365}$ 61-65.

NAGAYAMA T, SINOR AD, SIMON RP, CHEN J, GRAHAM SH, JIN K, GREENBERG DA (1999): Cannabinoids and neuroprotection in global and focal cerebral ischemia and in neuronal cultures. J Neurosci 19, 2987-2995.

NAMBI P (1996): Endothelin receptors in normal and diseased kidneys. Clin Exp Pharmacol Physiol 23, 326-330.

NAVARRO M, RUBIO P, DE FONSECA FR (1995): Behavioural consequences of maternal exposure to natural cannabinoids in rats. Psychopharmacology (Berl) 122, 1-14.

NAVARRO M, HERNANDEZ E, MUNOZ RM, DEL ARCO I, VILLANUA MA, CARRERA MR, RODRIGUEZ DE FONSECA F (1997): Acute administration of the CB1 cannabinoid receptor antagonist SR 141716A induces anxietylike responses in the rat. Neuroreport $\underline{8}, 491-496$. 


\section{Literaturverzeichnis}

NEGRETE JC, KNAPP WP (1986): The effects of cannabis use on the clinical condition of schizophrenics. NIDA Res Monogr 67, 321-327.

ONAIVI ES, CHAUDHURI G, ABACI AS, PARKER M, MANIER DH, MARTIN PR, HUBBARD JR (1999): Expression of cannabinoid receptors and their gene transcripts in human blood cells. Prog Neuropsychopharmacol Biol Psychiatry $\underline{23}$, 1063-1077.

O'SULLIVAN SE, TARLING EJ, BENNETT AJ, KENDALL DA, RANDALL MD (2005): Novel time-dependent vascular actions of Delta9tetrahydrocannabinol mediated by peroxisome proliferator-activated receptor gamma. Biochem Biophys Res Commun 337, 824-831.

PALAZZO E, DE NOVELLIS V, PETROSINO S, MARABESE I, VITA D, GIORDANO C, DI MARZO V, MANGONI GS, ROSSI F, MAIONE S (2006): Neuropathic pain and the endocannabinoid system in the dorsal raphe: pharmacological treatment and interactions with the serotonergic system. Eur J Neurosci 24, 2011-2020.

PANIKASHVILI D, MECHOULAM R, BENI SM, ALEXANDROVICH A, SHOHAMI E (2005): CB1 cannabinoid receptors are involved in neuroprotection via NF-kappa B inhibition. J Cereb Blood Flow Metab 25, 477-484.

PANIKASHVILI D, SHEIN NA, MECHOULAM R, TREMBOVLER V, KOHEN R, ALEXANDROVICH A, SHOHAMI E (2006): The endocannabinoid 2-AG protects the blood-brain barrier after closed head injury and inhibits mRNA expression of proinflammatory cytokines. Neurobiol Dis $\underline{22}, 257-264$.

PARMENTIER-BATTEUR S, JIN K, MAO XO, XIE L, GREENBERG DA (2002): Increased severity of stroke in CB1 cannabinoid receptor knock-out mice. J Neurosci 22, 9771-9775. 
PETTIT DA, HARRISON MP, OLSON JM, SPENCER RF, CABRAL GA (1998):

Immunohistochemical localization of the neural cannabinoid receptor in rat brain. J Neurosci Res 51, 391-402.

RIECHERS CC, KNABE W, SIREN AL, GARIEPY CE, YANAGISAWA M, EHRENREICH H (2004): Endothelin B receptor deficient transgenic rescue rats: a rescue phenomenon in the brain. Neuroscience $\underline{124}$, 719-723.

ROMERO J, GARCIA-PALOMERO E, BERRENDERO F, GARCIA-GIL L, HERNANDEZ ML, RAMOS JA, FERNANDEZ-RUIZ JJ (1997): Atypical location of cannabinoid receptors in white matter areas during rat brain development. Synapse 26, 317-323.

ROTTANBURG D, ROBINS AH, BEN-ARIE O, TEGGIN A, ELK R (1982): Cannabis-associated psychosis with hypomanic features. Lancet 1982, 2 , 13641366.

RUBINO T, FORLANI G, VIGANO D, ZIPPEL R, PAROLARO D (2004): Modulation of extracellular signal-regulated kinases cascade by chronic delta 9tetrahydrocannabinol treatment. Mol Cell Neurosci $\underline{25}$, 355-362.

RYBERG E, VU HK, LARSSON N, GROBLEWSKI T, HJORTH S, ELEBRING T, SJOGREN S, GREASLEY PJ (2005): Identification and characterisation of a novel splice variant of the human CB1 receptor. FEBS Lett 579, 259-264.

SCHWARTZ M, KIPNIS J (2005): Protective autoimmunity and neuroprotection in inflammatory and noninflammatory neurodegenerative diseases. J Neurol Sci 233, 163-166.

SHINOHARA H, UDAGAWA J, MORISHITA R, UEDA H, OTANI H, SEMBA R, KATO K, ASANO T (2004): Gi2 signaling enhances proliferation of neural progenitor cells in the developing brain. J Biol Chem $\underline{279}$ 41141-41148. 


\section{Literaturverzeichnis}

SHOUMAN B, FONTAINE RH, BAUD O, SCHWENDIMANN L, KELLER M, SPEDDING M, LELIEVRE V, GRESSENS P (2006): Endocannabinoids potently protect the newborn brain against AMPA-kainate receptormediated excitotoxic damage. Br J Pharmacol 148, 442-451.

SIREN AL, LEWCZUK P, HASSELBLATT M, DEMBOWSKI C, SCHILLING L, EHRENREICH H (2002): Endothelin B receptor deficiency augments neuronal damage upon exposure to hypoxia-ischemia in vivo. Brain Res 945 , 144-149.

STEIN EA, FULLER SA, EDGEMOND WS, CAMPBELL WB (1996): Physiological and behavioural effects of the endogenous cannabinoid, arachidonylethanolamide (anandamide), in the rat. Br J Pharmacol $\underline{119}$ 107-114.

SUNDRAM S (2006): Cannabis and neurodevelopment: implications for psychiatric disorders. Hum Psychopharmacol 21, 245-254.

TABAKMAN R, JIANG H, SHAHAR I, ARIEN-ZAKAY H, LEVINE RA, LAZAROVICI P (2005): Neuroprotection by NGF in the PC12 in vitro OGD model: involvement of mitogen-activated protein kinases and gene expression. Ann N Y Acad Sci 1053, 84-96.

TIRAPELLI CR, CASOLARI DA, YOGI A, MONTEZANO AC, TOSTES RC, LEGROS E, D'ORLEANS-JUSTE P, DE OLIVEIRA AM (2005): Functional characterization and expression of endothelin receptors in rat carotid artery: involvement of nitric oxide, a vasodilator prostanoid and the opening of K+ channels in ETB-induced relaxation. Br J Pharmacol $\underline{146}$, 903-912.

TOMIDA I, AZUARA-BLANCO A, HOUSE H, FLINT M, PERTWEE RG, ROBSON PJ (2006): Effect of sublingual application of cannabinoids on intraocular pressure: a pilot study. J Glaucoma $\underline{15}$, 349-353.

TOUYZ RM, SCHIFFRIN EL (2003): Role of endothelin in human hypertension. Can J Physiol Pharmacol 81, 533-541. 
ULLRICH O, MERKER K, TIMM J, TAUBER S (2007): Immune control by endocannabinoids - New mechanisms of neuroprotection? J Neuroimmunol 184 127-135.

UNZICKER C, ERBERICH H, MOLDRICH G, WOLDT H, BULLA J, MECHOULAM R, EHRENREICH H, SIREN AL (2005): Hippocampal cannabinoid-1 receptor upregulation upon endothelin-B receptor deficiency: a neuroprotective substitution effect? Neurochem Res 30, 1305-1309.

VAN DER STELT M, VELDHUIS WB, BAR PR, VELDINK GA, VLIEGENTHART JF, NICOLAY K (2001): Neuroprotection by Delta9-tetrahydrocannabinol, the main active compound in marijuana, against ouabain-induced in vivo excitotoxicity. J Neurosci $21,6475-6479$.

VINOD KY, HUNGUND BL (2006): Cannabinoid-1 receptor: a novel target for the treatment of neuropsychiatric disorders. Expert Opin Ther Targets $\underline{10}$, 203210.

WAGNER JA, HU K, BAUERSACHS J, KARCHER J, WIESLER M, GOPARAJU SK, KUNOS G, ERTL G (2001): Endogenous cannabinoids mediate hypotension after experimental myocardial infarction. J Am Coll Cardiol $\underline{38}$, 2048-2054.

WALTER L, FRANKLIN A, WITTING A, WADE C, XIE Y, KUNOS G, MACKIE K, STELLA N (2003): Nonpsychotropic cannabinoid receptors regulate microglial cell migration. J Neurosci 23 , 1398-1405.

WEINREB O, AMIT T, BAR-AM O, CHILLAG-TALMOR O, YOUDIM MB (2005): Novel neuroprotective mechanism of action of rasagiline is associated with its propargyl moiety: interaction of Bcl-2 family members with PKC pathway. Ann N Y Acad Sci 1053, 348-355.

YAGAMI T, UEDA K, ASAKURA K, KURODA T, HATA S, SAKAEDA T, KAMBAYASHI Y, FUJIMOTO M (2002): Effects of endothelin B receptor 
agonists on amyloid beta protein (25-35)-induced neuronal cell death. Brain Res $\underline{948}, 72-81$.

YAGAMI T, UEDA K, SAKAEDA T, OKAMURA N, NAKAZATO H, KURODA T, HATA S, SAKAGUCHI G, ITOH N, HASHIMOTO Y (2005): Effects of an endothelin B receptor agonist on secretory phospholipase A2-IIA-induced apoptosis in cortical neurons. Neuropharmacology 4ㄹ, 291-300.

YANAGISAWA M, MASAKI T (1989): Molecular biology and biochemistry of the endothelins. Trends Pharmacol Sci 10, 374-378.

YANAGISAWA M, KURIHARA H, KIMURA S, TOMOBE Y, KOBAYASHI M, MITSUI Y, YAZAKI Y, GOTO K, MASAKI T (1988): A novel potent vasoconstrictor peptide produced by vascular endothelial cells. Nature $\underline{32}, 411-415$.

YANG M, COID JW, PAN H (2005): Multilevel generalized linear models for modelling age-related gender difference in violent behaviour and associated factors in the general household population. Int J Methods Psychiatr Res $\underline{14}$ 130-145.

ZHANG F, YIN W, CHEN J (2004): Apoptosis in cerebral ischemia: executional and regulatory signaling mechanisms. Neurol Res $\underline{26}, 835-845$.

ZHANG Y, ZOU Y, XU M, ZHU P, WANG Z (2000): Effect of endothelin and endothelin A receptors on regional cerebral blood flow after traumatic brain injury in rabbits. Chin J Traumatol $\underline{3}, 185-188$. 


\section{Danksagung}

Zur Erlangung des Doktorgrades sind mehr als nur Interesse an der Wissenschaft, Durchhaltevermögen und eine Idee vonnöten. So danke ich an dieser Stelle all denen, die mich in meinem Vorhaben fachlich, finanziell, beratend und moralisch unterstützten:

Frau Prof. Dr. Dr. Hannelore Ehrenreich für die Überlassung der vorliegenden Arbeit, ihre exzellente Führung, Geduld und Vertrauen bei meiner Arbeit sowie die Kunst, mich im Eifer zu bremsen, wenn nötig;

Frau Prof. Dr. Anna-Leena Sirén, die mich bei der vorliegenden Arbeit und Projekten darüber hinaus theoretisch und praktisch in die Arbeit eines wissenschaftlichen Labors eingeführt, betreut und mir mit neuen Ideen die Umsetzung sehr erleichtert hat;

Herrn Prof. Dr. Eberhard Günther für die Betreuung und Leitung des Graduiertenkollegs "Molekularbiologische Analyse pathophysiologischer Prozesse", in dessen Rahmen diese Arbeit angefertigt wurde, sowie allen Stipendiaten und Kollegiaten für die Möglichkeit des wissenschaftlichen Austausches und die Möglichkeit des Erlernens wissenschaftlicher Methoden;

Frau Dr. Susann Kaufmann, die mich schon während der Arbeit mit besten Ideen zur Fortführung antrieb und bei der Korrektur eine unnachgiebige, aber sehr einfühlsame Hilfe war;

Herrn Dr. Jan Bulla für Beratung und Hilfestellung bei der Planung und Durchführung statistischer Methoden sowie für die Möglichkeit, eine naturwissenschaftliche Fragestellung mathematisch zu illuminieren;

Frau Swetlana Sperling für die exzellente Einführung in den Western Blot, die großartige Hilfe bei Tierversuchen und die äußerst angenehme Arbeitsatmosphäre im Labor, für die sie hauptverantwortlich ist. 


\section{Lebenslauf}

Am 18.01.1978 wurde ich als erstes Kind von Rosemarie Unzicker und HansJürgen Unzicker in Lahn (jetzt Wetzlar) geboren. Getauft wurde ich 1978, konfirmiert in der evangelischen Kirchengemeinde in Melsungen 1992.

Die Christian-Bitter-Grundschule besuchte ich in Melsungen von 1986-90. Im Anschluss folgten zwei Jahre in der Orientierungsstufe der Gesamtschule Melsungen, nachfolgend vier Jahre im Gymnasialzweig. Die allgemeine Hochschulreife (Abitur) erlangte ich nach weiteren drei Jahren an der Geschwister-Scholl-Schule in Melsungen 1997.

Meinen Grundwehrdienst leistete ich beim Panzergrenadierbattaillon 152 in Schwarzenborn, beim Panzerartilleriebatailllon 55 in Homberg/Efze und beim Standortsanitätszentrum in Fritzlar. Ein Pflegepraktikum absolvierte ich im Kinderkrankenhaus Park Schönfeld in Kassel.

Zum Wintersemester 1998 immatrikulierte ich mich an der Georg-AugustUniversität in Göttingen. Die Ärztliche Vorprüfung (Physikum) legte ich 2001, den ersten Abschnitt der Ärztlichen Prüfung (1. Staatsexamen) 2002 und den zweiten Abschnitt der Ärztlichen Prüfung (2. Staatsexamen) 2004 ab.

Von April 2001 bis Oktober 2002 war ich Stipendiat des Graduiertenkollegs „Molekularbiologische Analyse pathophysiologischer Prozesse" unter der Leitung von Herrn Prof. Dr. Günther. Im Rahmen dieses Kollegs entstand die vorliegende Arbeit am Max-Planck-Institut für experimentelle Medizin bei Frau Prof. Dr. Dr. Ehrenreich (Division Klinische Neurowissenschaften).

Es folgte 2004 das Praktische Jahr, das ich am Princess Margaret Hospital, University of Toronto, Toronto, Kanada bei Herrn Prof. Dr. Messner; im Victoria Hospital, London Regional Cancer Center, University of Western Ontario, London, Kanada bei Herrn Prof. Dr. Barr; im Kantonsspital Altdorf, Altdorf, Schweiz bei Herrn Dr. Amstad und am Johannesburg General Hospital, University of the Witwatersrand, Johannesburg, Südafrika bei Herrn Prof. Dr. Cronjé und Herrn Prof. Dr. Boffard absolvierte. Im Anschluss folgte 2005 der Abschluss des Studiums mit dem dritten Abschnitt der Ärztlichen Prüfung (3. Staatsexamen) an der Universität Göttingen.

Die Erteilung der Approbation als Arzt erlangte ich am 06.12.2005. Von Februar bis April 2006 war ich als wissenschaftlicher Angestellter mit ärztlichen Aufgaben an der Universitätsklinik Essen, Zentrum Innere Medizin, Klinik für Hämatologie bei Herrn Prof. Dr. Dührsen tätig. Seit Mai 2006 bin ich als wissenschaftlicher Angestellter mit ärztlichen Aufgaben an der Universitätsklinik Würzburg, Medizinische Klinik und Poliklinik II unter der Leitung von Herrn Prof. Dr. Einsele tätig. 